\title{
Generating an Executable Model of the Drosophila Central Complex
}

\author{
Neurokernel RFC \#6 v1.0 \\ Lev E. Givon, Aurel A. Lazar \\ Bionet Group \\ Department of Electrical Engineering \\ Columbia University, New York, NY 10027
}

May 2, 2016

\begin{abstract}
The central complex (CX) is a set of neuropils in the center of the fly brain that have been implicated as playing an important role in vision-mediated behavior and integration of spatial information for locomotor control. In contrast to currently available data regarding the neural circuitry of neuropils in the fly's vision and olfactory systems, comparable data for the CX neuropils is relatively incomplete; many categories of neurons remain only partly characterized, and the synaptic connectivity between CX neurons has yet to be experimentally determined. Successful modeling of the information processing functions of the CX neuropils therefore requires a means of easily constructing and testing a range of hypotheses regarding both the high-level structure of their neural circuitry and the properties of their constituent neurons and synapses. This document demonstrates how NeuroArch and Neurokernel may be used to algorithmically construct and evaluate executable neural circuit models of the CX neuropils and their interconnects based upon currently available information regarding the geometry and polarity of the arborizations of identified local and projection neurons in the CX.
\end{abstract}




\section{Contents}

$\begin{array}{lll}1 & \text { Introduction } & 7\end{array}$

2 Terminology $\quad 9$

2.1 Neuropil Nomenclature . . . . . . . . . . . . . . . . . . . . . . 9

2.2 Neuron Labeling . . . . . . . . . . . . . . . . . . . . . . 10

3 Structure of Neuropils in and Associated with the Central Complex 12

3.1 Protocerebral Bridge $(\mathrm{PB}) \ldots \ldots \ldots \ldots$

3.2 Fan-Shaped Body $(\mathrm{FB}) \ldots \ldots \ldots \ldots$

3.3 Ellipsoid Body $(\mathrm{EB}) \ldots \ldots \ldots \ldots \ldots$

3.4 Noduli $(\mathrm{NO}) \ldots \ldots \ldots \ldots \ldots$

3.5 Bulb $(\mathrm{BU}) \ldots \ldots \ldots \ldots$

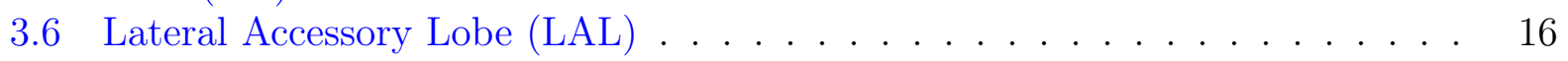

3.7 Crepine $(\mathrm{CRE}) \ldots \ldots \ldots \ldots \ldots \ldots$

3.8 Other Neuropils (IB, PS, SMP, WED) . . . . . . . . . . . . . 17

4 Central Complex Input Pathways and Neuron Responses 17

5 Identified Neurons in the Central Complex 18

5.1 Index of Identified Neurons . . . . . . . . . . . . . . . . . . . . 18

5.2 Neurotransmitter Profiles . . . . . . . . . . . . . . . . . . . . 22

5.3 Local Neurons . . . . . . . . . . . . . . . . . . . . . . . . . . . . . . . . . . . 23

5.3.1 PB Local Neurons . . . . . . . . . . . . . . . . . . . . . . . . . . . . . . . . . 23

5.3 .2 FB Local Neurons . . . . . . . . . . . . . . . . . . . . . . . 24

5.3 .3 EB Local Neurons . . . . . . . . . . . . . . . . . . . . . . . . . . . . . . . . . . . 25

5.4 Projection Neurons . . . . . . . . . . . . . . . . . . . 25

5.4 BU-EB Projection Neurons . . . . . . . . . . . . 25

5.4 .2 EB-FB-LAL-SMP Projection Neurons . . . . . . . . . . . . . 26

5.4 .3 EB-LAL-PB Projection Neurons . . . . . . . . . . . . . . . . 27

5.4.4 F Projection Neurons . . . . . . . . . . . . . . . . . . . . . 29

5.4 .5 IB-LAL-PS-PB Projection Neurons . . . . . . . . . . . . . . . . . . 29

5.4 PB-EB-BU Projection Neurons . . . . . . . . . . . . . . . . . . 29

5.4.7 PB-EB-NO Projection Neurons . . . . . . . . . . . . . . . . 30

5.4 PB-EB-LAL Projection Neurons . . . . . . . . . . . . . . . 31

5.4 PB-FB-CRE Projection Neurons . . . . . . . . . . . . . . . 34

5.4.10 PB-FB-NO Projection Neurons . . . . . . . . . . . . . . . . 35

5.4 .11 PB-FB-LAL Projection Neurons . . . . . . . . . . . . . . . . . 40

5.4 .12 WED-PS-PB Projection Neurons . . . . . . . . . . . . . 43 
6 Generating an Executable Circuit Model

6.1 Neuron Organization . . . . . . . . . . . . . . . . . . . 45

6.2 Executable Circuit Generation . . . . . . . . . . . . . . . . . 51

6.3 Executing the Circuit . . . . . . . . . . . . . . . . . . 61

6.4 Use Cases . . . . . . . . . . . . . . . . . . . . . . . . . . . . . . . . . . . . . 62

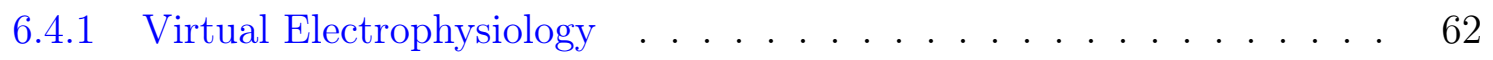

6.4 .2 Virtual Genetic Manipulation . . . . . . . . . . . . . . . . 65

6.5 Related Work . . . . . . . . . . . . . . . . . . 69

7 Acknowledgements $\quad 69$ 


\section{List of Figures}

1 Volumetric image of central complex and some accessory neuropils . . . . . 7

2 Observed EB-LAL-PB activity in response to visual input signal . . . . . . . 8

3 Example of CX neuron arborizations . . . . . . . . . . . . . . 11

4 Schematic of regions in $\mathrm{PB} \ldots \ldots \ldots \ldots$

5 Schematic of regions in FB . . . . . . . . . . . . . . . . 13

6 Schematic of regions in EB . . . . . . . . . . . . . . . . . . . . . . . . . . . . . .

7 Schematic of regions in $\mathrm{NO} \ldots \ldots \ldots \ldots$

8 Schematic of regions in $\mathrm{BU} \ldots \ldots \ldots$

9 Schematic of regions in LAL . . . . . . . . . . . . . . . . . . 16

10 Schematic of regions in CRE . . . . . . . . . . . . . . . . 17

11 Information flow between CX and accessory neuropils . . . . . . . . . 18

12 PB local neuron innervation pattern . . . . . . . . . . . . . . . . 24

13 FB local neuron innervation pattern . . . . . . . . . . . . . . . . . 25

14 BU-EB neurons . . . . . . . . . . . . . . . . . . 26

15 EB-LAL-PB neuropil innervation pattern . . . . . . . . . . . . . . 28

16 IB-LAL-PS-PB neuropil innervation pattern . . . . . . . . . . . . . . . . . . . . . . . . . . . . . . . . .

17 PB-EB-NO neuropil innervation pattern . . . . . . . . . . . . . . 31

18 PB-EB-LAL neuropil innervation pattern . . . . . . . . . . . . . . 33

19 PB-FB-CRE neuropil innervation pattern . . . . . . . . . . . . . . 35

20 PB-FB-NO neuropil innervation pattern . . . . . . . . . . . . . . 39

21 PB-FB-LAL neuropil innervation pattern (layer 2 of FB) . . . . . . . . . . 41

22 PB-FB-LAL neuropil innervation pattern . . . . . . . . . . . . . . . . . . . . . . . . . . 43

23 WED-PS-PB neuropil innervation pattern . . . . . . . . . . . . . . 45

24 Inferred synapses between PB local neurons . . . . . . . . . . . . . . . . 52

25 Inferred synapses between PB local and PB-EB-LAL neurons . . . . . . . . . 53

26 Inferred synapses between PB local and PB-EB-NO neurons . . . . . . . . 54

27 Inferred synapses between EB-LAL-PB neurons . . . . . . . . . . . . . 55

28 Inferred synapses between EB-LAL-PB and PB local neurons . . . . . . . . 56

29 Inferred synapses between EB-LAL-PB and PB-EB-LAL neurons . . . . . . 57

30 Inferred synapses between EB-LAL-PB and PB-EB-NO neurons . . . . . . 58

31 Inferred synapses between PB-EB-LAL and EB-LAL-PB neurons . . . . . . 59

32 Inferred synapses between PB-EB-NO and EB-LAL-PB neurons . . . . . . . 60

33 Moving bar visual input to generated CX model . . . . . . . . . . . . . . . 61

34 Schematic of information flow in CX circuit model . . . . . . . . . . . . . 62

35 Response of CX projection neurons innervating PB to moving bar input . . . 63

36 Response of CX projection neurons innervating BU/bu to moving bar input 64

37 Hypothesized innervation pattern of PB local neurons in no bridge mutant . 65

38 Response of mutant CX projection neurons innervating PB to moving bar input 67 
bioRxiv preprint doi: https://doi.org/10.1101/051318; this version posted May 23, 2016. The copyright holder for this preprint (which was not certified by peer review) is the author/funder, who has granted bioRxiv a license to display the preprint in perpetuity. It is made available under aCC-BY 4.0 International license.

LIST OF FIGURES

39 Response of mutant CX projection neurons innervating BU/bu to moving bar input . . . . . . . . . . . . . . . . . . . 


\section{List of Tables}

1 Geometric overlap between EB tiles and wedges. . . . . . . . . . . . . . . . 14

2 Identified local neurons in CX neuropils. . . . . . . . . . . . . . . . . . . . 19

3 Identified projection neurons connecting CX and accessory neuropils . . . . 20

4 Projection neurons connecting CX and accessory neuropils with unresolved neurite types. . . . . . . . . . . . . . . . . . 21

5 Neurotransmitters in the fruit fly CX . . . . . . . . . . . . . . . 22

6 Neurotransmitter profiles of specific neural pathways in the fruit fly CX (adapted from $[1$, Fig. $7 c]$ and $[2]) \ldots \ldots \ldots \ldots \ldots \ldots$

7 PB local neurons. . . . . . . . . . . . . . . . . . . . . . . . 24

8 One identified class of FB local neurons. . . . . . . . . . . . . . . . . . . . . . . . . . . . . . . 25

$9 \quad$ EB-LAL-PB neurons. . . . . . . . . . . . . . . . . . . 27

10 IB-LAL-PS-PB neurons. . . . . . . . . . . . . . . . . . . . . 29

11 PB-EB-NO neurons. . . . . . . . . . . . . . . . . . . . . 30

12 PB-EB-LAL neurons. . . . . . . . . . . . . . . . . . . . . . . 32

13 PB-FB-CRE neurons. . . . . . . . . . . . . . . . . . . . 34

14 PB-FB-NO neurons innervating region $(3, \mathrm{P})$ of $\mathrm{NO} \ldots \ldots . \ldots$

15 PB-FB-NO neurons innervating region $(3, \mathrm{M})$ of $\mathrm{NO} \ldots \ldots$

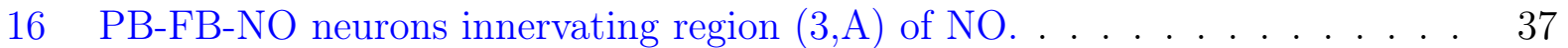

17 PB-FB-NO neurons innervating region $(2, \mathrm{D})$ of $\mathrm{NO} \ldots \ldots . \ldots . \ldots . . \ldots 37$

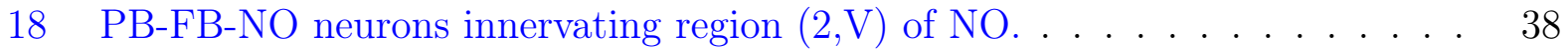

19 PB-FB-LAL neurons innervating layer 2 of FB[1, Fig. 6F]. . . . . . . . . . . 40

20 PB-FB-LAL neurons . . . . . . . . . . . . . . . . . . 42

21 PB-FB-LAL neurons . . . . . . . . . . . . . . . . . . . . . . . . . . . . . . . . . . . . . .

22 WED-PS-PB neurons. . . . . . . . . . . . . . . . . . 44

23 Assignment of neuron families to LPUs in generated CX model. . . . . . . . 45

24 Hypothesized arborizations of BU-EB neurons . . . . . . . . . . . . . 46

25 Hypothesized FB local neurons linking segments in layers 1, 2, 4, and 5, respectively. . . . . . . . . . . . . . . . . . . 47

26 Hypothesized FB local neurons linking adjacent segments within the same layer in layers 1-5. . . . . . . . . . . . . . . . . . . . . . . . 48

27 Hypothesized FB local neurons linking adjacent layers within the same segment for layers 1-5. . . . . . . . . . . . . . . . . . . . . . . 49

28 Hypothesized FB local neurons linking nonadjacent layers within the same segment. . . . . . . . . . . . . . . . . . 50

29 Fields in ArborizationData node . . . . . . . . . . . . . . . . 51

30 Hypothesized PB local neurons in the no bridge mutant. . . . . . . . . . . . 66 


\section{Introduction}

The brain of the fruit fly Drosophila melanogaster comprises approximately 50 neuropils. Most of these modules - referred to as local processing units (LPUs) are characterized by unique populations of local neurons; some - called hubs - do not contain any local neurons [3]. The central complex (CX) comprises between 2,000 and 5,000 neurons [4] organized in four neuropils: the protocerebral bridge (PB), fan-shaped body (FB), ellipsoid body (EB), and noduli (NO) (Figs. 1). The former three neuropils contain local neurons, while the latter does not [3]. In contrast to most neuropils in the fly brain, PB, FB, and EB are unpaired; NO comprises either 3 [5] or 4 [3] paired neuropils. When considered as components of a single structure, FB and EB are together referred to as the central body (CB). Accessory brain areas that are connected directly to neuropils in CX include AL, BU, CRE, IB, LAL, SMP, WED, and PS [1, Fig. 7] (see § 2.1 for the neuropil nomenclature).

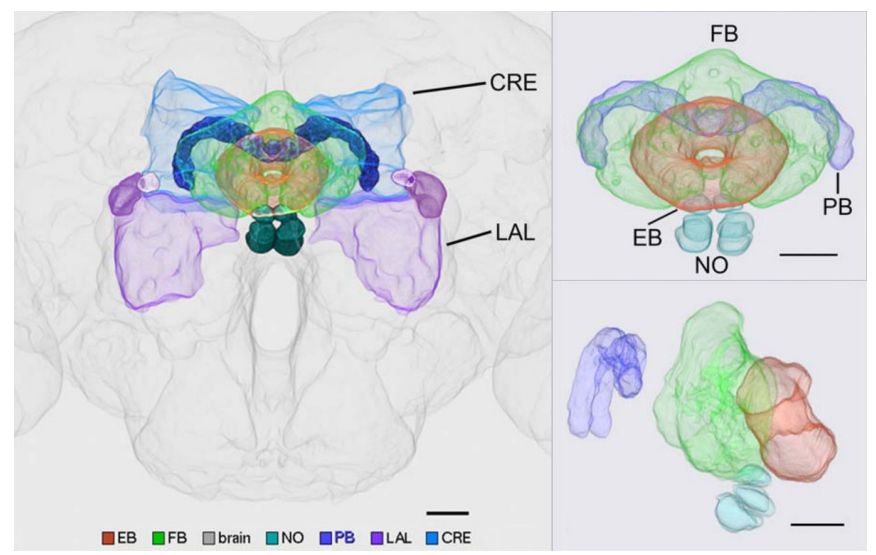

Figure 1: Volumetric image of central complex (PB, FB, EB, NO) and some accessory neuropils (CRE, LAL) arborized by CX neurons [5]. (C)2015 Wiley Periodicals, Inc.)

Genetic experiments have shown that the CX neuropils play essential roles in a range of important behaviors:

(i) EB appears to be involved in visual place learning [6], short-term orientation memory $[7,8]$, path integration, and left-right bargaining [4, p. 3];

(ii) FB appears to also play a role in left-right bargaining, as well as visual pattern memory and object recognition [4, p. 8];

(iii) PB plays a role in controlling step length and hence direction of walking [4, p. 7];

(iv) NO neuropils seem to be involved in flight control [6, p. 179].

While some functional models of the CX neuropils have been presented [4], they do not explicitly show how the CX circuitry implements the information processing functions associated with the above behaviors or how the various neuropils' individual functions combine to 
produce more comprehensive behaviors such as long-term motor skill learning or locomotor activity control.

Studies of neural activity in the CX of the fruit fly and arthropods have examined the response both of unidentified and specific CX neurons to visual inputs [9, 10, 11, 12]; owing to the limitations of electrophysiological techniques, these studies only examined the responses of individual neurons during each trial. Simultaneous observation of the aggregate neural responses of a set of isomorphic neurons in the fruit fly EB to visual input signals was achieved using calcium imaging [8, 13] (Fig. 2).

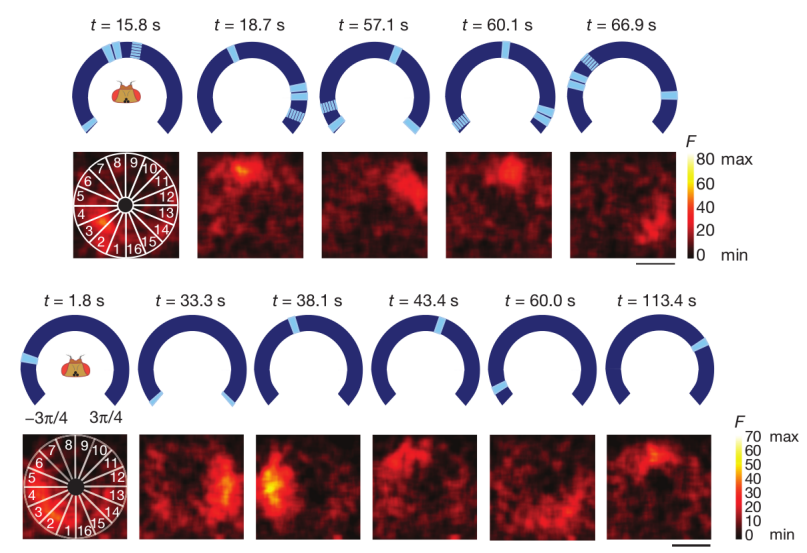

Figure 2: Observed activity of EB-LAL-PB neuron arborizations (§ 5.4.3) in EB in response to visual input at different points on the azimuth [13] (C)2015 Macmillan Publishers Ltd.)

Connectome information for the CX neuropils is currently less complete than that available for sensory neuropils such as those in the fly olfactory and vision systems, the latter of which has recently been mapped in great detail using electron microscopy [14]. Although a range of local and projection neurons in CX have been identified and grouped into isomorphic sets using Golgi staining, genetic tagging techniques, and confocal microscopy [15, 16, 1, 5], many other CX neurons have not been systematically characterized and the synaptic connectivity between them remains unknown owing to the limitations of the above optical imaging technologies and the very limited EM-based analysis of CX synapses done to date (for an example of the latter, see [2]). This ambiguity regarding the structure of the CX neural circuitry compounds the already difficult task of modeling a portion of the brain that does not receive direct sensory input.

In light of the incompleteness of the CX connectome, it is perhaps unsurprising that only a few computational models of the CX neuropils or the entire CX currently exist. A spiking neural network model of spatial memory formation and storage in EB is presented in [17]; while this model can replicate experimental results for specific behaviors using a ring attractor circuit inspired by that of EB, it does not attempt to account for the exact observed biological circuitry or explain how such a model interacts with the other CX neuropils. A model of CX was included in a more comprehensive insect brain simulation described in [18], but it employs generalized models of the CX neuropils that use artificial behavior selection 
networks which - although they superficially make use of spiking neuron models - do not employ the observed neural circuitry of the neuropils.

To enable further investigation of the information processing capabilities of the CX neuropils, we need to be able to efficiently generate and evaluate a range of different executable CX models given the limited available connectome data. While a similar approach involving $C$. elegans has been used to generate an ensemble of testable models regarding the neural basis for salt klinotaxis behavior [19], the greater total number of neurons in the fruit fly CX and the need to evaluate the CX models together with models of the neuropils that provide them with input calls for

(i) a database-driven approach to systematically creating an ensemble of CX different models of the neural circuitry that attempt to describe those characteristics of the circuitry that are as yet unknown, and

(ii) a means of integrating models of these CX neuropil models with those of accessory neuropils from which they receive input into a single executable partial brain model.

This RFC is organized as follows. We first present the nomenclature used to identify neuropils and a scheme for labeling neurons in terms of their arborization patterns in $\S 2$. We then review known data regarding the structure of neuropils in and connected to CX in $\S 3$, and describe what is known regarding input pathways into the CX neuropils and the nature of their neural responses in $\S 4$. We then present the arborization patterns of identified CX neurons in $\S 5$. Finally, we describe a scheme for construction of an executable circuit model of CX that utilizes this arborization data and specified structural assumptions to infer the presence of synapses in $\S 6$ and show how NeuroArch and Neurokernel expedite the process of executable circuit construction and evaluation.

\section{Terminology}

\subsection{Neuropil Nomenclature}

Drosophila neuropils are identified in this document using the nomenclature described in [20]. Some neuropils are referred to by different names either in other literature or in other insects; [20, Tab. S13] maps the employed nomenclature to that used in [3] and - for the most part - in [1]. For neuropils that occur in pairs, upper case denotes the neuropil on the left side of the fly brain (from a dorsal perspective the fly) while lower case denotes the neuropil on the right side of the fly brain.

- Antennal Lobe (AL).

- Anterior optic tubercle (AOTU) - Also known as optic tubercle (OPTU [3]).

- Antler (ATL) - Corresponds to dorsal part of caudalcentral protocerebrum (CCP) [20, Tab. S13]. 
- Bulb (BU) - Also known as lateral triangle (LT, LAT, Lat Tri [1, Tab. S13] or LTR $[15])$.

- Crepine (CRE) - Posterior part also known as dorsal part of IDFP [20, Tab. S13]; comprises a region called the rubus (RUB) [5, p. 1001] or round body (RB) [5, p. 1031].

- Lateral accessory lobe (LAL) - Also known ventral body (VBO [15]) or inferior dorsofrontal protocerebrum (IDFP) [1, Fig. S1]. Comprises the gall (GA) [20, Tab. S13], whose dorsal and ventral portions are referred to as the dorsal and ventral spindle bodies (DSB and VSB, respectively) [5, p. 1021].

- Ellipsoid body (EB) - Also known as lower central body (CBL [6]).

- Fan-shaped body (FB) - Also known as upper central body (CBU [6]).

- Inferior Bridge (IB) - Corresponds to ventral part of caudalcentral protocerebrum (CCP) [20, Tab. S13].

- Lobula (LO).

- Lobula Plate (LOP).

- Noduli (NO).

- Posterior slope (PS) - Corresponds to caudalmedial protocerebrum (CMP) and - possibly - part of the ventromedial protocerebrum (VMP) [20, Tab. S13].

- Protocerebral Bridge (PB).

- Superior medial protocerebrum (SMP) - Corresponds to superior dorsolateral protocerebrum (SDFP) and medial part of inner dorsolateral protocerebrum (IDLP) [20, Tab. S13].

- Ventrolateral protocerebrum (VLP) - Contains optic glomeruli [20, p. 42, Supp.].

- Wedge (WED) - Also known as the caudal ventrolateral protocerebrum (CVLP) [20, p. 42, Supp.].

\subsection{Neuron Labeling}

Most neurons innervating the various CX and accessory neuropils possess at least two distinct clusters of dendrites (postsynaptic terminals) and/or axons (presynaptic terminals) that occupy geometrically distinct regions of the innervated neuropils [15]. These clusters are referred to as arborizations (Fig. 3). Since many CX neurons belong to distinct sets of morphologically similar neurons with similar arborization patterns, it is useful to use the latter to uniquely label each CX neuron type. If neurotransmitter profiles are ignored and 
each CX neuron type is assumed to be represented by a single neuron, then each neuron's label unambiguously encodes the geometric regions of its arborizations and whether each arborization contains dendrites, axons, or both. This labeling scheme can be described in terms of the following parsing expression grammar (PEG) [21]; the grammar may be used to extract the arborizations of a particular neuron for constructing models of the CX circuitry (e.g., by using overlapping presynaptic and postsynaptic arborizations to infer synaptic connectivity). Note that a special case for handling the string LRB in the 〈name〉 rule (which corresponds to the left $\mathrm{RB}$ region of $\mathrm{CRE}$ ) is necessary to prevent that string from being incorrectly parsed into LB and RB.

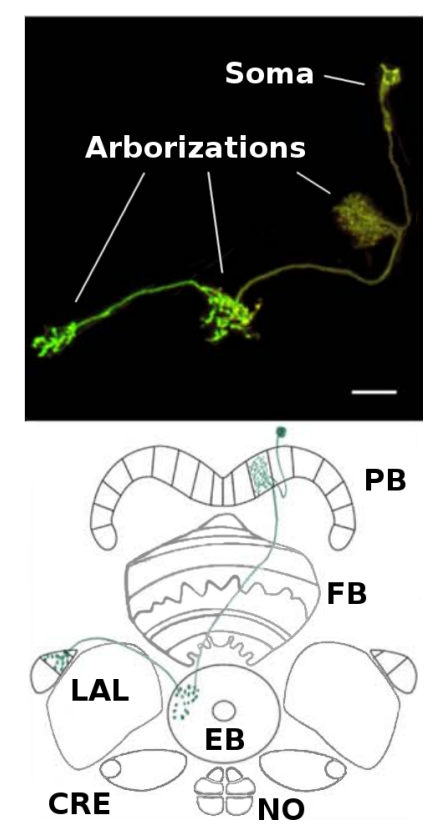

Figure 3: Example of neuron arborizations for a PB-EB-LAL neuron (§ 5.4.8) [5]. Each of the neuron arborizations occupies a specific region in different neuropils. (C)2015 Wiley Periodicals, Inc.)

$$
\begin{aligned}
&\langle\text { label }\rangle:=\langle\text { arborization }\rangle(\langle\text { hyphen }\rangle\langle\text { arborization }\rangle)+ \\
&\langle\text { arborization }\rangle:=\langle\text { neuropil }\rangle\langle\text { slash }\rangle\langle\text { regions }\rangle\langle\text { slash }\rangle\langle\text { neurite type }\rangle \\
&\langle\text { regions }\rangle:=\langle\text { region }\rangle(\langle\text { bar }\rangle\langle\text { region }\rangle) * \\
&\langle\text { neuropil }\rangle:=(\mathrm{BU} / \mathrm{bu} / \mathrm{CRE} / \mathrm{cre} / \mathrm{EB} / \mathrm{FB} / \mathrm{IB} / \mathrm{ib} / \mathrm{LAL} / \\
&\text { lal } / \mathrm{NO} / \mathrm{no} / \mathrm{PB} / \mathrm{PS} / \mathrm{ps} / \mathrm{SMP} / \mathrm{smp} / \mathrm{WED} / \text { wed }) \\
&\langle\text { region }\rangle:=\langle\text { tuple }\rangle /\langle\text { tuple } 3\rangle /\langle\text { name }\rangle \\
&\langle\text { tuple }\rangle\rangle:=\langle\text { left paren }\rangle\langle\text { name }\rangle\langle\text { comma }\rangle\langle\text { name }\rangle\langle\text { right paren }\rangle \\
&\langle\text { tuple3 }\rangle:=\langle\text { left paren }\rangle\langle\text { name }\rangle\langle\text { comma }\rangle\langle\text { name }\rangle\langle\text { comma }\rangle\langle\text { name }\rangle\langle\text { right paren }\rangle \\
&\langle\text { name }\rangle:=\mathrm{LRB} /(\langle\text { side }\rangle ?(\langle\text { integer }\rangle /\langle\text { range }\rangle /\langle\text { alpha }\rangle /\langle\text { list }\rangle)) /
\end{aligned}
$$




$$
\begin{aligned}
&(\langle\text { side }\rangle !(\langle\text { integer }\rangle /\langle\text { range }\rangle /\langle\text { alpha }\rangle /\langle\text { list }\rangle)) \\
&\langle\text { side }\rangle:=(\mathrm{L} / \mathrm{R} / \mathrm{LR} / \mathrm{RL}) \\
&\langle\text { neurite type }\rangle:=(\mathrm{s} / \mathrm{b} / \mathrm{bs} / \mathrm{sb}) \\
&\langle\text { range }\rangle:=\langle\text { left bracket }\rangle\langle\text { integer }\rangle\langle\text { hyphen }\rangle\langle\text { integer }\rangle\langle\text { right bracket }\rangle \\
&\langle\text { list }\rangle:=\langle\text { left bracket }\rangle\langle\text { alpha }\rangle(\langle\text { comma }\rangle\langle\text { alpha }\rangle) *\langle\text { right bracket }\rangle \\
&\langle\text { integer }\rangle:=[0-9]+ \\
&\langle\text { alpha }\rangle:=[\mathrm{a}-\mathrm{z}, \mathrm{A}-\mathrm{Z}, 0-9]+ \\
&\langle\text { hyphen }\rangle:=- \\
&\langle\text { bar }\rangle:=1 \\
&\langle\text { slash }\rangle:=/ \\
&\langle\text { comma }\rangle:= \\
&\langle\text { left paren }\rangle:=( \\
&\langle\text { right paren }\rangle:=) \\
&\langle\text { left bracket }\rangle:=[ \\
&\langle\text { right bracket }\rangle:=]
\end{aligned}
$$

Neuropils are denoted by their abbreviated names as specified in $\S 2.1$ and [20]; regions or compartments within neuropils are described and assigned names in $\S 3$. The neurite type may be spine (s), bouton (or bleb) (b), or a combination thereof (bs, sb). In the absence of detailed data regarding synapses, information flow polarity is assumed to be reflected by neurite type; spines are assumed to be postsynaptic (and accept input), while boutons are assumed to be presynaptic (and emit output) [5, p. 1002]. Left and right are assumed to be with respect to a dorsal view of the fly.

\section{Structure of Neuropils in and Associated with the Cen- tral Complex}

This section presents details regarding the high-level structure of the various CX neuropils and the accessory neuropils to which they are connected.

\subsection{Protocerebral Bridge (PB)}

The PB neuropil comprises 18 regions called glomeruli [5] connected to other substructures within the CX (Fig. 4). The local neuron population of the PB comprises 8 [5, p. 1007] or 10 [1, p. 1743] types of local neurons (Fig. 12, Tab. 7). A single PB region label matches the following regular expression:

$$
\langle\text { glomerulus }\rangle:=[\mathrm{L}, \mathrm{R}][1-9]
$$




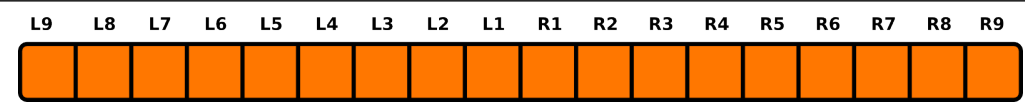

Figure 4: Schematic of regions in PB used to identify neurons by their arbors $[1,5]$.

\subsection{Fan-Shaped Body (FB)}

The FB neuropil comprises multiple lateral layers [6]; most recent work suggests the presence of 9 layers [5, p. 1011]. The neuropil is subdivided vertically into 8 [1] or 7 [5, p. 1010] columns called segments [15]; however, it seems that only some of its layers (1-5) exhibit clearly columnar structure [5, p. 1008] (5). Regions in FB are connected by local neurons called pontine neurons; some of these neurons connect adjacent layers, while others connect adjacent segments [15, p. 349, 352]. A representative class of pontine neurons comprising symmetric neurons that connect each segment in one side of FB with each segment in the other side such that the presynaptic and postsynaptic arborizations are 4 segments apart [15, p. 352] (although more recent work suggests that each neuron might be a bundle of 2 neurons [22, p. 1439]) is depicted in Tab. 8. Other classes dorsoventrally connecting different layers in FB may exist, but they have not been systematically identified. A single region in FB is denoted by a label matching the regular expression

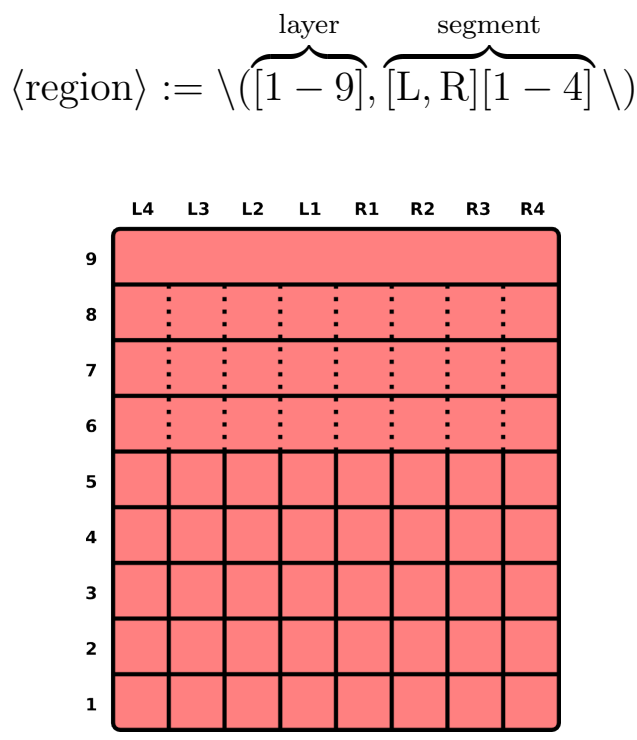

Figure 5: Schematic of regions in FB used to identify neurons by their arbors $[1,5]$.

\section{$3.3 \quad$ Ellipsoid Body (EB)}

The EB neuropil is a toroidal structure that comprises 16 wedges [5, p. 1013] (Fig. 6a), 8 tiles [5, p. 1018] (Fig. 6b), 3 shells (anterior, medial, posterior) [5, p. 1013], and 4 rings [1] (Fig. 6c). Wedges extend radially through full radius of the EB torus and occupy the posterior and medial shells or all 3 shells [5, p. 1013]. Tiles are restricted to the posterior 
shell [5, p. 1014]; tiles geometrically overlap with corresponding wedges as described in Tab. 1. Although EB appears to contain local neurons [3], these neurons have not yet been systematically identified; there is some evidence for EB pontine neurons in related fly species such as Neobellieria [11, p. 11]. Each region in EB is denoted by a label that matches the regular expression

$$
\langle\text { region }\rangle:=\overbrace{[1-8]}^{\text {tile }} \mid \backslash(\overbrace{[\mathrm{L}, \mathrm{R}][1-8]}^{\text {wedge }}, \overbrace{[\mathrm{P}, \mathrm{M}, \mathrm{A}]}^{\text {shell }}, \overbrace{[1-4]}^{\text {ring }} \backslash)
$$

For EB regions other than tiles, the region denoted by a label comprises the volume intersected by the specified wedges, shells, and rings. For example, (L1, [P, M], 4) represents the volume in which wedge L1, shells $\mathrm{P}$ and $\mathrm{M}$, and ring 4 overlap.

\begin{tabular}{|l|l|}
\hline Tile & Wedge \\
\hline $\mathrm{EB} / 1 / \mathrm{x}$ & $\mathrm{EB} /([\mathrm{L} 1, \mathrm{R} 1], \mathrm{P}, \mathrm{x}) / \mathrm{x}$ \\
$\mathrm{EB} / 2 / \mathrm{x}$ & $\mathrm{EB} /(\mathrm{R}[2,3], \mathrm{P}, \mathrm{x}) / \mathrm{x}$ \\
$\mathrm{EB} / 3 / \mathrm{x}$ & $\mathrm{EB} /(\mathrm{R}[4,5], \mathrm{P}, \mathrm{x}) / \mathrm{x}$ \\
$\mathrm{EB} / 4 / \mathrm{x}$ & $\mathrm{EB} /(\mathrm{R}[6,7], \mathrm{P}, \mathrm{x}) / \mathrm{x}$ \\
$\mathrm{EB} / 5 / \mathrm{x}$ & $\mathrm{EB} /([\mathrm{R} 8, \mathrm{~L} 8], \mathrm{P}, \mathrm{x}) / \mathrm{x}$ \\
$\mathrm{EB} / 6 / \mathrm{x}$ & $\mathrm{EB} /(\mathrm{L}[6,7], \mathrm{P}, \mathrm{x}) / \mathrm{x}$ \\
$\mathrm{EB} / 7 / \mathrm{x}$ & $\mathrm{EB} /(\mathrm{L}[4,5], \mathrm{P}, \mathrm{x}) / \mathrm{x}$ \\
$\mathrm{EB} / 8 / \mathrm{x}$ & $\mathrm{EB} /(\mathrm{L}[2,3], \mathrm{P}, \mathrm{x}) / \mathrm{x}$ \\
\hline
\end{tabular}

Table 1: Geometric overlap between EB tiles and wedges. 


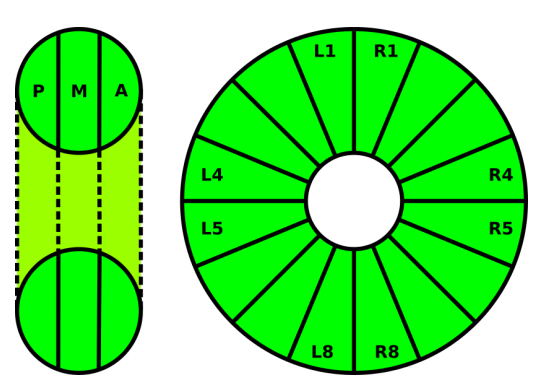

(a) Shells (L) and wedges (R)[5].

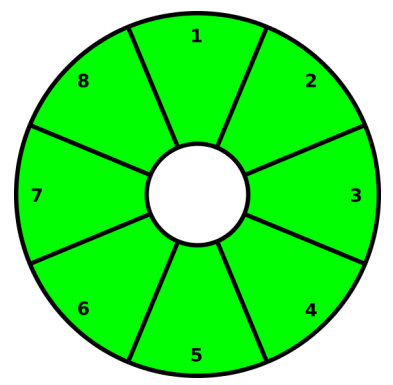

(b) Tiles [5].
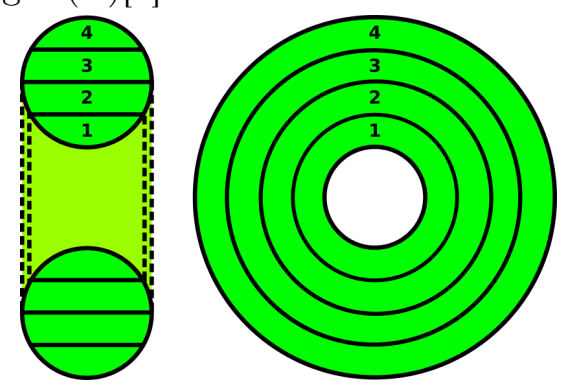

(c) Rings [16].

Figure 6: Schematics of regions in EB. All circular schematics are anterior; sagittal views in Figs. $6 \mathrm{a}$ and $6 \mathrm{c}$ are posterior to anterior from left to right).

\subsection{Noduli (NO)}

The NO neuropils comprise 3 distinct structures (NO1, NO2, NO3) divided into subcompartments (Fig. 7) [5, p. 1017]. In contrast to the other CX neuropils, the noduli lack segregated populations of local neurons [3, p. 5]. Each NO region label matches the following regular expressions:

$$
\langle\text { subcompartment }\rangle:= \begin{cases}{[\mathrm{L}, \mathrm{R}]} & \text { for NO1 } \\ {[\mathrm{L}, \mathrm{R}][\mathrm{V}, \mathrm{D}]} & \text { for NO2 } \\ {[\mathrm{L}, \mathrm{R}][\mathrm{A}, \mathrm{M}, \mathrm{P}]} & \text { for NO3 }\end{cases}
$$

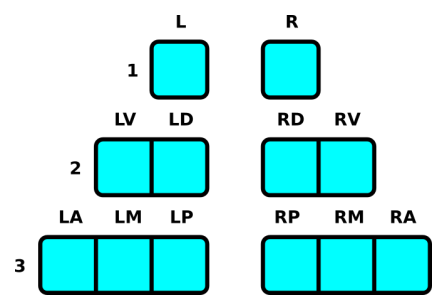

Figure 7: Schematic of regions in NO used to identify neurons by their arbors [5]. 


\subsection{Bulb (BU)}

Each of the BU neuropils comprises multiple regions referred to as microglomeruli. There appear to be 80 microglomeruli in each BU neuropil (Fig. 8) [1, p. 1741]. These microglomeruli ostensibly exhibit retinotopic organization [8]. Each of the BU region labels matches the regular expression

$$
\langle\text { microglomerulus }\rangle:=[\mathrm{L}, \mathrm{R}][0-9]+
$$

where the integer portion of the labels ranges from 1 to 80 .
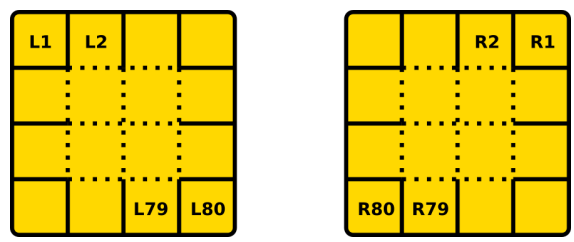

Figure 8: Schematic of regions in BU used to identify neurons by their arbors [1]. The relative positions of the regions does not necessarily correspond to their actual physical positions.

\subsection{Lateral Accessory Lobe (LAL)}

Each LAL neuropil comprises a region called the gall that is subdivided into a tip, dorsal, and ventral subregion; the remainder of LAL is referred to as the hammer body (HB) (Fig. 9) [1]. Each of these regions has a label that matches the regular expression

$$
\langle\text { region }\rangle:=[\mathrm{L}, \mathrm{R}](\mathrm{HB}|\mathrm{GT}| \mathrm{DG} \mid \mathrm{VG})
$$

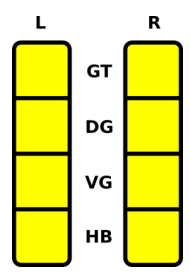

Figure 9: Schematic of regions in LAL used to identify neurons by their arbors [5].

\subsection{Crepine (CRE)}

Each CRE neuropil is divided into two regions (Fig. 10); these match the regular expression

$$
\langle\text { region }\rangle=[\mathrm{L}, \mathrm{R}](\mathrm{RB} \mid \mathrm{CRE})
$$




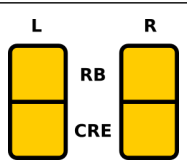

Figure 10: Schematic of regions in CRE used to identify neurons by their arbors [5].

\subsection{Other Neuropils (IB, PS, SMP, WED)}

Distinct regions of interest within IB, PS, SMP, and WED have not been identified; they are therefore regarded as comprising single regions on each side of the fly brain. Each region in these neuropils matches the regular expression

$$
\langle\text { region }\rangle:=[\mathrm{L}, \mathrm{R}](\mathrm{IB}|\mathrm{PS}| \mathrm{SMP} \mid \mathrm{WED})
$$

\section{Central Complex Input Pathways and Neuron Responses}

The neuropils in the CX are connected to various neuropils, but evidently not to any that directly receive sensory input except the antennal lobe (AL) [15, Fig. 24a]. Apart from connections between the CX neuropils and the accessory neuropils depicted in Fig. 11, connections have been observed between superior/inferior protocerebra and FB, between AOTU and BU [23, p. 9], and between VLP and PB [24, p. 9]. Preprocessed visual data from LO appears to enter the EB from BU via AOTU [25, p. 939], while additional visual input enters $\mathrm{PB}$ from other optic glomeruli in VLP [24, p. 9]. Other input enters FB via LAL. There also seems to be evidence of CX receiving mechanosensory information from the fly's legs [4, p. 6]. 


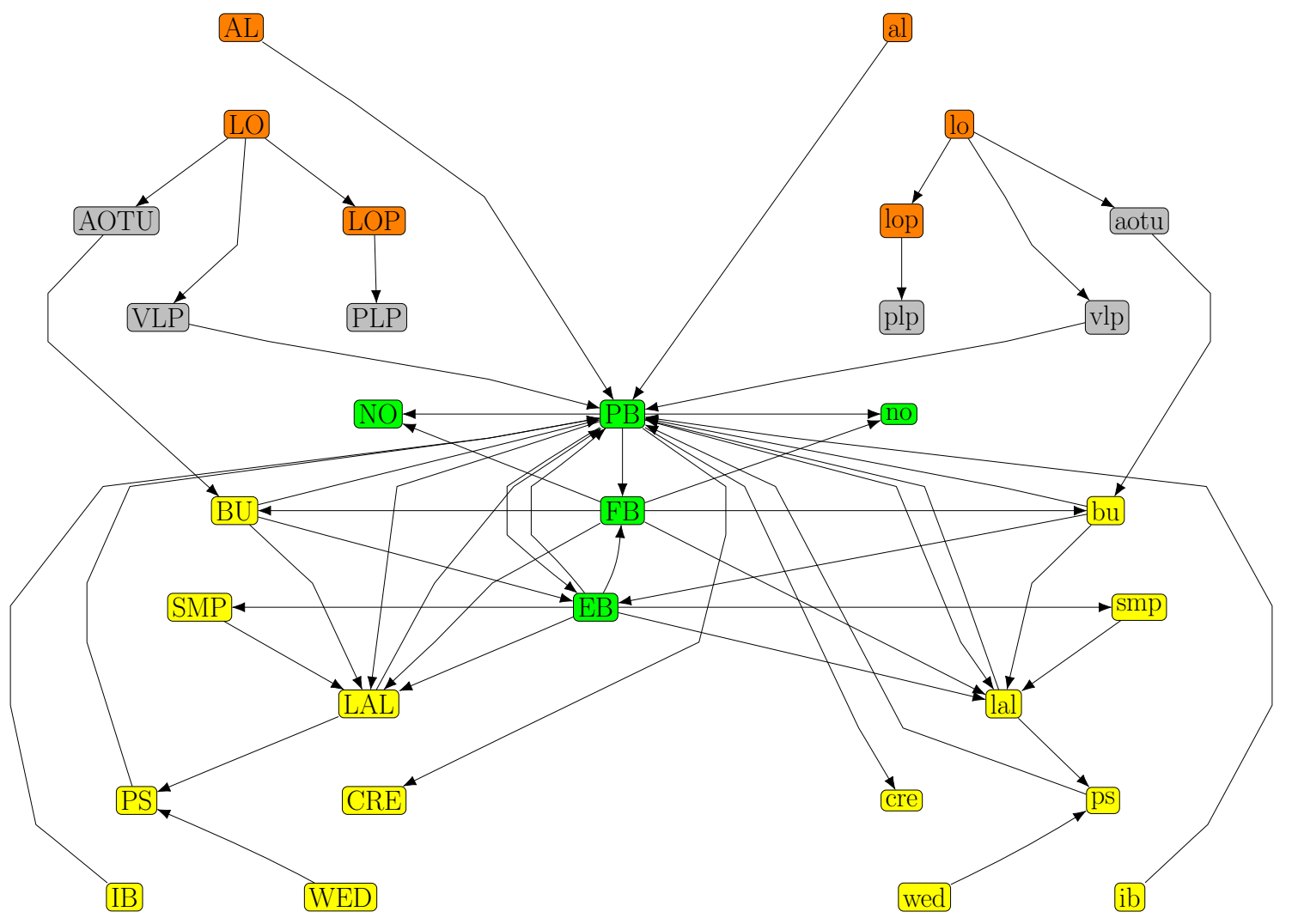

Figure 11: Information flow between CX neuropils (green), sensory neuropils (orange), neuropils that receive input from sensory neuropils (gray), and other accessory neuropils connected to the CX (yellow).

Spiking responses have been recorded from cells in FB during CX-related experiments using Drosophila [12, p. 64], from neurons supplying PB, tangential/pontine cells in FB, and ring cells in EB in Neobellieria [11], and from CX neurons in other insects [9].

\section{Identified Neurons in the Central Complex}

In all neuropil innervation diagrams depicted below, arrow heads represent presynaptic arborizations and arrow tails represent postsynaptic arborizations.

\subsection{Index of Identified Neurons}




\begin{tabular}{|l|l|}
\hline Neuropil & References \\
\hline FB & {$[15$, p. 349, 352], [22, p. 1439] } \\
\hline PB & {$[1$, p. 1743],[5, p. 1007] } \\
\hline
\end{tabular}

Table 2: Identified local neurons in CX neuropils. 
bioRxiv preprint doi: https://doi.org/10.1101/051318; this version posted May 23, 2016. The copyright holder for this preprint (which was not

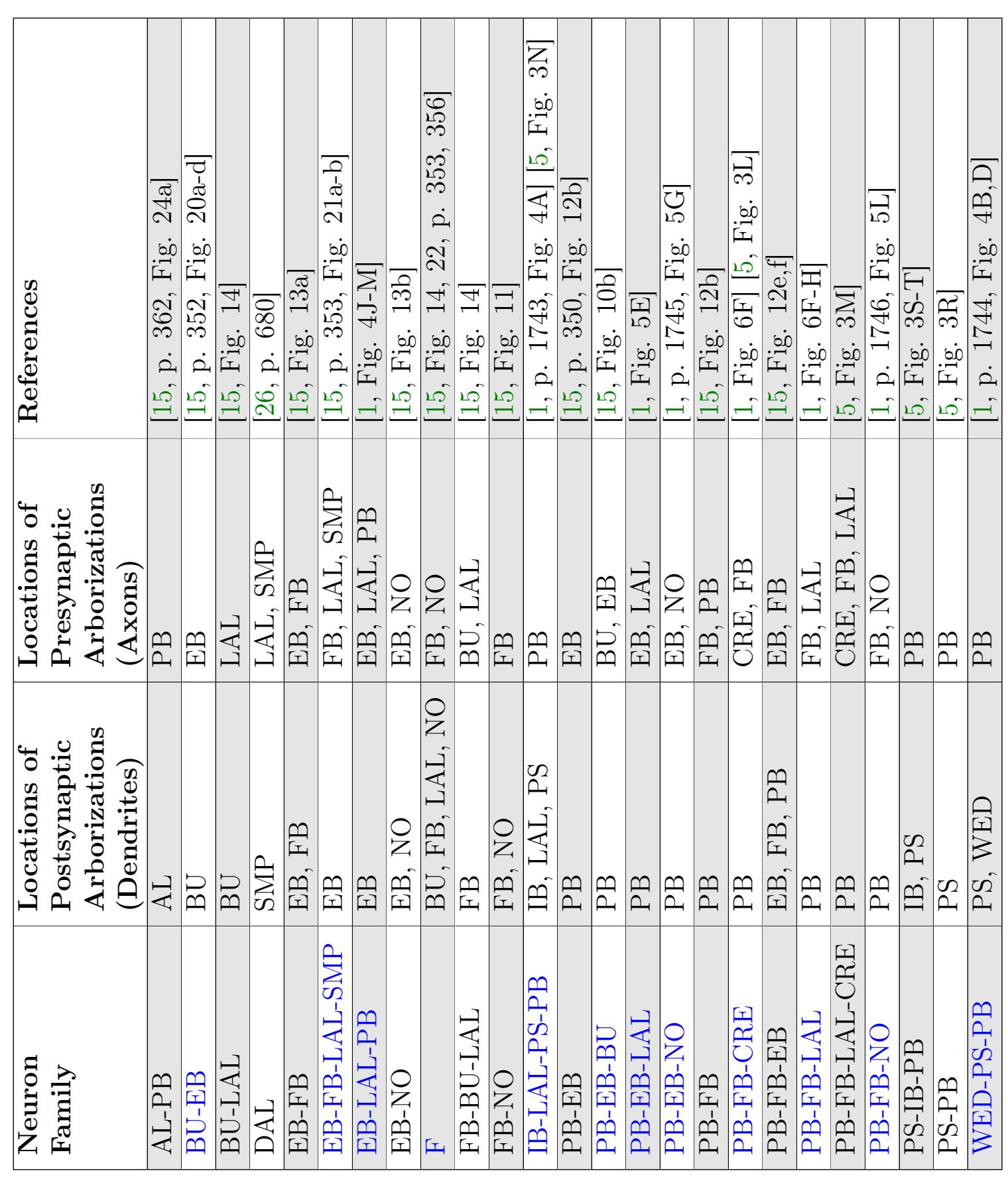




\begin{tabular}{|l|l|l|}
\hline Neuron Family & $\begin{array}{l}\text { Locations of Arboriza- } \\
\text { tions }\end{array}$ & References \\
\hline CC & LAL, NO & \\
\hline EB-NO & EB, NO & {$[15$, p. 351] } \\
\hline FB-EB & EB, FB & {$[15$, p. 351] } \\
\hline FB-NO & FB, NO & {$[15$, Fig. 11] } \\
\hline
\end{tabular}

Table 4: Projection neurons connecting CX and accessory neuropils with unresolved neurite types. 


\subsection{Neurotransmitter Profiles}

A range of neurotransmitters appear to be present in the CX neuropils (Tab. 5). Neurotransmitters associated with specific CX neural pathways have been identified (Tab. 6); however, the neurotransmitter associated with each specific arborization remains unclear.

\begin{tabular}{|c|c|c|c|}
\hline Neurotransmitters & Neuropil & Cell Type & References \\
\hline Acetylcholine & PB, FB, EB, NO & $?$ & {$[27]$} \\
Glutamate & PB, FB, EB, NO & Col, Tan & {$[28,27]$} \\
GABA & FB, EB & Tan & {$[15]$} \\
Dopamine & PB, FB, EB, NO & Tan & {$[29]$} \\
Histamine & $?$ & $?$ & {$[30]$} \\
Octopamine & PB, FB & Asc, Tan & {$[31]$} \\
Serotonin & FB, EB, NO & Tan & {$[32]$} \\
Nitric oxide & FB, EB & $?$ & {$[33]$} \\
\hline
\end{tabular}

Table 5: Neurotransmitters in the fruit fly CX (adapted from [6]). Columnar neurons include those that connect $\mathrm{PB}$ to other neuropils or connect FB and EB, NO, LAL, or other neuropils. Tangential neurons include PB local neurons, F neurons in FB, and BU-EB neurons in EB. Ascending neurons connect the subesophageal ganglion to FB. 


\begin{tabular}{|c|c|}
\hline Neuron Family & Neurotransmitter \\
\hline AL-PB & $?$ \\
BU-EB & Acetylcholine $[2$, p.1598], Glutamate, GABA \\
BU-LAL & $?$ \\
DAL & $?$ \\
EB-FB & $?$ \\
EB-FB-LAL-SMP & Dopamine \\
EB-LAL-PB & Acetylcholine \\
EB-NO & $?$ \\
F & Dopamine \\
FB local & Acetylcholine \\
FB-BU-LAL & $?$ \\
FB-EB & $?$ \\
FB-NO & $?$ \\
IB-LAL-PS-PB & Dopamine \\
PB local & $?$ \\
PB-EB & $?$ \\
PB-EB-BU & Acetylcholine, Glutamate \\
PB-EB-LAL & Acetylcholine \\
PB-EB-NO & Acetylcholine \\
PB-FB & $?$ \\
PB-FB-CRE & $?$ \\
PB-FB-LAL & Acetylcholine \\
PB-FB-NO & Acetylcholine \\
PS-IB-PB & $?$ \\
PS-PB & $?$ \\
WED-PS-PB & Acetylcholine \\
\hline
\end{tabular}

Table 6: Neurotransmitter profiles of specific neural pathways in the fruit fly CX (adapted from [1, Fig. 7c] and [2]).

\subsection{Local Neurons}

\subsubsection{PB Local Neurons}

Different studies of PB have identified 8 [5, p. 1007] or 10 [1, p. 1743] distinct local neurons. Tab. 7 and Fig. 12 assume the presence of 8 glomeruli on each side of PB as indicated by [5], that R2-R9 in [5] correspond to R1-R8 in [1], and that postsynaptic arborizations are spaced 7 glomeruli apart in all but the first 2 neuron types. The total number of each local neuron type is unclear. 


\begin{tabular}{|c|l|}
\hline & Label \\
\hline 1 & $\mathrm{~PB} / \mathrm{L} 9 / \mathrm{b}-\mathrm{PB} / \mathrm{L}[4-8] / \mathrm{s}$ \\
2 & $\mathrm{~PB} / \mathrm{L} 8|\mathrm{R} 1| \mathrm{R} 9 / \mathrm{b}-\mathrm{PB} / \mathrm{L}[1-9] \mid \mathrm{R}[1-9] / \mathrm{s}$ \\
3 & $\mathrm{~PB} / \mathrm{L} 7|\mathrm{R} 2 / \mathrm{b}-\mathrm{PB} / \mathrm{L}[1-9]| \mathrm{R}[1-9] / \mathrm{s}$ \\
4 & $\mathrm{~PB} / \mathrm{L} 6|\mathrm{R} 3 / \mathrm{b}-\mathrm{PB} / \mathrm{L}[1-9]| \mathrm{R}[1-9] / \mathrm{s}$ \\
5 & $\mathrm{~PB} / \mathrm{L} 5|\mathrm{R} 4 / \mathrm{b}-\mathrm{PB} / \mathrm{L}[1-9]| \mathrm{R}[1-9] / \mathrm{s}$ \\
6 & $\mathrm{~PB} / \mathrm{R} 5|\mathrm{~L} 4 / \mathrm{b}-\mathrm{PB} / \mathrm{R}[1-9]| \mathrm{L}[1-9] / \mathrm{s}$ \\
7 & $\mathrm{~PB} / \mathrm{R} 6|\mathrm{~L} 3 / \mathrm{b}-\mathrm{PB} / \mathrm{R}[1-9]| \mathrm{L}[1-9] / \mathrm{s}$ \\
8 & $\mathrm{~PB} / \mathrm{R} 7|\mathrm{~L} 2 / \mathrm{b}-\mathrm{PB} / \mathrm{R}[1-9]| \mathrm{L}[1-9] / \mathrm{s}$ \\
9 & $\mathrm{~PB} / \mathrm{R} 8|\mathrm{~L} 1| \mathrm{L} 9 / \mathrm{b}-\mathrm{PB} / \mathrm{R}[1-9] \mid \mathrm{L}[1-9] / \mathrm{s}$ \\
10 & $\mathrm{~PB} / \mathrm{R} 9 / \mathrm{b}-\mathrm{PB} / \mathrm{R}[4-8] / \mathrm{s}$ \\
\hline
\end{tabular}

Table 7: PB local neurons.

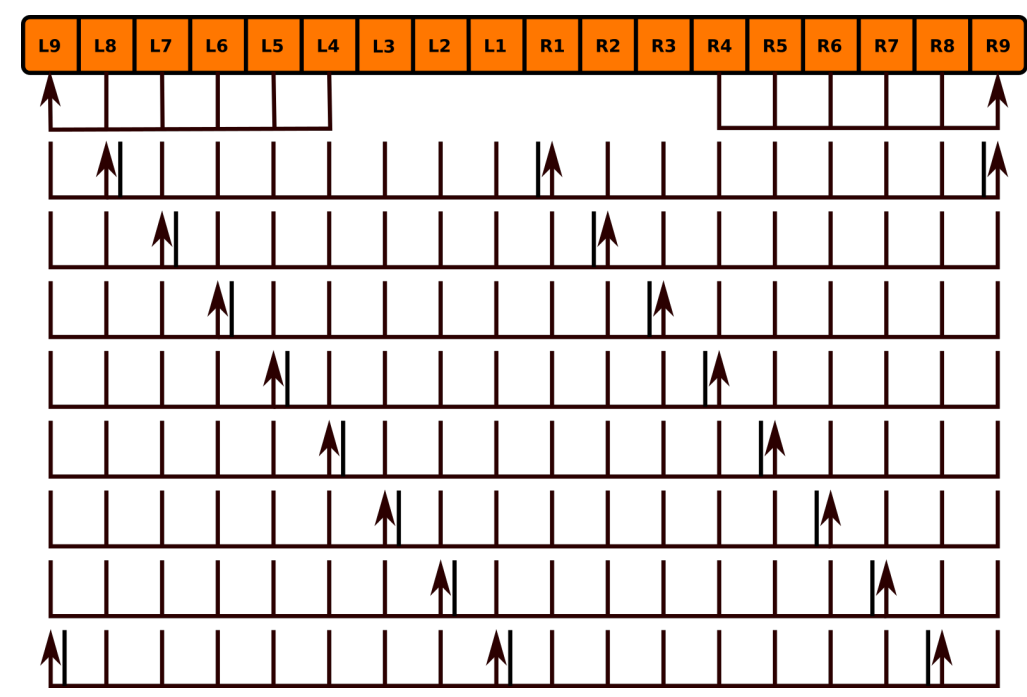

Figure 12: Innervation pattern of PB local neurons (Tab. 7).

\subsubsection{FB Local Neurons}

Several classes of local neurons referred to as pontine neurons have been observed to connect different regions of FB with each other [15, p. 349], [16, p. 1507]. One class (Tab. 8) comprises symmetric neurons that connect each segment on one side of the FB with each segment on the other side such that the presynaptic and postsynaptic arborizations are 4 segments apart [15, p. 352] (although more recent work suggests that each neuron might be a bundle of 2 neurons [22, p. 1439]). Judging by the structure of pontine neurons in other insects [34], arborizations might not be strictly confined to targeted regions. Other classes dorsoventrally connecting different layers in FB may exist, but they have not been systematically identified [15, p. 349]. It is unclear whether local neurons other than pontine neurons exist in the FB. 


\begin{tabular}{|l|l|}
\hline & Label \\
\hline 1 & $\mathrm{FB} /(3, \mathrm{~L} 4) / \mathrm{s}-\mathrm{FB} /(3, \mathrm{R} 1) / \mathrm{b}$ \\
2 & $\mathrm{FB} /(3, \mathrm{~L} 3) / \mathrm{s}-\mathrm{FB} /(3, \mathrm{R} 2) / \mathrm{b}$ \\
3 & $\mathrm{FB} /(3, \mathrm{~L} 2) / \mathrm{s}-\mathrm{FB} /(3, \mathrm{R} 3) / \mathrm{b}$ \\
4 & $\mathrm{FB} /(3, \mathrm{~L} 1) / \mathrm{s}-\mathrm{FB} /(3, \mathrm{R} 4) / \mathrm{b}$ \\
5 & $\mathrm{FB} /(3, \mathrm{R} 4) / \mathrm{s}-\mathrm{FB} /(3, \mathrm{~L} 1) / \mathrm{b}$ \\
6 & $\mathrm{FB} /(3, \mathrm{R} 3) / \mathrm{s}-\mathrm{FB} /(3, \mathrm{~L} 2) / \mathrm{b}$ \\
7 & $\mathrm{FB} /(3, \mathrm{R} 2) / \mathrm{s}-\mathrm{FB} /(3, \mathrm{~L} 3) / \mathrm{b}$ \\
8 & $\mathrm{FB} /(3, \mathrm{R} 1) / \mathrm{s}-\mathrm{FB} /(3, \mathrm{~L} 4) / \mathrm{b}$ \\
\hline
\end{tabular}

Table 8: One identified class of FB local neurons.

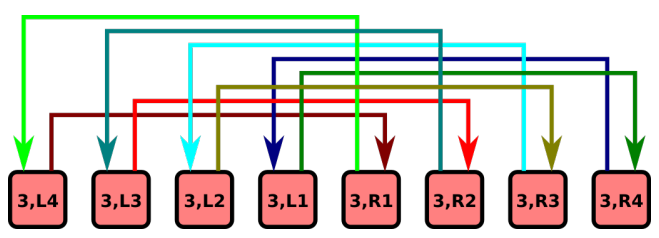

Figure 13: Innervation pattern of FB local neurons (Tab. 8).

\subsubsection{EB Local Neurons}

Although there appear to be local neurons in EB [3], they do not appear to have been systematically identified yet.

\subsection{Projection Neurons}

\subsubsection{BU-EB Projection Neurons}

Neurons with postsynaptic arborizations in BU and presynaptic arborizations in EB are typically referred to as ring or $\mathrm{R}$ neurons [15, p. 352] by virtue of the shape of their EB arborizations. 5 types of ring neurons (R1, R2, R3, R4m, R4d) have been observed [16, p. 1509]; specific ring neuron types appear to be essential to different visual behaviors [35, p. 120]. Each ring neuron type arborizes in a single microglomerulus [8, p. 262] and a different portion of the EB radius (Fig. 14); these types correspond to different sets of BU microglomeruli (and hence comprise multiple neurons). About 20 of each of these types of neurons have been estimated in each hemisphere of the fruit fly brain [16, p. 1510]; combined with visual confirmation of the presence of 80 microglomeruli $(\S 3.5)$, this suggests that there are 16 of each neuron type present in BU. Some ring neurons are GABAergic [1, p. 1750], while others are glutamatergic [1, Fig. $7 \mathrm{C}]$; their synaptic connections to other neurons in EB therefore seem to be inhibitory. There is recent evidence that some ring neurons may be cholinergic and hence possess excitatory synapses [2, p. 1598]. Coincident synapses (i.e., those in which two independent presynaptic zones coincide with a single postsynaptic zone) 
have been observed in EB between ring neurons in specific domains and other neurons both in and outside of those domains. [2, p. 1592]; it seems that such synapses may also exist between other neurons that innervate EB [2, p. 1594]. Connections between AOTU and BU have been observed [23, p. 9]; these presumably constitute a pathway for input visual information from LO via AOTU [25, p. 939] to EB via ring neurons.

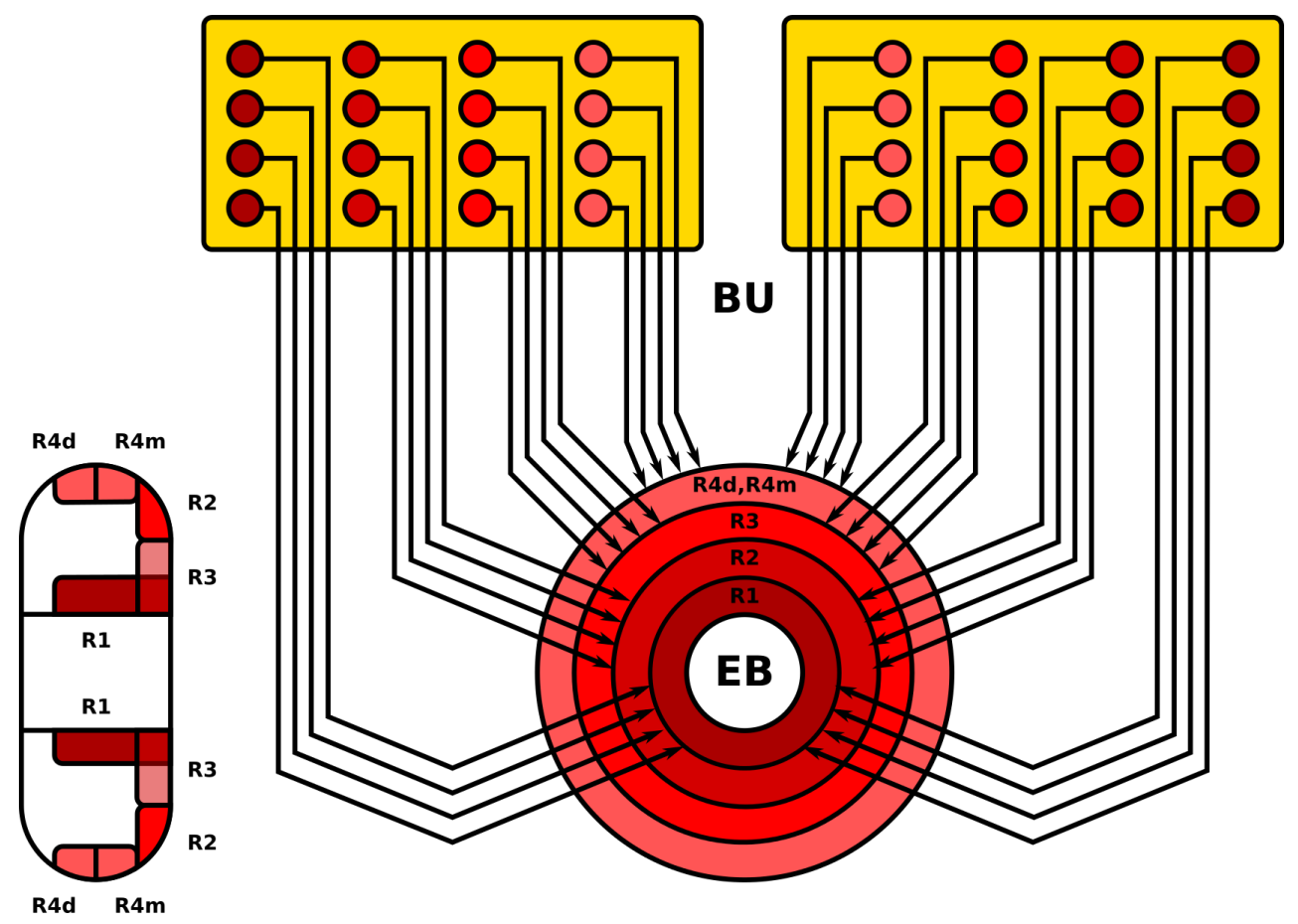

Figure 14: Spatial organization of ring neuron arborizations in BU microglomeruli (yellow) and regions in EB (red); posterior is left of sagittal section of EB, anterior is right. The depicted EB regions do not exactly correspond to the rings in Fig. 6c. Only a fraction of the microglomeruli/neurons are depicted. The spatial organization of each neuron type's microglomeruli is unclear.

\subsubsection{EB-FB-LAL-SMP Projection Neurons}

Neurons with presynaptic ring-shaped arborizations in EB and postsynaptic arborizations in other neuropils are referred to as extrinsic ring neurons. Two types (ExR1, ExR2) have been observed; these neurons appear to constitute a dopaminergic pathway [1, Fig. 7C]. ExR1 neurons are presynaptic in EB, FB, and LAL, and postsynaptic in SMP [15, p. 353] [VirtualFlyBrain]. ExR2 appears to have presynaptic arborizations in EB and arborizations in SMP, but the remainder of the neuron's structure has not been reconstructed. 


\subsubsection{EB-LAL-PB Projection Neurons}

These neurons correspond to the EB-PB-VBO or EIP neurons in [1, Fig. 2]; they constitute a cholinergic pathway [1, Fig. 7C]. The neuron arborizations in Tab. 9 and Fig. 15 make the assumption that the $\mathrm{C}, \mathrm{O}$, and $\mathrm{P}$ rings in [1] collectively correspond to the $\mathrm{P}$ and $\mathrm{M}$ shells in [5] and that the $\mathrm{C}$ and $\mathrm{P}$ rings collectively correspond to the $\mathrm{P}$ shell.

\begin{tabular}{|c|l|}
\hline & Label \\
\hline 1 & $\mathrm{~EB} /(\mathrm{L} 8, \mathrm{P},[1-4]) / \mathrm{s}-\mathrm{EB} /(\mathrm{L} 8, \mathrm{P},[1-4]) / \mathrm{b}-\mathrm{lal} / \mathrm{RDG} / \mathrm{b}-\mathrm{PB} / \mathrm{L} 9 / \mathrm{b}$ \\
2 & $\mathrm{~EB} /([\mathrm{L} 7, \mathrm{R} 8],[\mathrm{P}, \mathrm{M}],[1-4]) / \mathrm{s}-\mathrm{EB} /(\mathrm{L} 8,[\mathrm{P}, \mathrm{M}],[1-4]) / \mathrm{b}-\mathrm{LAL} / \mathrm{LDG} / \mathrm{b}-\mathrm{PB} / \mathrm{R} 1 \mid \mathrm{L} 1 / \mathrm{b}$ \\
3 & $\mathrm{~EB} /([\mathrm{L} 8, \mathrm{~L} 6],[\mathrm{P}, \mathrm{M}],[1-4]) / \mathrm{s}-\mathrm{EB} /(\mathrm{L} 7,[\mathrm{P}, \mathrm{M}],[1-4]) / \mathrm{b}-\mathrm{lal} / \mathrm{RVG} / \mathrm{b}-\mathrm{PB} / \mathrm{L} 8 / \mathrm{b}$ \\
4 & $\mathrm{~EB} /([\mathrm{L} 5, \mathrm{~L} 7],[\mathrm{P}, \mathrm{M}],[1-4]) / \mathrm{s}-\mathrm{EB} /(\mathrm{L} 6,[\mathrm{P}, \mathrm{M}],[1-4]) / \mathrm{b}-\mathrm{LAL} / \mathrm{LVG} / \mathrm{b}-\mathrm{PB} / \mathrm{R} 2 / \mathrm{b}$ \\
5 & $\mathrm{~EB} /([\mathrm{L} 6, \mathrm{~L} 4],[\mathrm{P}, \mathrm{M}],[1-4]) / \mathrm{s}-\mathrm{EB} /(\mathrm{L} 5,[\mathrm{P}, \mathrm{M}],[1-4]) / \mathrm{b}-\mathrm{lal} / \mathrm{RDG} / \mathrm{b}-\mathrm{PB} / \mathrm{L} 7 / \mathrm{b}$ \\
6 & $\mathrm{~EB} /([\mathrm{L} 3, \mathrm{~L} 5],[\mathrm{P}, \mathrm{M}],[1-4]) / \mathrm{s}-\mathrm{EB} /(\mathrm{L} 4,[\mathrm{P}, \mathrm{M}],[1-4]) / \mathrm{b}-\mathrm{LAL} / \mathrm{LDG} / \mathrm{b}-\mathrm{PB} / \mathrm{R} 3 / \mathrm{b}$ \\
7 & $\mathrm{~EB} /([\mathrm{L} 4, \mathrm{~L} 2],[\mathrm{P}, \mathrm{M}],[1-4]) / \mathrm{s}-\mathrm{EB} /(\mathrm{L} 3,[\mathrm{P}, \mathrm{M}],[1-4]) / \mathrm{b}-\mathrm{lal} / \mathrm{RVG} / \mathrm{b}-\mathrm{PB} / \mathrm{L} 6 / \mathrm{b}$ \\
8 & $\mathrm{~EB} /([\mathrm{L} 1, \mathrm{~L} 3],[\mathrm{P}, \mathrm{M}],[1-4]) / \mathrm{s}-\mathrm{EB} /(\mathrm{L} 2,[\mathrm{P}, \mathrm{M}],[1-4]) / \mathrm{b}-\mathrm{LAL} / \mathrm{LVG} / \mathrm{b}-\mathrm{PB} / \mathrm{R} 4 / \mathrm{b}$ \\
9 & $\mathrm{~EB} /([\mathrm{L} 2, \mathrm{R} 1],[\mathrm{P}, \mathrm{M}],[1-4]) / \mathrm{s}-\mathrm{EB} /(\mathrm{L} 1,[\mathrm{P}, \mathrm{M}],[1-4]) / \mathrm{b}-\mathrm{lal} / \mathrm{RDG} / \mathrm{b}-\mathrm{PB} / \mathrm{L} 5 / \mathrm{b}$ \\
10 & $\mathrm{~EB} /([\mathrm{R} 2, \mathrm{~L} 1],[\mathrm{P}, \mathrm{M}],[1-4]) / \mathrm{s}-\mathrm{EB} /(\mathrm{R} 1,[\mathrm{P}, \mathrm{M}],[1-4]) / \mathrm{b}-\mathrm{LAL} / \mathrm{LDG} / \mathrm{b}-\mathrm{PB} / \mathrm{R} 5 / \mathrm{b}$ \\
11 & $\mathrm{~EB} /([\mathrm{R} 1, \mathrm{R} 3],[\mathrm{P}, \mathrm{M}],[1-4]) / \mathrm{s}-\mathrm{EB} /(\mathrm{R} 2,[\mathrm{P}, \mathrm{M}],[1-4]) / \mathrm{b}-\mathrm{lal} / \mathrm{RVG} / \mathrm{b}-\mathrm{PB} / \mathrm{L} 4 / \mathrm{b}$ \\
12 & $\mathrm{~EB} /([\mathrm{R} 4, \mathrm{R} 2],[\mathrm{P}, \mathrm{M}],[1-4]) / \mathrm{s}-\mathrm{EB} /(\mathrm{R} 3,[\mathrm{P}, \mathrm{M}],[1-4]) / \mathrm{b}-\mathrm{LAL} / \mathrm{LVG} / \mathrm{b}-\mathrm{PB} / \mathrm{R} 6 / \mathrm{b}$ \\
13 & $\mathrm{~EB} /([\mathrm{R} 3, \mathrm{R} 5],[\mathrm{P}, \mathrm{M}],[1-4]) / \mathrm{s}-\mathrm{EB} /(\mathrm{R} 4,[\mathrm{P}, \mathrm{M}],[1-4]) / \mathrm{b}-\mathrm{lal} / \mathrm{RDG} / \mathrm{b}-\mathrm{PB} / \mathrm{L} 3 / \mathrm{b}$ \\
14 & $\mathrm{~EB} /([\mathrm{R} 6, \mathrm{R} 4],[\mathrm{P}, \mathrm{M}],[1-4]) / \mathrm{s}-\mathrm{EB} /(\mathrm{R} 5,[\mathrm{P}, \mathrm{M}],[1-4]) / \mathrm{b}-\mathrm{LAL} / \mathrm{LDG} / \mathrm{b}-\mathrm{PB} / \mathrm{R} 7 / \mathrm{b}$ \\
15 & $\mathrm{~EB} /([\mathrm{R} 5, \mathrm{R} 7],[\mathrm{P}, \mathrm{M}],[1-4]) / \mathrm{s}-\mathrm{EB} /(\mathrm{R} 6,[\mathrm{P}, \mathrm{M}],[1-4]) / \mathrm{b}-\mathrm{lal} / \mathrm{RVG} / \mathrm{b}-\mathrm{PB} / \mathrm{L} 2 / \mathrm{b}$ \\
16 & $\mathrm{~EB} /([\mathrm{R} 8, \mathrm{R} 6],[\mathrm{P}, \mathrm{M}],[1-4]) / \mathrm{s}-\mathrm{EB} /(\mathrm{R} 7,[\mathrm{P}, \mathrm{M}],[1-4]) / \mathrm{b}-\mathrm{LAL} / \mathrm{LVG} / \mathrm{b}-\mathrm{PB} / \mathrm{R} 8 / \mathrm{b}$ \\
17 & $\mathrm{~EB} /([\mathrm{R} 7, \mathrm{~L} 8],[\mathrm{P}, \mathrm{M}],[1-4]) / \mathrm{s}-\mathrm{EB} /(\mathrm{R} 8,[\mathrm{P}, \mathrm{M}],[1-4]) / \mathrm{b}-\mathrm{lal} / \mathrm{RDG} / \mathrm{b}-\mathrm{PB} / \mathrm{L} 1 \mid \mathrm{R} 1 / \mathrm{b}$ \\
18 & $\mathrm{~EB} /(\mathrm{R} 8, \mathrm{P},[1-4]) / \mathrm{s}-\mathrm{EB} /(\mathrm{R} 8, \mathrm{P},[1-4]) / \mathrm{b}-\mathrm{LAL} / \mathrm{LDG} / \mathrm{b}-\mathrm{PB} / \mathrm{R} 9 / \mathrm{b}$ \\
\hline
\end{tabular}

Table 9: EB-LAL-PB neurons. 
bioRxiv preprint doi: https://doi org/10.1101/051318; this version posted May 23,2016 . The copyright holder for this preprint (which was not certified by peer review) is the author/funder, who has granted bioRxiv a license to display the preprint in perpetuity. It is made available under aCC-BY 4.0 International license.

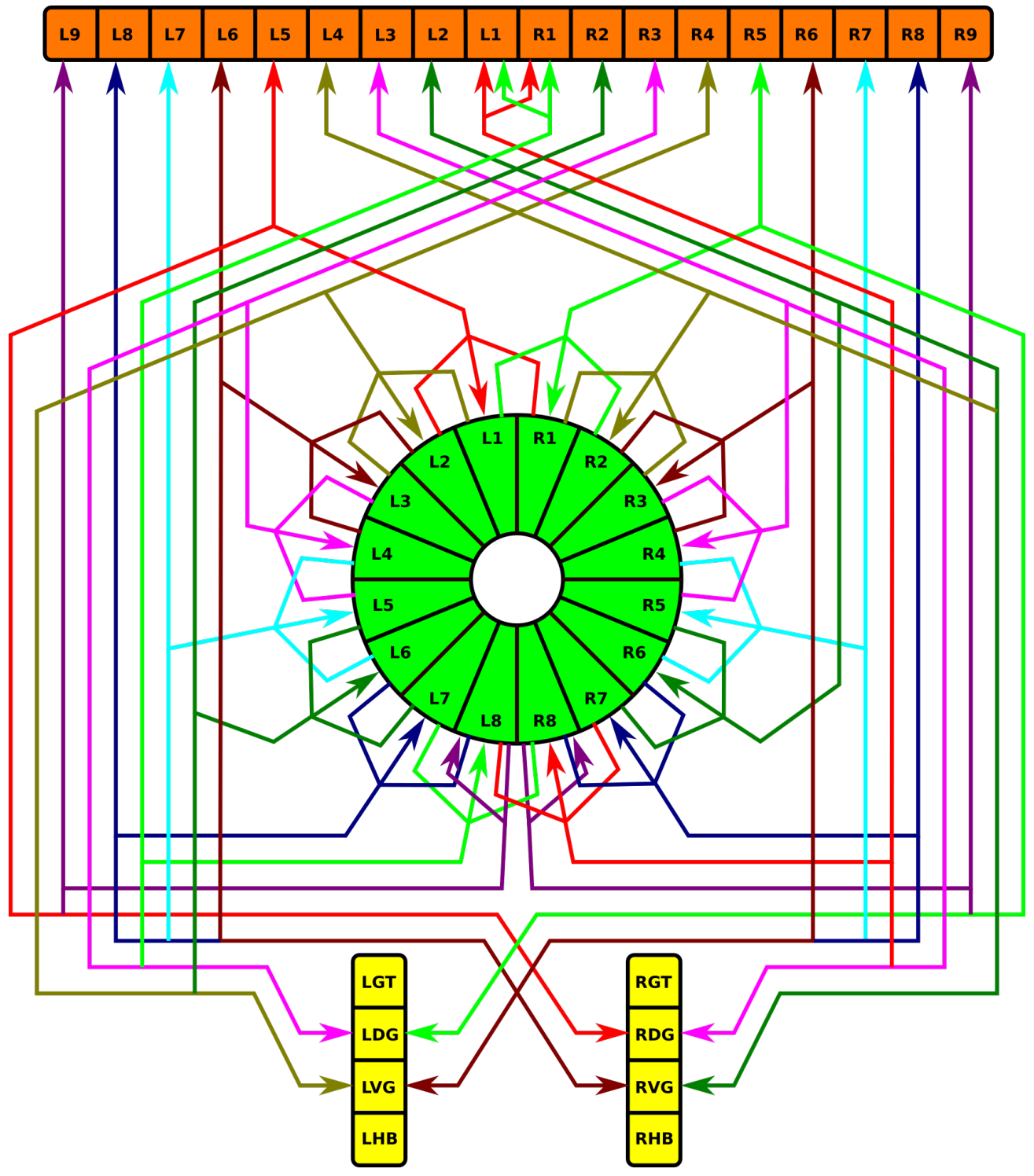

Figure 15: Neuropil innervation pattern for EB-LAL-PB neurons (Tab. 9). 


\subsubsection{F Projection Neurons}

F neurons innervate entire layers of FB, with some types associated with specific layers [15, p. 353]. Fm neurons have bleb-like (presynaptic) arborizations in layer 2 of FB; Fm1 neurons have spiny (postsynaptic arborizations in SLP or SIP, Fm2 neurons have spiny arborizations in LAL, and Fm3 neurons have spiny arborizations in ICL [15, p. 353]. Some Fl neurons have spiny branches in LAL [15, p. 354], while other Fl neurons have spiny branches that innervate the entire BU [15, p. 354].

\subsubsection{IB-LAL-PS-PB Projection Neurons}

These neurons corresponds to the CVLP-IDFP-VMP-PB or CIVP neurons in [1, Fig. 2] and the PB-LAL-PS neurons in [5, Fig. 3N]. They receive indirect input from the vision system and innervate all glomeruli in PB indicated in Tab. 10:

\begin{tabular}{|l|l|}
\hline & Label \\
\hline 1 & $\mathrm{IB} / \mathrm{L} / \mathrm{s}-\mathrm{LAL} / \mathrm{LHB} / \mathrm{s}-\mathrm{PS} / \mathrm{L} / \mathrm{s}-\mathrm{PB} / \mathrm{L}[2-9] \mid \mathrm{R}[2-9] / \mathrm{b}$ \\
2 & $\mathrm{ib} / \mathrm{R} / \mathrm{s}-\mathrm{lal} / \mathrm{RHB} / \mathrm{s}-\mathrm{ps} / \mathrm{R} / \mathrm{s}-\mathrm{PB} / \mathrm{L}[2-9] \mid \mathrm{R}[2-9] / \mathrm{b}$ \\
\hline
\end{tabular}

Table 10: IB-LAL-PS-PB neurons.

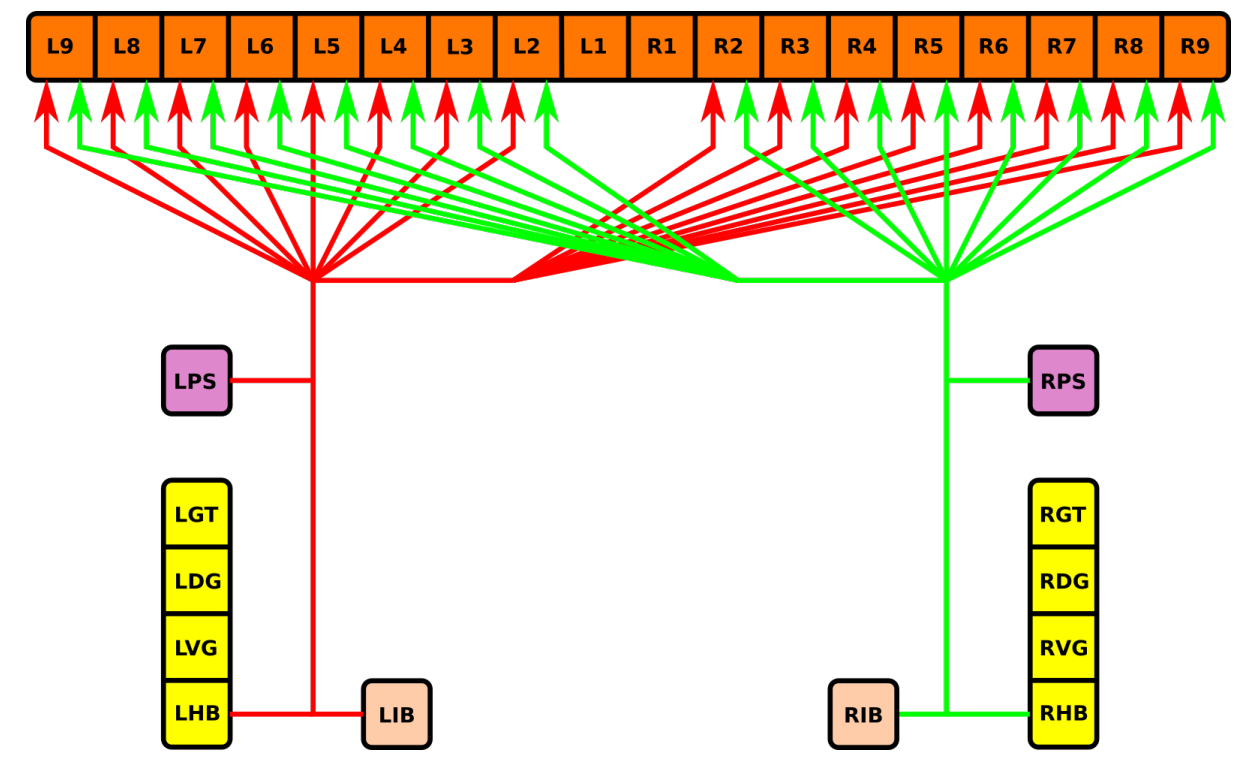

Figure 16: Neuropil innervation pattern for IB-LAL-PS-PB neurons (Tab. 10).

\subsubsection{PB-EB-BU Projection Neurons}

Neurons with postsynaptic arborizations in PB and presynaptic arborizations in EB and BU have been observed. These correspond to the PB-EB-LTR neurons in [15, Fig. 10b]. Details regarding possible neuron types have not been determined. 


\subsubsection{PB-EB-NO Projection Neurons}

Neurons with postsynaptic arborizations in PB and presynaptic arborizations in EB and NO are referred to as PEN neurons in [1, p. 1745]. The constitute a cholinergic pathway [1, Fig. 7C]. The connections in Tab. 11 and Fig. 17 are based upon [5, Fig. 14a], which differ from those described in [1, Fig. $5 \mathrm{~g}]$.

\begin{tabular}{|c|l|}
\hline & Label \\
\hline 1 & $\mathrm{~PB} / \mathrm{L} 9 / \mathrm{s}-\mathrm{EB} / 6 / \mathrm{b}-\mathrm{no} /(1, \mathrm{R}) / \mathrm{b}$ \\
2 & $\mathrm{~PB} / \mathrm{L} 8 / \mathrm{s}-\mathrm{EB} / 7 / \mathrm{b}-\mathrm{no} /(1, \mathrm{R}) / \mathrm{b}$ \\
3 & $\mathrm{~PB} / \mathrm{L} 7 / \mathrm{s}-\mathrm{EB} / 8 / \mathrm{b}-\mathrm{no} /(1, \mathrm{R}) / \mathrm{b}$ \\
4 & $\mathrm{~PB} / \mathrm{L} 6 / \mathrm{s}-\mathrm{EB} / 1 / \mathrm{b}-\mathrm{no} /(1, \mathrm{R}) / \mathrm{b}$ \\
5 & $\mathrm{~PB} / \mathrm{L} 5 / \mathrm{s}-\mathrm{EB} / 2 / \mathrm{b}-\mathrm{no} /(1, \mathrm{R}) / \mathrm{b}$ \\
6 & $\mathrm{~PB} / \mathrm{L} 4 / \mathrm{s}-\mathrm{EB} / 3 / \mathrm{b}-\mathrm{no} /(1, \mathrm{R}) / \mathrm{b}$ \\
7 & $\mathrm{~PB} / \mathrm{L} 3 / \mathrm{s}-\mathrm{EB} / 4 / \mathrm{b}-\mathrm{no} /(1, \mathrm{R}) / \mathrm{b}$ \\
8 & $\mathrm{~PB} / \mathrm{L} 2 / \mathrm{s}-\mathrm{EB} / 5 / \mathrm{b}-\mathrm{no} /(1, \mathrm{R}) / \mathrm{b}$ \\
9 & $\mathrm{~PB} / \mathrm{R} 2 / \mathrm{s}-\mathrm{EB} / 5 / \mathrm{b}-\mathrm{NO} /(1, \mathrm{~L}) / \mathrm{b}$ \\
10 & $\mathrm{~PB} / \mathrm{R} 3 / \mathrm{s}-\mathrm{EB} / 6 / \mathrm{b}-\mathrm{NO} /(1, \mathrm{~L}) / \mathrm{b}$ \\
11 & $\mathrm{~PB} / \mathrm{R} 4 / \mathrm{s}-\mathrm{EB} / 7 / \mathrm{b}-\mathrm{NO} /(1, \mathrm{~L}) / \mathrm{b}$ \\
12 & $\mathrm{~PB} / \mathrm{R} 5 / \mathrm{s}-\mathrm{EB} / 8 / \mathrm{b}-\mathrm{NO} /(1, \mathrm{~L}) / \mathrm{b}$ \\
13 & $\mathrm{~PB} / \mathrm{R} 6 / \mathrm{s}-\mathrm{EB} / 1 / \mathrm{b}-\mathrm{NO} /(1, \mathrm{~L}) / \mathrm{b}$ \\
14 & $\mathrm{~PB} / \mathrm{R} 7 / \mathrm{s}-\mathrm{EB} / 2 / \mathrm{b}-\mathrm{NO} /(1, \mathrm{~L}) / \mathrm{b}$ \\
15 & $\mathrm{~PB} / \mathrm{R} 8 / \mathrm{s}-\mathrm{EB} / 3 / \mathrm{b}-\mathrm{NO} /(1, \mathrm{~L}) / \mathrm{b}$ \\
16 & $\mathrm{~PB} / \mathrm{R} 9 / \mathrm{s}-\mathrm{EB} / 4 / \mathrm{b}-\mathrm{NO} /(1, \mathrm{~L}) / \mathrm{b}$ \\
\hline
\end{tabular}

Table 11: PB-EB-NO neurons. 
bioRxiv preprint doi: https://doi.org/10.1101/051318; this version posted May 23, 2016. The copyright holder for this preprint (which was not certified by peer review) is the author/funder, who has granted bioRxiv a license to display the preprint in perpetuity. It is made available under aCC-BY 4.0 International license.

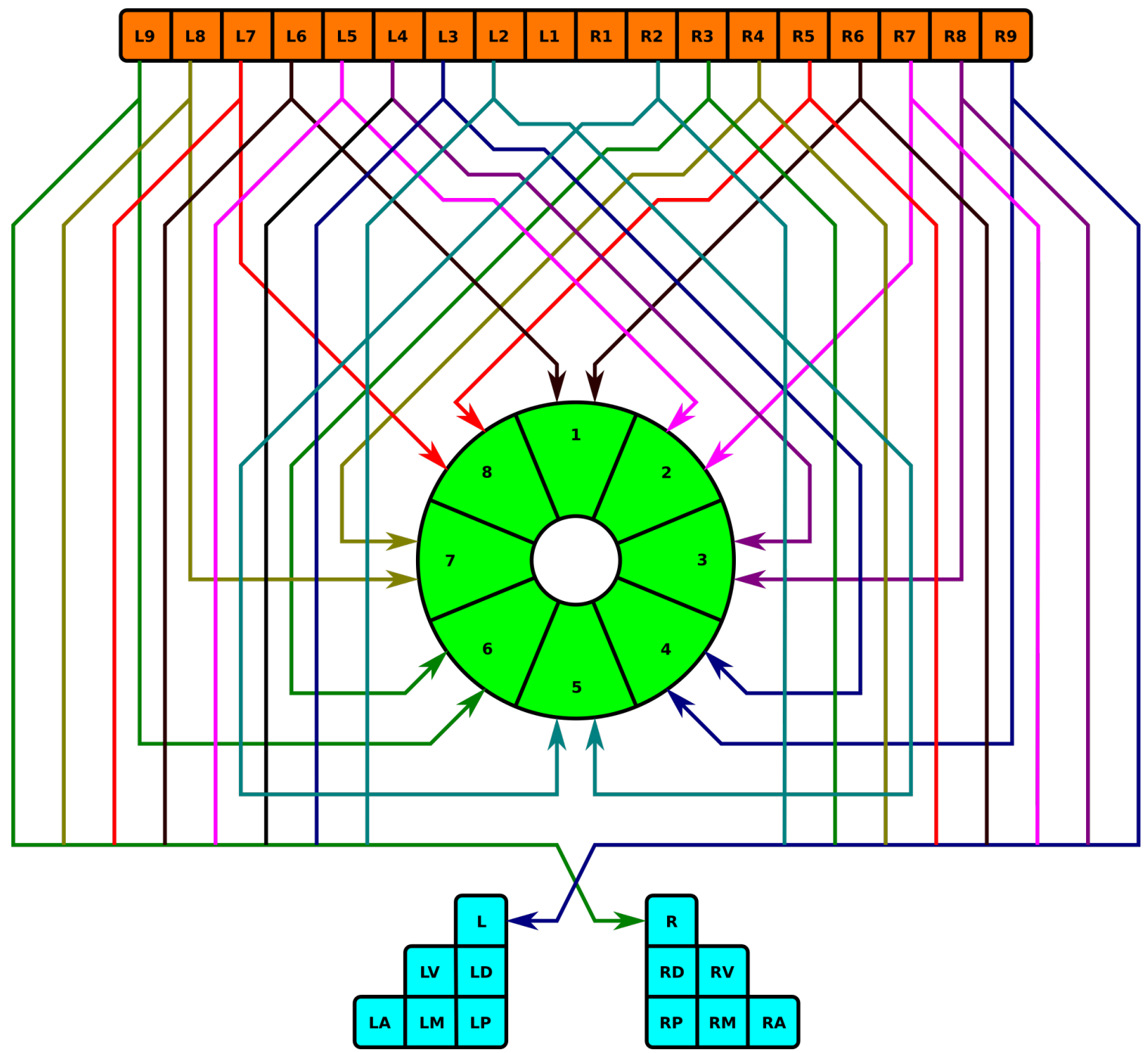

Figure 17: Neuropil innervation pattern for PB-EB-NO neurons (Tab. 11).

\subsubsection{PB-EB-LAL Projection Neurons}

These neurons have postsynaptic arborizations in PB and presynaptic arborizations in EB and LAL; they correspond to PB-EB-IDFP or PEI neurons in [1, Fig. 2]. These neurons constitute a cholinergic pathway [1, Fig. 7C]. The connections in Tab. 12 and Fig. 18 are based upon [5, Fig. 14b], which differ from those described in [1, Fig. 5e]. 


\begin{tabular}{|c|l|}
\hline & Label \\
\hline 1 & $\mathrm{~PB} / \mathrm{L} 8 / \mathrm{s}-\mathrm{EB} / 6 / \mathrm{b}-\mathrm{lal} / \mathrm{RVG} / \mathrm{b}$ \\
2 & $\mathrm{~PB} / \mathrm{L} 7 / \mathrm{s}-\mathrm{EB} / 7 / \mathrm{b}-\mathrm{lal} / \mathrm{RDG} / \mathrm{b}$ \\
3 & $\mathrm{~PB} / \mathrm{L} 6 / \mathrm{s}-\mathrm{EB} / 8 / \mathrm{b}-\mathrm{lal} / \mathrm{RVG} / \mathrm{b}$ \\
4 & $\mathrm{~PB} / \mathrm{L} 5 / \mathrm{s}-\mathrm{EB} / 1 / \mathrm{b}-\mathrm{lal} / \mathrm{RDG} / \mathrm{b}$ \\
5 & $\mathrm{~PB} / \mathrm{L} 4 / \mathrm{s}-\mathrm{EB} / 2 / \mathrm{b}-\mathrm{lal} / \mathrm{RVG} / \mathrm{b}$ \\
6 & $\mathrm{~PB} / \mathrm{L} 3 / \mathrm{s}-\mathrm{EB} / 3 / \mathrm{b}-\mathrm{lal} / \mathrm{RDG} / \mathrm{b}$ \\
7 & $\mathrm{~PB} / \mathrm{L} 2 / \mathrm{s}-\mathrm{EB} / 4 / \mathrm{b}-\mathrm{lal} / \mathrm{RVG} / \mathrm{b}$ \\
8 & $\mathrm{~PB} / \mathrm{L} 1 / \mathrm{s}-\mathrm{EB} / 5 / \mathrm{b}-\mathrm{lal} / \mathrm{RDG} / \mathrm{b}$ \\
9 & $\mathrm{~PB} / \mathrm{R} 1 / \mathrm{s}-\mathrm{EB} / 5 / \mathrm{b}-\mathrm{LAL} / \mathrm{LDG} / \mathrm{b}$ \\
10 & $\mathrm{~PB} / \mathrm{R} 2 / \mathrm{s}-\mathrm{EB} / 4 / \mathrm{b}-\mathrm{LAL} / \mathrm{LVG} / \mathrm{b}$ \\
11 & $\mathrm{~PB} / \mathrm{R} 3 / \mathrm{s}-\mathrm{EB} / 3 / \mathrm{b}-\mathrm{LAL} / \mathrm{LDG} / \mathrm{b}$ \\
12 & $\mathrm{~PB} / \mathrm{R} 4 / \mathrm{s}-\mathrm{EB} / 2 / \mathrm{b}-\mathrm{LAL} / \mathrm{LVG} / \mathrm{b}$ \\
13 & $\mathrm{~PB} / \mathrm{R} 5 / \mathrm{s}-\mathrm{EB} / 1 / \mathrm{b}-\mathrm{LAL} / \mathrm{LDG} / \mathrm{b}$ \\
14 & $\mathrm{~PB} / \mathrm{R} 6 / \mathrm{s}-\mathrm{EB} / 8 / \mathrm{b}-\mathrm{LAL} / \mathrm{LVG} / \mathrm{b}$ \\
15 & $\mathrm{~PB} / \mathrm{R} 7 / \mathrm{s}-\mathrm{EB} / 7 / \mathrm{b}-\mathrm{LAL} / \mathrm{LDG} / \mathrm{b}$ \\
16 & $\mathrm{~PB} / \mathrm{R} 8 / \mathrm{s}-\mathrm{EB} / 6 / \mathrm{b}-\mathrm{LAL} / \mathrm{LVG} / \mathrm{b}$ \\
\hline
\end{tabular}

Table 12: PB-EB-LAL neurons. 
bioRxiv preprint doi: https://doi.org/10.1101/051318; this version posted May 23, 2016. The copyright holder for this preprint (which was not certified by peer review) is the author/funder, who has granted bioRxiv a license to display the preprint in perpetuity. It is made available under aCC-BY 4.0 International license.

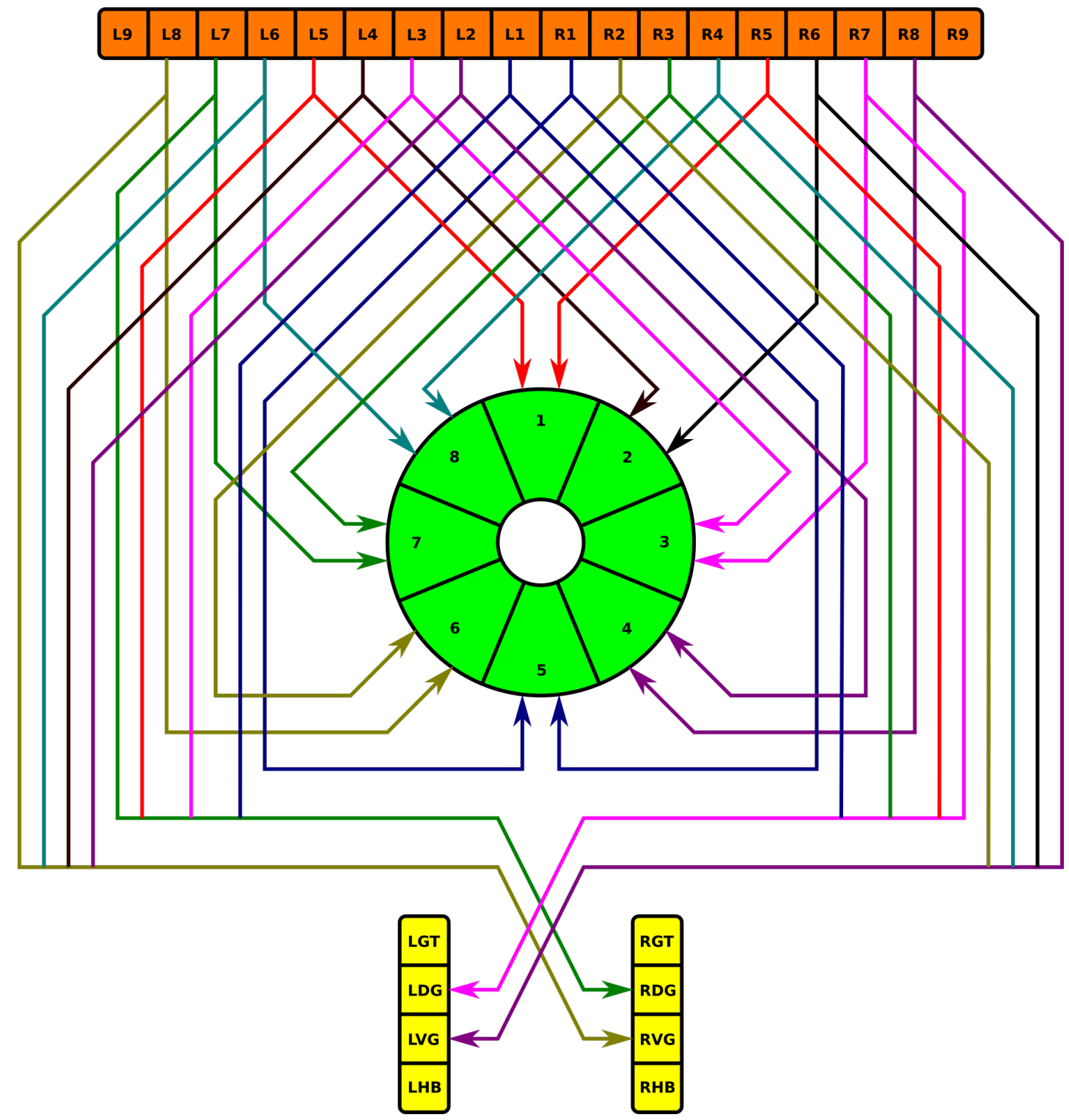

Figure 18: Neuropil innervation pattern for PB-EB-LAL neurons (Tab. 12). 


\subsubsection{PB-FB-CRE Projection Neurons}

The neurons in Tab. 13 and Fig. 19 correspond to the PB-FB-VBO or PFI neurons that connect to RB in [1, Fig. 2]. They constitute a cholinergic pathway [1, Fig. 7C].

\begin{tabular}{|c|l|}
\hline & Label \\
\hline 1 & $\mathrm{~PB} / \mathrm{L} 1 / \mathrm{s}-\mathrm{FB} /([3-4], \mathrm{L} 4) / \mathrm{s}-\mathrm{CRE} / \mathrm{LRB} / \mathrm{b}$ \\
2 & $\mathrm{~PB} / \mathrm{R} 1 / \mathrm{s}-\mathrm{FB} /([3-4], \mathrm{L} 4) / \mathrm{s}-\mathrm{CRE} / \mathrm{LRB} / \mathrm{b}$ \\
3 & $\mathrm{~PB} / \mathrm{R} 2 / \mathrm{s}-\mathrm{FB} /([3-4], \mathrm{L} 3) / \mathrm{s}-\mathrm{CRE} / \mathrm{LRB} / \mathrm{b}$ \\
4 & $\mathrm{~PB} / \mathrm{R} 3 / \mathrm{s}-\mathrm{FB} /([3-4], \mathrm{L} 2) / \mathrm{s}-\mathrm{CRE} / \mathrm{LRB} / \mathrm{b}$ \\
5 & $\mathrm{~PB} / \mathrm{R} 4 / \mathrm{s}-\mathrm{FB} /([3-4], \mathrm{L} 1) / \mathrm{s}-\mathrm{CRE} / \mathrm{LRB} / \mathrm{b}$ \\
6 & $\mathrm{~PB} / \mathrm{R} 4 / \mathrm{s}-\mathrm{FB} /([3-4], \mathrm{R} 1) / \mathrm{s}-\mathrm{CRE} / \mathrm{LRB} / \mathrm{b}$ \\
7 & $\mathrm{~PB} / \mathrm{R} 5 / \mathrm{s}-\mathrm{FB} /([3-4], \mathrm{R} 2) / \mathrm{s}-\mathrm{CRE} / \mathrm{LRB} / \mathrm{b}$ \\
8 & $\mathrm{~PB} / \mathrm{R} 6 / \mathrm{s}-\mathrm{FB} /([3-4], \mathrm{R} 3) / \mathrm{s}-\mathrm{CRE} / \mathrm{LRB} / \mathrm{b}$ \\
9 & $\mathrm{~PB} / \mathrm{R} 7 / \mathrm{s}-\mathrm{FB} /([3-4], \mathrm{R} 4) / \mathrm{s}-\mathrm{CRE} / \mathrm{LRB} / \mathrm{b}$ \\
10 & $\mathrm{~PB} / \mathrm{L} 7 / \mathrm{s}-\mathrm{FB} /([3-4], \mathrm{L} 4) / \mathrm{s}-\mathrm{cre} / \mathrm{RRB} / \mathrm{b}$ \\
11 & $\mathrm{~PB} / \mathrm{L} 6 / \mathrm{s}-\mathrm{FB} /([3-4], \mathrm{L} 3) / \mathrm{s}-\mathrm{cre} / \mathrm{RRB} / \mathrm{b}$ \\
12 & $\mathrm{~PB} / \mathrm{L} 5 / \mathrm{s}-\mathrm{FB} /([3-4], \mathrm{L} 2) / \mathrm{s}-\mathrm{cre} / \mathrm{RRB} / \mathrm{b}$ \\
13 & $\mathrm{~PB} / \mathrm{L} 4 / \mathrm{s}-\mathrm{FB} /([3-4], \mathrm{L} 1) / \mathrm{s}-\mathrm{cre} / \mathrm{RRB} / \mathrm{b}$ \\
14 & $\mathrm{~PB} / \mathrm{L} 4 / \mathrm{s}-\mathrm{FB} /([3-4], \mathrm{R} 1) / \mathrm{s}-\mathrm{cre} / \mathrm{RRB} / \mathrm{b}$ \\
15 & $\mathrm{~PB} / \mathrm{L} 3 / \mathrm{s}-\mathrm{FB} /([3-4], \mathrm{R} 2) / \mathrm{s}-\mathrm{cre} / \mathrm{RRB} / \mathrm{b}$ \\
16 & $\mathrm{~PB} / \mathrm{L} 2 / \mathrm{s}-\mathrm{FB} /([3-4], \mathrm{R} 3) / \mathrm{s}-\mathrm{cre} / \mathrm{RRB} / \mathrm{b}$ \\
17 & $\mathrm{~PB} / \mathrm{L} 1 / \mathrm{s}-\mathrm{FB} /([3-4], \mathrm{R} 4) / \mathrm{s}-\mathrm{cre} / \mathrm{RRB} / \mathrm{b}$ \\
18 & $\mathrm{~PB} / \mathrm{R} 1 / \mathrm{s}-\mathrm{FB} /([3-4], \mathrm{R} 4) / \mathrm{s}-\mathrm{cre} / \mathrm{RRB} / \mathrm{b}$ \\
\hline
\end{tabular}

Table 13: PB-FB-CRE neurons. 


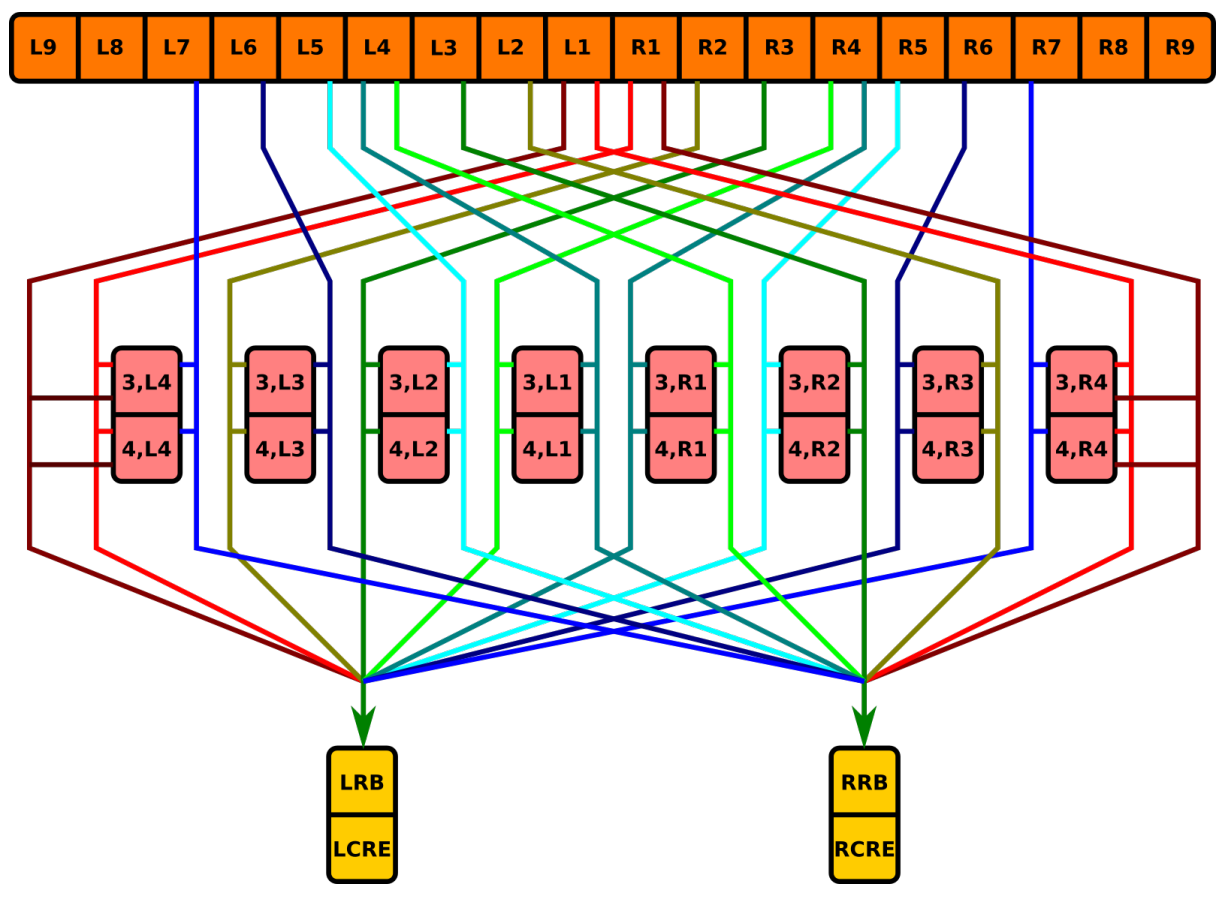

Figure 19: Neuropil innervation pattern for PB-FB-CRE neurons (Tab. 13).

\subsubsection{PB-FB-NO Projection Neurons}

Neurons with postsynaptic arborizations in PB and presynaptic arborizations in FB and NO are referred to as the vertical fiber system [15, Fig. 5b]; they correspond to the PFN neurons described in [1, p. 1745]. These neurons constitute a cholinergic pathway [1, Fig. 7C]. The 5 sets of PB-FB-NO neurons are listed in Tabs. 14, 15, 16, 17, and 18 and depicted in Fig. 20. 


\begin{tabular}{|c|l|}
\hline & Label \\
\hline 1 & $\mathrm{~PB} / \mathrm{L} 2 / \mathrm{s}-\mathrm{FB} /(1, \mathrm{R} 4) / \mathrm{b}-\mathrm{no} /(3, \mathrm{RP}) / \mathrm{b}$ \\
2 & $\mathrm{~PB} / \mathrm{L} 3 / \mathrm{s}-\mathrm{FB} /(1, \mathrm{R} 4) / \mathrm{b}-\mathrm{no} /(3, \mathrm{RP}) / \mathrm{b}$ \\
3 & $\mathrm{~PB} / \mathrm{L} 4 / \mathrm{s}-\mathrm{FB} /(1, \mathrm{R} 3) / \mathrm{b}-\mathrm{no} /(3, \mathrm{RP}) / \mathrm{b}$ \\
4 & $\mathrm{~PB} / \mathrm{L} 5 / \mathrm{s}-\mathrm{FB} /(1, \mathrm{R} 2) / \mathrm{b}-\mathrm{no} /(3, \mathrm{RP}) / \mathrm{b}$ \\
5 & $\mathrm{~PB} / \mathrm{L} 6 / \mathrm{s}-\mathrm{FB} /(1, \mathrm{R} 1) \mid(1, \mathrm{~L} 1) / \mathrm{b}-\mathrm{no} /(3, \mathrm{RP}) / \mathrm{b}$ \\
6 & $\mathrm{~PB} / \mathrm{L} 7 / \mathrm{s}-\mathrm{FB} /(1, \mathrm{~L} 2) / \mathrm{b}-\mathrm{no} /(3, \mathrm{RP}) / \mathrm{b}$ \\
7 & $\mathrm{~PB} / \mathrm{L} 8 / \mathrm{s}-\mathrm{FB} /(1, \mathrm{~L} 3) / \mathrm{b}-\mathrm{no} /(3, \mathrm{RP}) / \mathrm{b}$ \\
8 & $\mathrm{~PB} / \mathrm{L} 9 / \mathrm{s}-\mathrm{FB} /(1, \mathrm{~L} 4) / \mathrm{b}-\mathrm{no} /(3, \mathrm{RP}) / \mathrm{b}$ \\
9 & $\mathrm{~PB} / \mathrm{R} 2 / \mathrm{s}-\mathrm{FB} /(1, \mathrm{~L} 4) / \mathrm{b}-\mathrm{NO} /(3, \mathrm{LP}) / \mathrm{b}$ \\
10 & $\mathrm{~PB} / \mathrm{R} 3 / \mathrm{s}-\mathrm{FB} /(1, \mathrm{~L} 4) / \mathrm{b}-\mathrm{NO} /(3, \mathrm{LP}) / \mathrm{b}$ \\
11 & $\mathrm{~PB} / \mathrm{R} 4 / \mathrm{s}-\mathrm{FB} /(1, \mathrm{~L} 3) / \mathrm{b}-\mathrm{NO} /(3, \mathrm{LP}) / \mathrm{b}$ \\
12 & $\mathrm{~PB} / \mathrm{R} 5 / \mathrm{s}-\mathrm{FB} /(1, \mathrm{~L} 2) / \mathrm{b}-\mathrm{NO} /(3, \mathrm{LP}) / \mathrm{b}$ \\
13 & $\mathrm{~PB} / \mathrm{R} 6 / \mathrm{s}-\mathrm{FB} /(1, \mathrm{~L} 1) \mid(1, \mathrm{R} 1) / \mathrm{b}-\mathrm{NO} /(3, \mathrm{LP}) / \mathrm{b}$ \\
14 & $\mathrm{~PB} / \mathrm{R} 7 / \mathrm{s}-\mathrm{FB} /(1, \mathrm{R} 2) / \mathrm{b}-\mathrm{NO} /(3, \mathrm{LP}) / \mathrm{b}$ \\
15 & $\mathrm{~PB} / \mathrm{R} 8 / \mathrm{s}-\mathrm{FB} /(1, \mathrm{R} 3) / \mathrm{b}-\mathrm{NO} /(3, \mathrm{LP}) / \mathrm{b}$ \\
16 & $\mathrm{~PB} / \mathrm{R} 9 / \mathrm{s}-\mathrm{FB} /(1, \mathrm{R} 4) / \mathrm{b}-\mathrm{NO} /(3, \mathrm{LP}) / \mathrm{b}$ \\
\hline
\end{tabular}

Table 14: PB-FB-NO neurons innervating region $(3, \mathrm{P})$ of NO.

\begin{tabular}{|c|l|}
\hline & Label \\
\hline 1 & $\mathrm{~PB} / \mathrm{L} 2 / \mathrm{s}-\mathrm{FB} /(1, \mathrm{R} 4) / \mathrm{b}-\mathrm{no} /(3, \mathrm{RM}) / \mathrm{b}$ \\
2 & $\mathrm{~PB} / \mathrm{L} 3 / \mathrm{s}-\mathrm{FB} /(1, \mathrm{R} 4) / \mathrm{b}-\mathrm{no} /(3, \mathrm{RM}) / \mathrm{b}$ \\
3 & $\mathrm{~PB} / \mathrm{L} 4 / \mathrm{s}-\mathrm{FB} /(1, \mathrm{R} 3) / \mathrm{b}-\mathrm{no} /(3, \mathrm{RM}) / \mathrm{b}$ \\
4 & $\mathrm{~PB} / \mathrm{L} 5 / \mathrm{s}-\mathrm{FB} /(1, \mathrm{R} 2) / \mathrm{b}-\mathrm{no} /(3, \mathrm{RM}) / \mathrm{b}$ \\
5 & $\mathrm{~PB} / \mathrm{L} 6 / \mathrm{s}-\mathrm{FB} /(1, \mathrm{R} 1) \mid(1, \mathrm{~L} 1) / \mathrm{b}-\mathrm{no} /(3, \mathrm{RM}) / \mathrm{b}$ \\
6 & $\mathrm{~PB} / \mathrm{L} 7 / \mathrm{s}-\mathrm{FB} /(1, \mathrm{~L} 2) / \mathrm{b}-\mathrm{no} /(3, \mathrm{RM}) / \mathrm{b}$ \\
7 & $\mathrm{~PB} / \mathrm{L} 8 / \mathrm{s}-\mathrm{FB} /(1, \mathrm{~L} 3) / \mathrm{b}-\mathrm{no} /(3, \mathrm{RM}) / \mathrm{b}$ \\
8 & $\mathrm{~PB} / \mathrm{L} 9 / \mathrm{s}-\mathrm{FB} /(1, \mathrm{~L} 4) / \mathrm{b}-\mathrm{no} /(3, \mathrm{RM}) / \mathrm{b}$ \\
9 & $\mathrm{~PB} / \mathrm{R} 2 / \mathrm{s}-\mathrm{FB} /(1, \mathrm{~L} 4) / \mathrm{b}-\mathrm{NO} /(3, \mathrm{LM}) / \mathrm{b}$ \\
10 & $\mathrm{~PB} / \mathrm{R} 3 / \mathrm{s}-\mathrm{FB} /(1, \mathrm{~L} 4) / \mathrm{b}-\mathrm{NO} /(3, \mathrm{LM}) / \mathrm{b}$ \\
11 & $\mathrm{~PB} / \mathrm{R} 4 / \mathrm{s}-\mathrm{FB} /(1, \mathrm{~L} 3) / \mathrm{b}-\mathrm{NO} /(3, \mathrm{LM}) / \mathrm{b}$ \\
12 & $\mathrm{~PB} / \mathrm{R} 5 / \mathrm{s}-\mathrm{FB} /(1, \mathrm{~L} 2) / \mathrm{b}-\mathrm{NO} /(3, \mathrm{LM}) / \mathrm{b}$ \\
13 & $\mathrm{~PB} / \mathrm{R} 6 / \mathrm{s}-\mathrm{FB} /(1, \mathrm{~L} 1) \mid(1, \mathrm{R} 1) / \mathrm{b}-\mathrm{NO} /(3, \mathrm{LM}) / \mathrm{b}$ \\
14 & $\mathrm{~PB} / \mathrm{R} 7 / \mathrm{s}-\mathrm{FB} /(1, \mathrm{R} 2) / \mathrm{b}-\mathrm{NO} /(3, \mathrm{LM}) / \mathrm{b}$ \\
15 & $\mathrm{~PB} / \mathrm{R} 8 / \mathrm{s}-\mathrm{FB} /(1, \mathrm{R} 3) / \mathrm{b}-\mathrm{NO} /(3, \mathrm{LM}) / \mathrm{b}$ \\
16 & $\mathrm{~PB} / \mathrm{R} 9 / \mathrm{s}-\mathrm{FB} /(1, \mathrm{R} 4) / \mathrm{b}-\mathrm{NO} /(3, \mathrm{LM}) / \mathrm{b}$ \\
\hline
\end{tabular}

Table 15: PB-FB-NO neurons innervating region $(3, \mathrm{M})$ of NO. 


\begin{tabular}{|c|l|}
\hline & Label \\
\hline 1 & $\mathrm{~PB} / \mathrm{L} 2 / \mathrm{s}-\mathrm{FB} /(2, \mathrm{R} 4) / \mathrm{b}-\mathrm{no} /(3, \mathrm{RA}) / \mathrm{b}$ \\
2 & $\mathrm{~PB} / \mathrm{L} 3 / \mathrm{s}-\mathrm{FB} /(2, \mathrm{R} 4) / \mathrm{b}-\mathrm{no} /(3, \mathrm{RA}) / \mathrm{b}$ \\
3 & $\mathrm{~PB} / \mathrm{L} 4 / \mathrm{s}-\mathrm{FB} /(2, \mathrm{R} 3) / \mathrm{b}-\mathrm{no} /(3, \mathrm{RA}) / \mathrm{b}$ \\
4 & $\mathrm{~PB} / \mathrm{L} 5 / \mathrm{s}-\mathrm{FB} /(2, \mathrm{R} 2) / \mathrm{b}-\mathrm{no} /(3, \mathrm{RA}) / \mathrm{b}$ \\
5 & $\mathrm{~PB} / \mathrm{L} 6 / \mathrm{s}-\mathrm{FB} /(2, \mathrm{R} 1) \mid(1, \mathrm{~L} 1) / \mathrm{b}-\mathrm{no} /(3, \mathrm{RA}) / \mathrm{b}$ \\
6 & $\mathrm{~PB} / \mathrm{L} 7 / \mathrm{s}-\mathrm{FB} /(2, \mathrm{~L} 2) / \mathrm{b}-\mathrm{no} /(3, \mathrm{RA}) / \mathrm{b}$ \\
7 & $\mathrm{~PB} / \mathrm{L} 8 / \mathrm{s}-\mathrm{FB} /(2, \mathrm{~L} 3) / \mathrm{b}-\mathrm{no} /(3, \mathrm{RA}) / \mathrm{b}$ \\
8 & $\mathrm{~PB} / \mathrm{L} 9 / \mathrm{s}-\mathrm{FB} /(2, \mathrm{~L} 4) / \mathrm{b}-\mathrm{no} /(3, \mathrm{RA}) / \mathrm{b}$ \\
9 & $\mathrm{~PB} / \mathrm{R} 2 / \mathrm{s}-\mathrm{FB} /(2, \mathrm{~L} 4) / \mathrm{b}-\mathrm{NO} /(3, \mathrm{LA}) / \mathrm{b}$ \\
10 & $\mathrm{~PB} / \mathrm{R} 3 / \mathrm{s}-\mathrm{FB} /(2, \mathrm{~L} 4) / \mathrm{b}-\mathrm{NO} /(3, \mathrm{LA}) / \mathrm{b}$ \\
11 & $\mathrm{~PB} / \mathrm{R} 4 / \mathrm{s}-\mathrm{FB} /(2, \mathrm{~L} 3) / \mathrm{b}-\mathrm{NO} /(3, \mathrm{LA}) / \mathrm{b}$ \\
12 & $\mathrm{~PB} / \mathrm{R} 5 / \mathrm{s}-\mathrm{FB} /(2, \mathrm{~L} 2) / \mathrm{b}-\mathrm{NO} /(3, \mathrm{LA}) / \mathrm{b}$ \\
13 & $\mathrm{~PB} / \mathrm{R} 6 / \mathrm{s}-\mathrm{FB} /(2, \mathrm{~L} 1) \mid(1, \mathrm{R} 1) / \mathrm{b}-\mathrm{NO} /(3, \mathrm{LA}) / \mathrm{b}$ \\
14 & $\mathrm{~PB} / \mathrm{R} 7 / \mathrm{s}-\mathrm{FB} /(2, \mathrm{R} 2) / \mathrm{b}-\mathrm{NO} /(3, \mathrm{LA}) / \mathrm{b}$ \\
15 & $\mathrm{~PB} / \mathrm{R} 8 / \mathrm{s}-\mathrm{FB} /(2, \mathrm{R} 3) / \mathrm{b}-\mathrm{NO} /(3, \mathrm{LA}) / \mathrm{b}$ \\
16 & $\mathrm{~PB} / \mathrm{R} 9 / \mathrm{s}-\mathrm{FB} /(2, \mathrm{R} 4) / \mathrm{b}-\mathrm{NO} /(3, \mathrm{LA}) / \mathrm{b}$ \\
\hline
\end{tabular}

Table 16: PB-FB-NO neurons innervating region $(3, \mathrm{~A})$ of $\mathrm{NO}$.

\begin{tabular}{|c|l|}
\hline & Label \\
\hline 1 & $\mathrm{~PB} / \mathrm{L} 2 / \mathrm{s}-\mathrm{FB} /(3, \mathrm{R} 4) / \mathrm{b}-\mathrm{no} /(2, \mathrm{RD}) / \mathrm{b}$ \\
2 & $\mathrm{~PB} / \mathrm{L} 3 / \mathrm{s}-\mathrm{FB} /(3, \mathrm{R} 4) / \mathrm{b}-\mathrm{no} /(2, \mathrm{RD}) / \mathrm{b}$ \\
3 & $\mathrm{~PB} / \mathrm{L} 4 / \mathrm{s}-\mathrm{FB} /(3, \mathrm{R} 3) / \mathrm{b}-\mathrm{no} /(2, \mathrm{RD}) / \mathrm{b}$ \\
4 & $\mathrm{~PB} / \mathrm{L} 5 / \mathrm{s}-\mathrm{FB} /(3, \mathrm{R} 2) / \mathrm{b}-\mathrm{no} /(2, \mathrm{RD}) / \mathrm{b}$ \\
5 & $\mathrm{~PB} / \mathrm{L} 6 / \mathrm{s}-\mathrm{FB} /(3, \mathrm{R} 1) \mid(1, \mathrm{~L} 1) / \mathrm{b}-\mathrm{no} /(2, \mathrm{RD}) / \mathrm{b}$ \\
6 & $\mathrm{~PB} / \mathrm{L} 7 / \mathrm{s}-\mathrm{FB} /(3, \mathrm{~L} 2) / \mathrm{b}-\mathrm{no} /(2, \mathrm{RD}) / \mathrm{b}$ \\
7 & $\mathrm{~PB} / \mathrm{L} 8 / \mathrm{s}-\mathrm{FB} /(3, \mathrm{~L} 3) / \mathrm{b}-\mathrm{no} /(2, \mathrm{RD}) / \mathrm{b}$ \\
8 & $\mathrm{~PB} / \mathrm{L} 9 / \mathrm{s}-\mathrm{FB} /(3, \mathrm{~L} 4) / \mathrm{b}-\mathrm{no} /(2, \mathrm{RD}) / \mathrm{b}$ \\
9 & $\mathrm{~PB} / \mathrm{R} 2 / \mathrm{s}-\mathrm{FB} /(3, \mathrm{~L} 4) / \mathrm{b}-\mathrm{NO} /(2, \mathrm{LD}) / \mathrm{b}$ \\
10 & $\mathrm{~PB} / \mathrm{R} 3 / \mathrm{s}-\mathrm{FB} /(3, \mathrm{~L} 4) / \mathrm{b}-\mathrm{NO} /(2, \mathrm{LD}) / \mathrm{b}$ \\
11 & $\mathrm{~PB} / \mathrm{R} 4 / \mathrm{s}-\mathrm{FB} /(3, \mathrm{~L} 3) / \mathrm{b}-\mathrm{NO} /(2, \mathrm{LD}) / \mathrm{b}$ \\
12 & $\mathrm{~PB} / \mathrm{R} 5 / \mathrm{s}-\mathrm{FB} /(3, \mathrm{~L} 2) / \mathrm{b}-\mathrm{NO} /(2, \mathrm{LD}) / \mathrm{b}$ \\
13 & $\mathrm{~PB} / \mathrm{R} 6 / \mathrm{s}-\mathrm{FB} /(3, \mathrm{~L} 1) \mid(1, \mathrm{R} 1) / \mathrm{b}-\mathrm{NO} /(2, \mathrm{LD}) / \mathrm{b}$ \\
14 & $\mathrm{~PB} / \mathrm{R} 7 / \mathrm{s}-\mathrm{FB} /(3, \mathrm{R} 2) / \mathrm{b}-\mathrm{NO} /(2, \mathrm{LD}) / \mathrm{b}$ \\
15 & $\mathrm{~PB} / \mathrm{R} 8 / \mathrm{s}-\mathrm{FB} /(3, \mathrm{R} 3) / \mathrm{b}-\mathrm{NO} /(2, \mathrm{LD}) / \mathrm{b}$ \\
16 & $\mathrm{~PB} / \mathrm{R} 9 / \mathrm{s}-\mathrm{FB} /(3, \mathrm{R} 4) / \mathrm{b}-\mathrm{NO} /(2, \mathrm{LD}) / \mathrm{b}$ \\
\hline
\end{tabular}

Table 17: PB-FB-NO neurons innervating region $(2, \mathrm{D})$ of $\mathrm{NO}$. 


\begin{tabular}{|c|l|}
\hline & Label \\
\hline 1 & $\mathrm{~PB} / \mathrm{L} 2 / \mathrm{s}-\mathrm{FB} /(3, \mathrm{R} 4) / \mathrm{b}-\mathrm{no} /(2, \mathrm{RV}) / \mathrm{b}$ \\
2 & $\mathrm{~PB} / \mathrm{L} 3 / \mathrm{s}-\mathrm{FB} /(3, \mathrm{R} 4) / \mathrm{b}-\mathrm{no} /(2, \mathrm{RV}) / \mathrm{b}$ \\
3 & $\mathrm{~PB} / \mathrm{L} 4 / \mathrm{s}-\mathrm{FB} /(3, \mathrm{R} 3) / \mathrm{b}-\mathrm{no} /(2, \mathrm{RV}) / \mathrm{b}$ \\
4 & $\mathrm{~PB} / \mathrm{L} 5 / \mathrm{s}-\mathrm{FB} /(3, \mathrm{R} 2) / \mathrm{b}-\mathrm{no} /(2, \mathrm{RV}) / \mathrm{b}$ \\
5 & $\mathrm{~PB} / \mathrm{L} 6 / \mathrm{s}-\mathrm{FB} /(3, \mathrm{R} 1) \mid(1, \mathrm{~L} 1) / \mathrm{b}-\mathrm{no} /(2, \mathrm{RV}) / \mathrm{b}$ \\
6 & $\mathrm{~PB} / \mathrm{L} 7 / \mathrm{s}-\mathrm{FB} /(3, \mathrm{~L} 2) / \mathrm{b}-\mathrm{no} /(2, \mathrm{RV}) / \mathrm{b}$ \\
7 & $\mathrm{~PB} / \mathrm{L} 8 / \mathrm{s}-\mathrm{FB} /(3, \mathrm{~L} 3) / \mathrm{b}-\mathrm{no} /(2, \mathrm{RV}) / \mathrm{b}$ \\
8 & $\mathrm{~PB} / \mathrm{L} 9 / \mathrm{s}-\mathrm{FB} /(3, \mathrm{~L} 4) / \mathrm{b}-\mathrm{no} /(2, \mathrm{RV}) / \mathrm{b}$ \\
9 & $\mathrm{~PB} / \mathrm{R} 2 / \mathrm{s}-\mathrm{FB} /(3, \mathrm{~L} 4) / \mathrm{b}-\mathrm{NO} /(2, \mathrm{LV}) / \mathrm{b}$ \\
10 & $\mathrm{~PB} / \mathrm{R} 3 / \mathrm{s}-\mathrm{FB} /(3, \mathrm{~L} 4) / \mathrm{b}-\mathrm{NO} /(2, \mathrm{LV}) / \mathrm{b}$ \\
11 & $\mathrm{~PB} / \mathrm{R} 4 / \mathrm{s}-\mathrm{FB} /(3, \mathrm{~L} 3) / \mathrm{b}-\mathrm{NO} /(2, \mathrm{LV}) / \mathrm{b}$ \\
12 & $\mathrm{~PB} / \mathrm{R} 5 / \mathrm{s}-\mathrm{FB} /(3, \mathrm{~L} 2) / \mathrm{b}-\mathrm{NO} /(2, \mathrm{LV}) / \mathrm{b}$ \\
13 & $\mathrm{~PB} / \mathrm{R} 6 / \mathrm{s}-\mathrm{FB} /(3, \mathrm{~L} 1) \mid(1, \mathrm{R} 1) / \mathrm{b}-\mathrm{NO} /(2, \mathrm{LV}) / \mathrm{b}$ \\
14 & $\mathrm{~PB} / \mathrm{R} 7 / \mathrm{s}-\mathrm{FB} /(3, \mathrm{R} 2) / \mathrm{b}-\mathrm{NO} /(2, \mathrm{LV}) / \mathrm{b}$ \\
15 & $\mathrm{~PB} / \mathrm{R} 8 / \mathrm{s}-\mathrm{FB} /(3, \mathrm{R} 3) / \mathrm{b}-\mathrm{NO} /(2, \mathrm{LV}) / \mathrm{b}$ \\
16 & $\mathrm{~PB} / \mathrm{R} 9 / \mathrm{s}-\mathrm{FB} /(3, \mathrm{R} 4) / \mathrm{b}-\mathrm{NO} /(2, \mathrm{LV}) / \mathrm{b}$ \\
\hline
\end{tabular}

Table 18: PB-FB-NO neurons innervating region $(2, \mathrm{~V})$ of NO. 
bioRxiv preprint doi: https://doi org/101101/051318; this version posted May 23, 2016. The copyright holder for this preprint (which was not certified by peer review) is the author/funder, who has granted bioRxiv a license to display the preprint in perpetuity. It is made available under aCC-BY 4.0 International license.

5.4 Projection Neurons

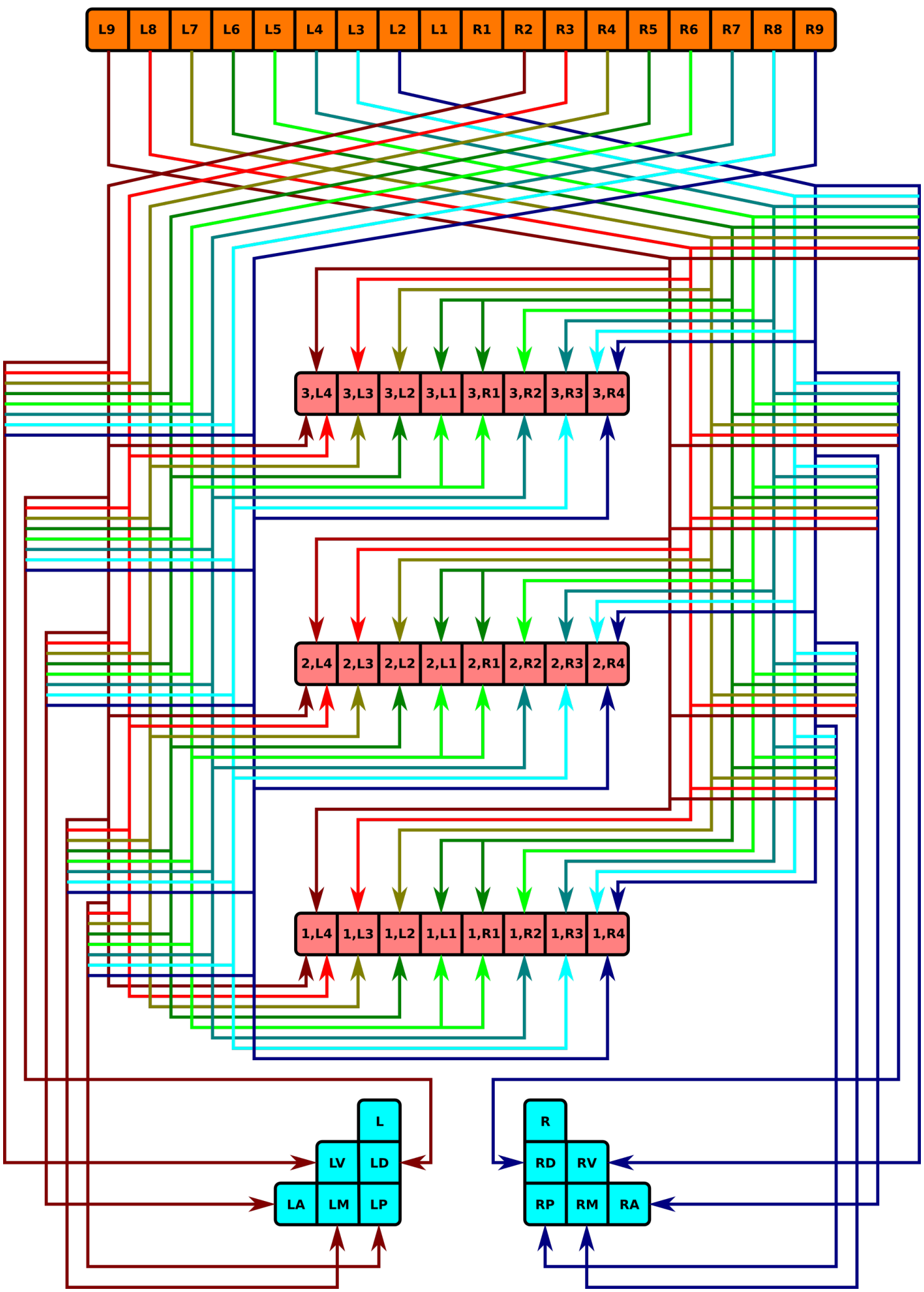

Figure 20: Neuropil innervation pattern for PB-FB-NO neurons (Tabs. 14, 15, 16, 17, 18). 


\subsubsection{PB-FB-LAL Projection Neurons}

Neurons with postsynaptic arborizations in $\mathrm{PB}$ and FB and presynaptic arborizations in LAL are referred to as PFI neurons in [1, p. 1745]. They correspond to the PB-FB-VBO or PFI neurons that connect to HB in [1, Fig. 2], and are also referred to as the horizontal fiber system [15, Fig. 6b]. ${ }^{1}$ These neurons constitute a cholinergic pathway [1, Fig. 7C].

\begin{tabular}{|c|l|}
\hline & Label \\
\hline 1 & $\mathrm{~PB} / \mathrm{L} 1 / \mathrm{s}-\mathrm{FB} /(2, \mathrm{~L}[3-4]) / \mathrm{s}-\mathrm{LAL} / \mathrm{LHB} / \mathrm{b}$ \\
2 & $\mathrm{~PB} / \mathrm{R} 1 \mid \mathrm{L} 1 / \mathrm{s}-\mathrm{FB} /(2, \mathrm{~L}[3-4]) / \mathrm{s}-\mathrm{LAL} / \mathrm{LHB} / \mathrm{b}$ \\
3 & $\mathrm{~PB} / \mathrm{R} 1 / \mathrm{s}-\mathrm{FB} /(2, \mathrm{~L}[2-3]) / \mathrm{s}-\mathrm{LAL} / \mathrm{LHB} / \mathrm{b}$ \\
4 & $\mathrm{~PB} / \mathrm{R} 2 / \mathrm{s}-\mathrm{FB} /(2, \mathrm{~L}[1-2]) / \mathrm{s}-\mathrm{LAL} / \mathrm{LHB} / \mathrm{b}$ \\
5 & $\mathrm{~PB} / \mathrm{R} 3 / \mathrm{s}-\mathrm{FB} /(2,[\mathrm{~L} 1, \mathrm{R} 1]) / \mathrm{s}-\mathrm{LAL} / \mathrm{LHB} / \mathrm{b}$ \\
6 & $\mathrm{~PB} / \mathrm{R} 4 / \mathrm{s}-\mathrm{FB} /(2, \mathrm{R}[1-2]) / \mathrm{s}-\mathrm{LAL} / \mathrm{LHB} / \mathrm{b}$ \\
7 & $\mathrm{~PB} / \mathrm{R} 5 / \mathrm{s}-\mathrm{FB} /(2, \mathrm{R}[2-3]) / \mathrm{s}-\mathrm{LAL} / \mathrm{LHB} / \mathrm{b}$ \\
8 & $\mathrm{~PB} / \mathrm{R} 6 / \mathrm{s}-\mathrm{FB} /(2, \mathrm{R}[3-4]) / \mathrm{s}-\mathrm{LAL} / \mathrm{LHB} / \mathrm{b}$ \\
9 & $\mathrm{~PB} / \mathrm{R} 7 / \mathrm{s}-\mathrm{FB} /(2, \mathrm{R}[3-4]) / \mathrm{s}-\mathrm{LAL} / \mathrm{LHB} / \mathrm{b}$ \\
10 & $\mathrm{~PB} / \mathrm{L} 7 / \mathrm{s}-\mathrm{FB} /(2, \mathrm{~L}[3-4]) / \mathrm{s}-\mathrm{lal} / \mathrm{RHB} / \mathrm{b}$ \\
11 & $\mathrm{~PB} / \mathrm{L} 6 / \mathrm{s}-\mathrm{FB} /(2, \mathrm{~L}[3-4]) / \mathrm{s}-\mathrm{lal} / \mathrm{RHB} / \mathrm{b}$ \\
12 & $\mathrm{~PB} / \mathrm{L} 5 / \mathrm{s}-\mathrm{FB} /(2, \mathrm{~L}[2-3]) / \mathrm{s}-\mathrm{lal} / \mathrm{RHB} / \mathrm{b}$ \\
13 & $\mathrm{~PB} / \mathrm{L} 4 / \mathrm{s}-\mathrm{FB} /(2, \mathrm{~L}[1-2]) / \mathrm{s}-\mathrm{lal} / \mathrm{RHB} / \mathrm{b}$ \\
14 & $\mathrm{~PB} / \mathrm{L} 3 / \mathrm{s}-\mathrm{FB} /(2,[\mathrm{R} 1, \mathrm{~L} 1]) / \mathrm{s}-\mathrm{lal} / \mathrm{RHB} / \mathrm{b}$ \\
15 & $\mathrm{~PB} / \mathrm{L} 2 / \mathrm{s}-\mathrm{FB} /(2, \mathrm{R}[1-2]) / \mathrm{s}-\mathrm{lal} / \mathrm{RHB} / \mathrm{b}$ \\
16 & $\mathrm{~PB} / \mathrm{L} 1 / \mathrm{s}-\mathrm{FB} /(2, \mathrm{R}[2-3]) / \mathrm{s}-\mathrm{lal} / \mathrm{RHB} / \mathrm{b}$ \\
17 & $\mathrm{~PB} / \mathrm{L} 1 \mid \mathrm{R} 1 / \mathrm{s}-\mathrm{FB} /(2, \mathrm{R}[3-4]) / \mathrm{s}-\mathrm{lal} / \mathrm{RHB} / \mathrm{b}$ \\
18 & $\mathrm{~PB} / \mathrm{R} 1 / \mathrm{s}-\mathrm{FB} /(2, \mathrm{R}[3-4]) / \mathrm{s}-\mathrm{lal} / \mathrm{RHB} / \mathrm{b}$ \\
\hline
\end{tabular}

Table 19: PB-FB-LAL neurons innervating layer 2 of FB[1, Fig. 6F].

\footnotetext{
${ }^{1}$ These sources appear to consider CRE as part of LAL; this document treats CRE separately.
} 
bioRxiv preprint doi: https://doi org/101101/051318; this version posted May 23, 2016. The copyright holder for this preprint (which was not certified by peer review) is the author/funder, who has granted bioRxiv a license to display the preprint in perpetuity. It is made available under aCC-BY 4.0 International license.

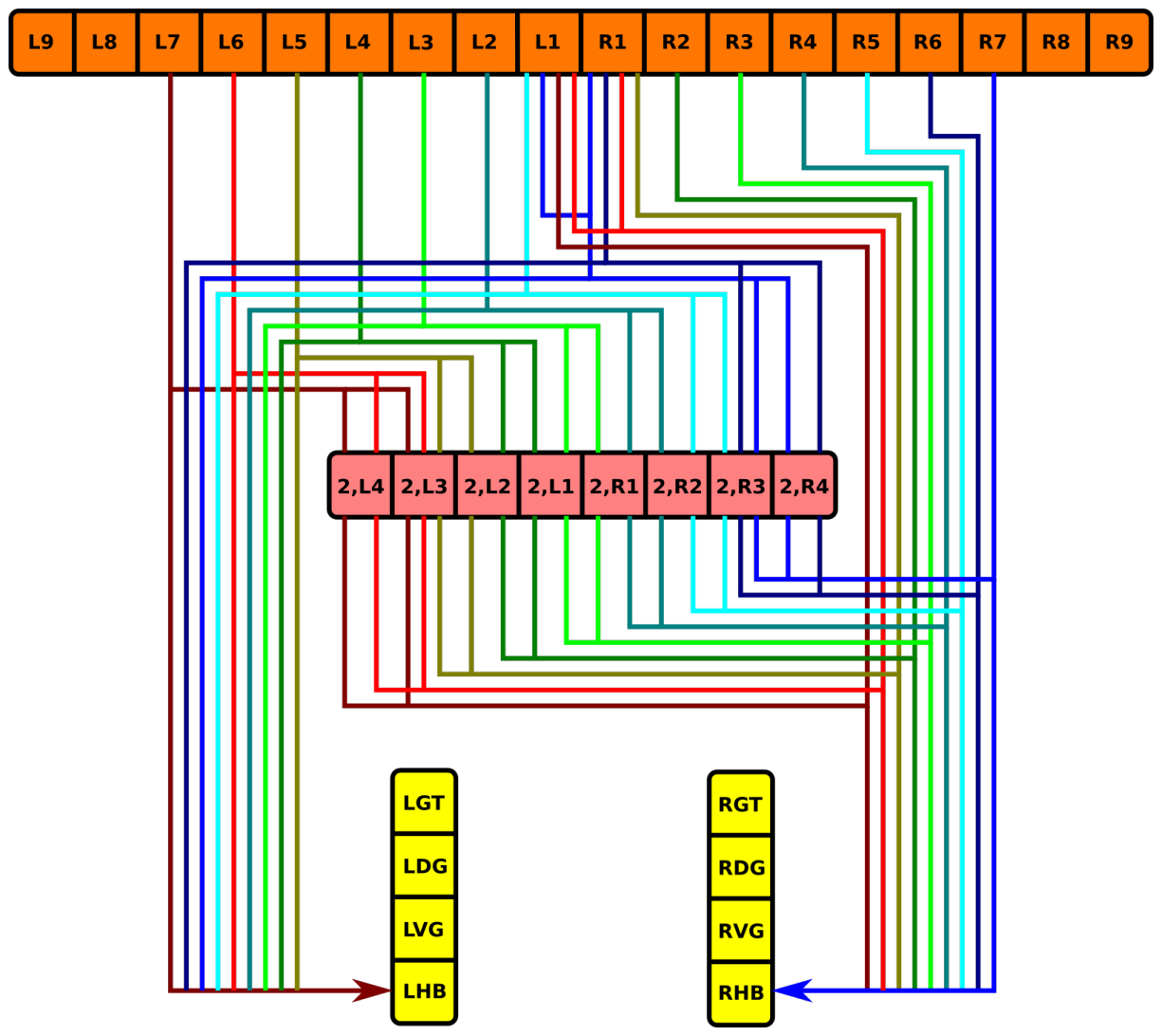

Figure 21: Neuropil innervation pattern for PB-FB-LAL neurons innervating layer 2 of FB (Tab. 19). 


\begin{tabular}{|c|l|}
\hline & Label \\
\hline 1 & $\mathrm{~PB} / \mathrm{L} 1 / \mathrm{s}-\mathrm{FB} /([1-4], \mathrm{L}[3-4]) / \mathrm{s}-\mathrm{LAL} / \mathrm{LHB} / \mathrm{b}$ \\
2 & $\mathrm{~PB} / \mathrm{L} 1 \mid \mathrm{R} 1 / \mathrm{s}-\mathrm{FB} /([1-4], \mathrm{L}[2-3]) / \mathrm{s}-\mathrm{LAL} / \mathrm{LHB} / \mathrm{b}$ \\
3 & $\mathrm{~PB} / \mathrm{R} 1 / \mathrm{s}-\mathrm{FB} /([1-4], \mathrm{L}[1-2]) / \mathrm{s}-\mathrm{LAL} / \mathrm{LHB} / \mathrm{b}$ \\
4 & $\mathrm{~PB} / \mathrm{R} 2 / \mathrm{s}-\mathrm{FB} /([1-4],[\mathrm{L} 1, \mathrm{R} 1]) / \mathrm{s}-\mathrm{LAL} / \mathrm{LHB} / \mathrm{b}$ \\
5 & $\mathrm{~PB} / \mathrm{R} 3 / \mathrm{s}-\mathrm{FB} /([1-4], \mathrm{R}[1-2]) / \mathrm{s}-\mathrm{LAL} / \mathrm{LHB} / \mathrm{b}$ \\
6 & $\mathrm{~PB} / \mathrm{R} 4 / \mathrm{s}-\mathrm{FB} /([1-4], \mathrm{R}[2-3]) / \mathrm{s}-\mathrm{LAL} / \mathrm{LHB} / \mathrm{b}$ \\
7 & $\mathrm{~PB} / \mathrm{R} 5 / \mathrm{s}-\mathrm{FB} /([1-4], \mathrm{R}[3-4]) / \mathrm{s}-\mathrm{LAL} / \mathrm{LHB} / \mathrm{b}$ \\
8 & $\mathrm{~PB} / \mathrm{R} 6 / \mathrm{s}-\mathrm{FB} /([1-4], \mathrm{R}[3-4]) / \mathrm{s}-\mathrm{LAL} / \mathrm{LHB} / \mathrm{b}$ \\
9 & $\mathrm{~PB} / \mathrm{L} 6 / \mathrm{s}-\mathrm{FB} /([1-4], \mathrm{L}[3-4]) / \mathrm{s}-\mathrm{lal} / \mathrm{RHB} / \mathrm{b}$ \\
10 & $\mathrm{~PB} / \mathrm{L} 5 / \mathrm{s}-\mathrm{FB} /([1-4], \mathrm{L}[3-4]) / \mathrm{s}-\mathrm{lal} / \mathrm{RHB} / \mathrm{b}$ \\
11 & $\mathrm{~PB} / \mathrm{L} 4 / \mathrm{s}-\mathrm{FB} /([1-4], \mathrm{L}[2-3]) / \mathrm{s}-\mathrm{lal} / \mathrm{RHB} / \mathrm{b}$ \\
12 & $\mathrm{~PB} / \mathrm{L} 3 / \mathrm{s}-\mathrm{FB} /([1-4], \mathrm{L}[1-2]) / \mathrm{s}-\mathrm{lal} / \mathrm{RHB} / \mathrm{b}$ \\
13 & $\mathrm{~PB} / \mathrm{L} 2 / \mathrm{s}-\mathrm{FB} /([1-4],[\mathrm{L} 1, \mathrm{R} 1]) / \mathrm{s}-\mathrm{lal} / \mathrm{RHB} / \mathrm{b}$ \\
14 & $\mathrm{~PB} / \mathrm{L} 1 / \mathrm{s}-\mathrm{FB} /([1-4], \mathrm{R}[1-2]) / \mathrm{s}-\mathrm{lal} / \mathrm{RHB} / \mathrm{b}$ \\
15 & $\mathrm{~PB} / \mathrm{L} 1 \mid \mathrm{R} 1 / \mathrm{s}-\mathrm{FB} /([1-4], \mathrm{R}[2-3]) / \mathrm{s}-\mathrm{lal} / \mathrm{RHB} / \mathrm{b}$ \\
16 & $\mathrm{~PB} / \mathrm{R} 1 / \mathrm{s}-\mathrm{FB} /([1-4], \mathrm{R}[3-4]) / \mathrm{s}-\mathrm{lal} / \mathrm{RHB} / \mathrm{b}$ \\
\hline
\end{tabular}

Table 20: PB-FB-LAL neurons [1, Fig. 6G].

\begin{tabular}{|l|l|}
\hline & Label \\
\hline 1 & $\mathrm{~PB} / \mathrm{L} 3 / \mathrm{s}-\mathrm{FB} /([1-4], \mathrm{L}[3-4]) / \mathrm{s}-\mathrm{LAL} / \mathrm{LHB} / \mathrm{b}-\mathrm{lal} / \mathrm{RHB} / \mathrm{b}$ \\
2 & $\mathrm{~PB} / \mathrm{L} 1 / \mathrm{s}-\mathrm{FB} /([1-4], \mathrm{L}[1-2]) / \mathrm{s}-\mathrm{LAL} / \mathrm{LHB} / \mathrm{b}-\mathrm{lal} / \mathrm{RHB} / \mathrm{b}$ \\
3 & $\mathrm{~PB} / \mathrm{R} 1 / \mathrm{s}-\mathrm{FB} /([1-4], \mathrm{R}[1-2]) / \mathrm{s}-\mathrm{LAL} / \mathrm{LHB} / \mathrm{b}-\mathrm{lal} / \mathrm{RHB} / \mathrm{b}$ \\
4 & $\mathrm{~PB} / \mathrm{R} 3 / \mathrm{s}-\mathrm{FB} /([1-4], \mathrm{R}[3-4]) / \mathrm{s}-\mathrm{LAL} / \mathrm{LHB} / \mathrm{b}-\mathrm{lal} / \mathrm{RHB} / \mathrm{b}$ \\
\hline
\end{tabular}

Table 21: PB-FB-LAL neurons [1, Fig. 6G]. 


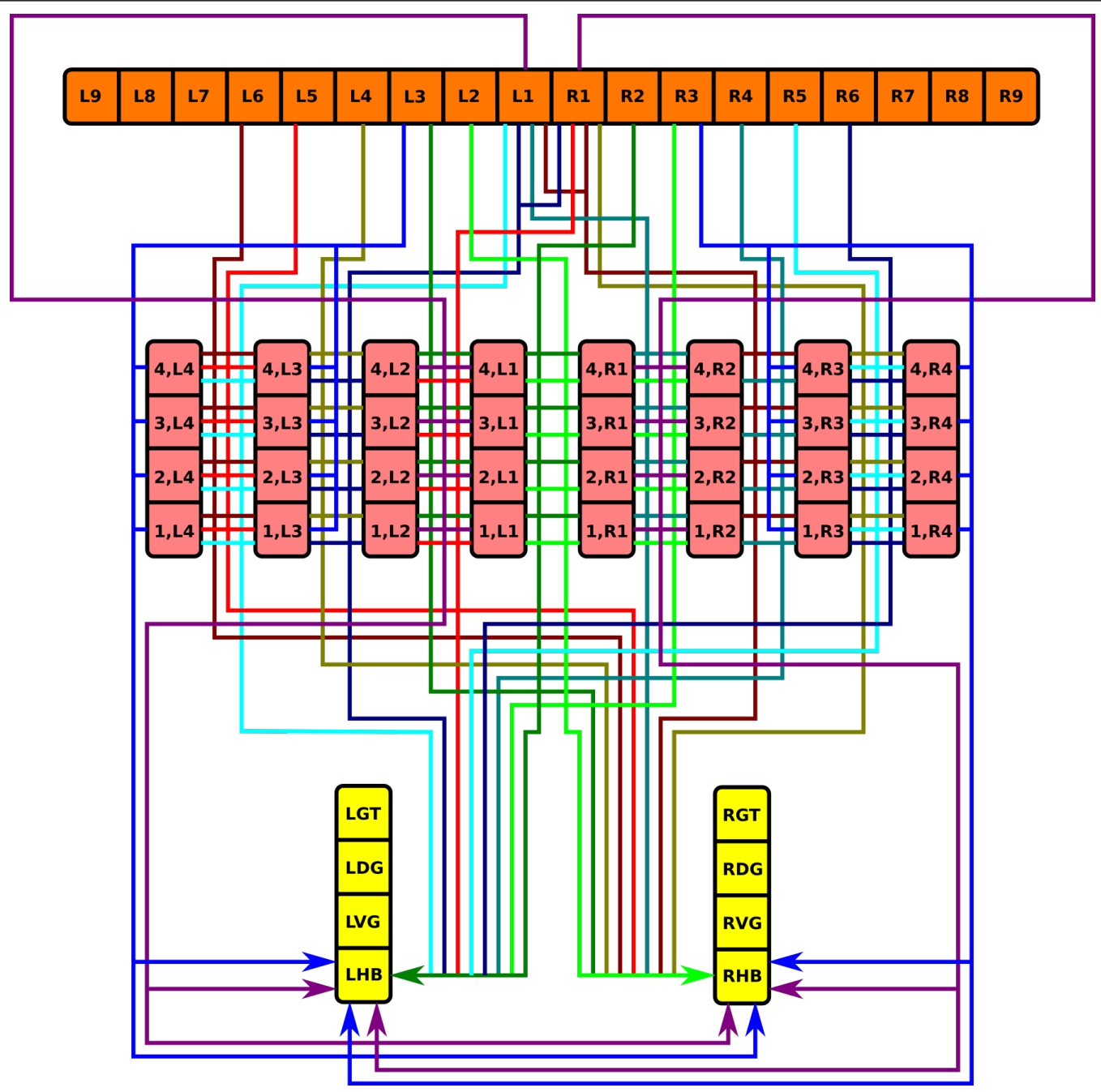

Figure 22: Neuropil innervation pattern for PB-FB-LAL neurons (Tab. 20, 21).

\subsubsection{WED-PS-PB Projection Neurons}

The neurons in Tab. 22 correspond to CCP-VMP-PB or CVP neurons in [1, Fig. 2] and receive input from the vision system. They constitute a cholinergic pathway [1, Fig. 7C]. 


\begin{tabular}{|c|l|}
\hline & Label \\
\hline 1 & $\mathrm{WED} / \mathrm{L} / \mathrm{s}-\mathrm{PS} / \mathrm{L} / \mathrm{s}-\mathrm{PB} / \mathrm{L} 2 \mid \mathrm{L} 3 / \mathrm{b}$ \\
2 & $\mathrm{WED} / \mathrm{L} / \mathrm{s}-\mathrm{PS} / \mathrm{L} / \mathrm{s}-\mathrm{PB} / \mathrm{L} 3 \mid \mathrm{L} 4 / \mathrm{b}$ \\
3 & $\mathrm{WED} / \mathrm{L} / \mathrm{s}-\mathrm{PS} / \mathrm{L} / \mathrm{s}-\mathrm{PB} / \mathrm{L} 4 \mid \mathrm{L} 5 / \mathrm{b}$ \\
4 & $\mathrm{WED} / \mathrm{L} / \mathrm{s}-\mathrm{PS} / \mathrm{L} / \mathrm{s}-\mathrm{PB} / \mathrm{L} 5 \mid \mathrm{L} 6 / \mathrm{b}$ \\
5 & $\mathrm{WED} / \mathrm{L} / \mathrm{s}-\mathrm{PS} / \mathrm{L} / \mathrm{s}-\mathrm{PB} / \mathrm{L} 6 \mid \mathrm{L} 7 / \mathrm{b}$ \\
6 & $\mathrm{WED} / \mathrm{L} / \mathrm{s}-\mathrm{PS} / \mathrm{L} / \mathrm{s}-\mathrm{PB} / \mathrm{L} 7 \mid \mathrm{L} 8 / \mathrm{b}$ \\
7 & $\mathrm{WED} / \mathrm{L} / \mathrm{s}-\mathrm{PS} / \mathrm{L} / \mathrm{s}-\mathrm{PB} / \mathrm{L} 8 \mid \mathrm{L} 9 / \mathrm{b}$ \\
8 & $\mathrm{wed} / \mathrm{R} / \mathrm{s}-\mathrm{ps} / \mathrm{R} / \mathrm{s}-\mathrm{PB} / \mathrm{L} 2 \mid \mathrm{L} 3 / \mathrm{b}$ \\
9 & $\mathrm{wed} / \mathrm{R} / \mathrm{s}-\mathrm{ps} / \mathrm{R} / \mathrm{s}-\mathrm{PB} / \mathrm{L} 3 \mid \mathrm{L} 4 / \mathrm{b}$ \\
10 & $\mathrm{wed} / \mathrm{R} / \mathrm{s}-\mathrm{ps} / \mathrm{R} / \mathrm{s}-\mathrm{PB} / \mathrm{L} 4 \mid \mathrm{L} 5 / \mathrm{b}$ \\
11 & $\mathrm{wed} / \mathrm{R} / \mathrm{s}-\mathrm{ps} / \mathrm{R} / \mathrm{s}-\mathrm{PB} / \mathrm{L} 5 \mid \mathrm{L} 6 / \mathrm{b}$ \\
12 & $\mathrm{wed} / \mathrm{R} / \mathrm{s}-\mathrm{ps} / \mathrm{R} / \mathrm{s}-\mathrm{PB} / \mathrm{L} 6 \mid \mathrm{L} 7 / \mathrm{b}$ \\
13 & $\mathrm{wed} / \mathrm{R} / \mathrm{s}-\mathrm{ps} / \mathrm{R} / \mathrm{s}-\mathrm{PB} / \mathrm{L} 7 \mid \mathrm{L} 8 / \mathrm{b}$ \\
14 & $\mathrm{wed} / \mathrm{R} / \mathrm{s}-\mathrm{ps} / \mathrm{R} / \mathrm{s}-\mathrm{PB} / \mathrm{L} 8 \mid \mathrm{L} 9 / \mathrm{b}$ \\
15 & $\mathrm{WED} / \mathrm{L} / \mathrm{s}-\mathrm{PS} / \mathrm{L} / \mathrm{s}-\mathrm{PB} / \mathrm{R} 2 \mid \mathrm{R} 3 / \mathrm{b}$ \\
16 & $\mathrm{WED} / \mathrm{L} / \mathrm{s}-\mathrm{PS} / \mathrm{L} / \mathrm{s}-\mathrm{PB} / \mathrm{R} 3 \mid \mathrm{R} 4 / \mathrm{b}$ \\
17 & $\mathrm{WED} / \mathrm{L} / \mathrm{s}-\mathrm{PS} / \mathrm{L} / \mathrm{s}-\mathrm{PB} / \mathrm{R} 4 \mid \mathrm{R} 5 / \mathrm{b}$ \\
18 & $\mathrm{WED} / \mathrm{L} / \mathrm{s}-\mathrm{PS} / \mathrm{L} / \mathrm{s}-\mathrm{PB} / \mathrm{R} 5 \mid \mathrm{R} 6 / \mathrm{b}$ \\
19 & $\mathrm{WED} / \mathrm{L} / \mathrm{s}-\mathrm{PS} / \mathrm{L} / \mathrm{s}-\mathrm{PB} / \mathrm{R} 6 \mid \mathrm{R} 7 / \mathrm{b}$ \\
20 & $\mathrm{WED} / \mathrm{L} / \mathrm{s}-\mathrm{PS} / \mathrm{L} / \mathrm{s}-\mathrm{PB} / \mathrm{R} 7 \mid \mathrm{R} 8 / \mathrm{b}$ \\
21 & $\mathrm{WED} / \mathrm{L} / \mathrm{s}-\mathrm{PS} / \mathrm{L} / \mathrm{s}-\mathrm{PB} / \mathrm{R} 8 \mid \mathrm{R} 9 / \mathrm{b}$ \\
22 & $\mathrm{wed} / \mathrm{R} / \mathrm{s}-\mathrm{ps} / \mathrm{R} / \mathrm{s}-\mathrm{PB} / \mathrm{R} 2 \mid \mathrm{R} 3 / \mathrm{b}$ \\
23 & $\mathrm{wed} / \mathrm{R} / \mathrm{s}-\mathrm{ps} / \mathrm{R} / \mathrm{s}-\mathrm{PB} / \mathrm{R} 3 \mid \mathrm{R} 4 / \mathrm{b}$ \\
24 & $\mathrm{wed} / \mathrm{R} / \mathrm{s}-\mathrm{ps} / \mathrm{R} / \mathrm{s}-\mathrm{PB} / \mathrm{R} 4 \mid \mathrm{R} 5 / \mathrm{b}$ \\
25 & $\mathrm{wed} / \mathrm{R} / \mathrm{s}-\mathrm{ps} / \mathrm{R} / \mathrm{s}-\mathrm{PB} / \mathrm{R} 5 \mid \mathrm{R} 6 / \mathrm{b}$ \\
27 & $\mathrm{wed} / \mathrm{R} / \mathrm{s}-\mathrm{ps} / \mathrm{R} / \mathrm{s}-\mathrm{PB} / \mathrm{R} 6 \mid \mathrm{R} 7 / \mathrm{b}$ \\
\hline & $\mathrm{wed} / \mathrm{R} / \mathrm{s}-\mathrm{ps} / \mathrm{R} / \mathrm{s}-\mathrm{PB} / \mathrm{R} 7 \mid \mathrm{R} 8 / \mathrm{b}$ \\
\hline & $\mathrm{R} / \mathrm{s}-\mathrm{ps} / \mathrm{R} / \mathrm{s}-\mathrm{PB} / \mathrm{R} 8 \mid \mathrm{R} 9 / \mathrm{b}$ \\
\hline
\end{tabular}

Table 22: WED-PS-PB neurons. 


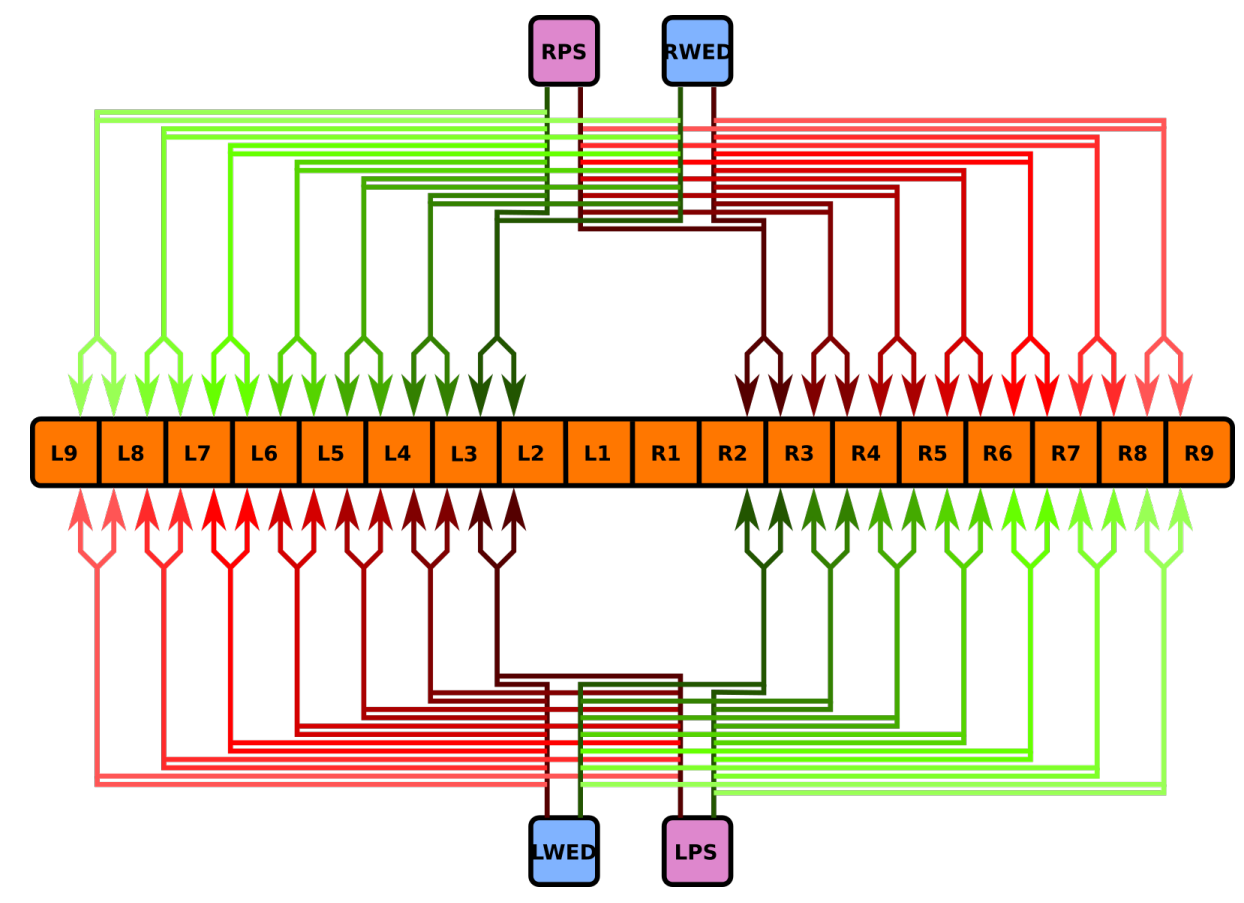

Figure 23: Neuropil innervation pattern for WED-PS-PB neurons (Tab. 22).

\section{Generating an Executable Circuit Model}

\subsection{Neuron Organization}

In light of the current lack of data regarding synapses between the various neurons identified in the central complex neuropils, data regarding the arborizations of these neurons was used to infer the presence or absence of synapses to generate an executable model of the central complex. Local and projection neurons were assigned to LPUs as indicated in Tab. 23.

\begin{tabular}{|l|l|}
\hline LPU & Neuron Families \\
\hline BU, bu & BU-EB \\
EB & EB-LAL-PB \\
FB & FB local \\
PB & PB local, PB-EB-NO, \\
& PB-EB-LAL, PB-FB-CRE, \\
& PB-FB-NO, PB-FB-LAL, \\
& WED-PS-PB, IB-LAL-PS- \\
& PB \\
\hline
\end{tabular}

Table 23: Assignment of neuron families to LPUs in generated CX model. 
Although the BU-EB neurons have not been systematically characterized, available information regarding these neurons $(\S 5.4 .1)$ was used to hypothesize the following arborization structure for a total of 80 neurons in each hemisphere of the fly brain (Tab. 24).

\begin{tabular}{|c|c|c|}
\hline $\begin{array}{l}\text { Ring } \\
\text { Neuron } \\
\text { Name }\end{array}$ & $\begin{array}{l}\text { Microglomerulus } \\
\text { Range }\end{array}$ & Label \\
\hline $\mathrm{R} 1$ & $1 . .16$ & $\begin{array}{l}\mathrm{BU} / \mathrm{Lx} / \mathrm{s}-\mathrm{EB} /(\mathrm{LR}[1-8],[\mathrm{M}, \mathrm{A}], 1) / \mathrm{b} \\
\mathrm{bu} / \mathrm{Rx} / \mathrm{s}-\mathrm{EB} /(\mathrm{LR}[1-8],[\mathrm{M}, \mathrm{A}], 1) / \mathrm{b}\end{array}$ \\
\hline $\mathrm{R} 2$ & $33 . .48$ & $\begin{array}{l}\mathrm{BU} / \mathrm{Lx} / \mathrm{s}-\mathrm{EB} /(\mathrm{LR}[1-8], \mathrm{A},[3,4]) / \mathrm{b} \\
\mathrm{bu} / \mathrm{Rx} / \mathrm{s}-\mathrm{EB} /(\mathrm{LR}[1-8], \mathrm{A},[3,4]) / \mathrm{b}\end{array}$ \\
\hline R3 & $17 . .32$ & $\begin{array}{l}\mathrm{BU} / \mathrm{Lx} / \mathrm{s}-\mathrm{EB} /(\mathrm{LR}[1-8], \mathrm{A},[1,2]) / \mathrm{b} \\
\mathrm{bu} / \mathrm{Rx} / \mathrm{s}-\mathrm{EB} /(\operatorname{LR}[1-8], \mathrm{A},[1,2]) / \mathrm{b}\end{array}$ \\
\hline $\mathrm{R} 4 \mathrm{~m}$ & $49 . .64$ & $\begin{array}{l}\mathrm{BU} / \mathrm{Lx} / \mathrm{s}-\mathrm{EB} /(\mathrm{LR}[1-8], \mathrm{A}, 4) / \mathrm{b} \\
\mathrm{bu} / \mathrm{Rx} / \mathrm{s}-\mathrm{EB} /(\mathrm{LR}[1-8], \mathrm{A}, 4) / \mathrm{b}\end{array}$ \\
\hline $\mathrm{R} 4 \mathrm{~d}$ & $65 . .80$ & $\begin{array}{l}\mathrm{BU} / \mathrm{Lx} / \mathrm{s}-\mathrm{EB} /(\mathrm{LR}[1-8], \mathrm{M}, 4) / \mathrm{b} \\
\mathrm{bu} / \mathrm{Rx} / \mathrm{s}-\mathrm{EB} /(\mathrm{LR}[1-8], \mathrm{M}, 4) / \mathrm{b}\end{array}$ \\
\hline
\end{tabular}

Table 24: Hypothesized arborizations of BU-EB neurons. Each microglomerulus corresponds to a single neuron, where the " $\mathrm{x}$ " character in the neuron label is replaced with the microglomerulus number.

Likewise, we also hypothesized isomorphic sets of pontine neurons that link the following regions in FB based upon [15, p. 349]:

- nonadjacent segments in layers 1, 2, 4, and 5 (Tab. 25);

- adjacent segments within the same layer in layers 1-5 [15, Fig. 9a] (Tab. 26).

- adjacent layers within the same segment for layers 1-5 [15, Fig. 9a] (Tab. 27).

- nonadjacent layers within the same segment, with both presynaptic and postsynaptic terminals in each layer [15, Fig. 9b] (Tab. 28); based upon the latter source, we assume two sets of neurons connecting layers 1 and 8 and 2 and 7 , respectively. 


\begin{tabular}{|c|l|}
\hline & $\mathrm{Label}$ \\
\hline 1 & $\mathrm{FB} /(1, \mathrm{~L} 4) / \mathrm{s}-\mathrm{FB} /(1, \mathrm{R} 1) / \mathrm{b}$ \\
2 & $\mathrm{FB} /(1, \mathrm{~L} 3) / \mathrm{s}-\mathrm{FB} /(1, \mathrm{R} 2) / \mathrm{b}$ \\
3 & $\mathrm{FB} /(1, \mathrm{~L} 2) / \mathrm{s}-\mathrm{FB} /(1, \mathrm{R} 3) / \mathrm{b}$ \\
4 & $\mathrm{FB} /(1, \mathrm{~L} 1) / \mathrm{s}-\mathrm{FB} /(1, \mathrm{R} 4) / \mathrm{b}$ \\
5 & $\mathrm{FB} /(1, \mathrm{R} 4) / \mathrm{s}-\mathrm{FB} /(1, \mathrm{~L} 1) / \mathrm{b}$ \\
6 & $\mathrm{FB} /(1, \mathrm{R} 3) / \mathrm{s}-\mathrm{FB} /(1, \mathrm{~L} 2) / \mathrm{b}$ \\
7 & $\mathrm{FB} /(1, \mathrm{R} 2) / \mathrm{s}-\mathrm{FB} /(1, \mathrm{~L} 3) / \mathrm{b}$ \\
8 & $\mathrm{FB} /(1, \mathrm{R} 1) / \mathrm{s}-\mathrm{FB} /(1, \mathrm{~L} 4) / \mathrm{b}$ \\
9 & $\mathrm{FB} /(2, \mathrm{~L} 4) / \mathrm{s}-\mathrm{FB} /(2, \mathrm{R} 1) / \mathrm{b}$ \\
10 & $\mathrm{FB} /(2, \mathrm{~L} 3) / \mathrm{s}-\mathrm{FB} /(2, \mathrm{R} 2) / \mathrm{b}$ \\
11 & $\mathrm{FB} /(2, \mathrm{~L} 2) / \mathrm{s}-\mathrm{FB} /(2, \mathrm{R} 3) / \mathrm{b}$ \\
12 & $\mathrm{FB} /(2, \mathrm{~L} 1) / \mathrm{s}-\mathrm{FB} /(2, \mathrm{R} 4) / \mathrm{b}$ \\
13 & $\mathrm{FB} /(2, \mathrm{R} 4) / \mathrm{s}-\mathrm{FB} /(2, \mathrm{~L} 1) / \mathrm{b}$ \\
14 & $\mathrm{FB} /(2, \mathrm{R} 3) / \mathrm{s}-\mathrm{FB} /(2, \mathrm{~L} 2) / \mathrm{b}$ \\
15 & $\mathrm{FB} /(2, \mathrm{R} 2) / \mathrm{s}-\mathrm{FB} /(2, \mathrm{~L} 3) / \mathrm{b}$ \\
16 & $\mathrm{FB} /(2, \mathrm{R} 1) / \mathrm{s}-\mathrm{FB} /(2, \mathrm{~L} 4) / \mathrm{b}$ \\
17 & $\mathrm{FB} /(4, \mathrm{~L} 4) / \mathrm{s}-\mathrm{FB} /(4, \mathrm{R} 1) / \mathrm{b}$ \\
18 & $\mathrm{FB} /(4, \mathrm{~L} 3) / \mathrm{s}-\mathrm{FB} /(4, \mathrm{R} 2) / \mathrm{b}$ \\
19 & $\mathrm{FB} /(4, \mathrm{~L} 2) / \mathrm{s}-\mathrm{FB} /(4, \mathrm{R} 3) / \mathrm{b}$ \\
20 & $\mathrm{FB} /(4, \mathrm{~L} 1) / \mathrm{s}-\mathrm{FB} /(4, \mathrm{R} 4) / \mathrm{b}$ \\
21 & $\mathrm{FB} /(4, \mathrm{R} 4) / \mathrm{s}-\mathrm{FB} /(4, \mathrm{~L} 1) / \mathrm{b}$ \\
22 & $\mathrm{FB} /(4, \mathrm{R} 3) / \mathrm{s}-\mathrm{FB} /(4, \mathrm{~L} 2) / \mathrm{b}$ \\
23 & $\mathrm{FB} /(4, \mathrm{R} 2) / \mathrm{s}-\mathrm{FB} /(4, \mathrm{~L} 3) / \mathrm{b}$ \\
24 & $\mathrm{FB} /(4, \mathrm{R} 1) / \mathrm{s}-\mathrm{FB} /(4, \mathrm{~L} 4) / \mathrm{b}$ \\
25 & $\mathrm{FB} /(5, \mathrm{~L} 4) / \mathrm{s}-\mathrm{FB} /(5, \mathrm{R} 1) / \mathrm{b}$ \\
26 & $\mathrm{FB} /(5, \mathrm{~L} 3) / \mathrm{s}-\mathrm{FB} /(5, \mathrm{R} 2) / \mathrm{b}$ \\
27 & $\mathrm{FB} /(5, \mathrm{~L} 2) / \mathrm{s}-\mathrm{FB} /(5, \mathrm{R} 3) / \mathrm{b}$ \\
28 & $\mathrm{FB} /(5, \mathrm{~L} 1) / \mathrm{s}-\mathrm{FB} /(5, \mathrm{R} 4) / \mathrm{b}$ \\
29 & $\mathrm{FB} /(5, \mathrm{R} 4) / \mathrm{s}-\mathrm{FB} /(5, \mathrm{~L} 1) / \mathrm{b}$ \\
30 & $\mathrm{FB} /(5, \mathrm{R} 3) / \mathrm{s}-\mathrm{FB} /(5, \mathrm{~L} 2) / \mathrm{b}$ \\
31 & $\mathrm{FB} /(5, \mathrm{R} 2) / \mathrm{s}-\mathrm{FB} /(5, \mathrm{~L} 3) / \mathrm{b}$ \\
32 & $\mathrm{FB} /(5, \mathrm{R} 1) / \mathrm{s}-\mathrm{FB} /(5, \mathrm{~L} 4) / \mathrm{b}$ \\
\hline
\end{tabular}

Table 25: Hypothesized FB local neurons linking segments in layers 1, 2, 4, and 5, respectively. 


\begin{tabular}{|c|l|}
\hline & $\mathrm{Label}$ \\
\hline 1 & $\mathrm{FB} /(1, \mathrm{~L} 4) / \mathrm{s}-\mathrm{FB} /(1, \mathrm{~L} 3) / \mathrm{b}$ \\
2 & $\mathrm{FB} /(1, \mathrm{~L} 3) / \mathrm{s}-\mathrm{FB} /(1, \mathrm{~L} 2) / \mathrm{b}$ \\
3 & $\mathrm{FB} /(1, \mathrm{~L} 2) / \mathrm{s}-\mathrm{FB} /(1, \mathrm{~L} 1) / \mathrm{b}$ \\
4 & $\mathrm{FB} /(1, \mathrm{~L} 1) / \mathrm{s}-\mathrm{FB} /(1, \mathrm{R} 1) / \mathrm{b}$ \\
5 & $\mathrm{FB} /(1, \mathrm{R} 1) / \mathrm{s}-\mathrm{FB} /(1, \mathrm{R} 2) / \mathrm{b}$ \\
6 & $\mathrm{FB} /(1, \mathrm{R} 2) / \mathrm{s}-\mathrm{FB} /(1, \mathrm{R} 3) / \mathrm{b}$ \\
7 & $\mathrm{FB} /(1, \mathrm{R} 3) / \mathrm{s}-\mathrm{FB} /(1, \mathrm{R} 4) / \mathrm{b}$ \\
8 & $\mathrm{FB} /(2, \mathrm{~L} 4) / \mathrm{s}-\mathrm{FB} /(2, \mathrm{~L} 3) / \mathrm{b}$ \\
9 & $\mathrm{FB} /(2, \mathrm{~L} 3) / \mathrm{s}-\mathrm{FB} /(2, \mathrm{~L} 2) / \mathrm{b}$ \\
10 & $\mathrm{FB} /(2, \mathrm{~L} 2) / \mathrm{s}-\mathrm{FB} /(2, \mathrm{~L} 1) / \mathrm{b}$ \\
11 & $\mathrm{FB} /(2, \mathrm{~L} 1) / \mathrm{s}-\mathrm{FB} /(2, \mathrm{R} 1) / \mathrm{b}$ \\
12 & $\mathrm{FB} /(2, \mathrm{R} 1) / \mathrm{s}-\mathrm{FB} /(2, \mathrm{R} 2) / \mathrm{b}$ \\
13 & $\mathrm{FB} /(2, \mathrm{R} 2) / \mathrm{s}-\mathrm{FB} /(2, \mathrm{R} 3) / \mathrm{b}$ \\
14 & $\mathrm{FB} /(2, \mathrm{R} 3) / \mathrm{s}-\mathrm{FB} /(2, \mathrm{R} 4) / \mathrm{b}$ \\
15 & $\mathrm{FB} /(3, \mathrm{~L} 4) / \mathrm{s}-\mathrm{FB} /(3, \mathrm{~L} 3) / \mathrm{b}$ \\
16 & $\mathrm{FB} /(3, \mathrm{~L} 3) / \mathrm{s}-\mathrm{FB} /(3, \mathrm{~L} 2) / \mathrm{b}$ \\
17 & $\mathrm{FB} /(3, \mathrm{~L} 2) / \mathrm{s}-\mathrm{FB} /(3, \mathrm{~L} 1) / \mathrm{b}$ \\
18 & $\mathrm{FB} /(3, \mathrm{~L} 1) / \mathrm{s}-\mathrm{FB} /(3, \mathrm{R} 1) / \mathrm{b}$ \\
19 & $\mathrm{FB} /(3, \mathrm{R} 1) / \mathrm{s}-\mathrm{FB} /(3, \mathrm{R} 2) / \mathrm{b}$ \\
20 & $\mathrm{FB} /(3, \mathrm{R} 2) / \mathrm{s}-\mathrm{FB} /(3, \mathrm{R} 3) / \mathrm{b}$ \\
21 & $\mathrm{FB} /(3, \mathrm{R} 3) / \mathrm{s}-\mathrm{FB} /(3, \mathrm{R} 4) / \mathrm{b}$ \\
22 & $\mathrm{FB} /(4, \mathrm{~L} 4) / \mathrm{s}-\mathrm{FB} /(4, \mathrm{~L} 3) / \mathrm{b}$ \\
23 & $\mathrm{FB} /(4, \mathrm{~L} 3) / \mathrm{s}-\mathrm{FB} /(4, \mathrm{~L} 2) / \mathrm{b}$ \\
24 & $\mathrm{FB} /(4, \mathrm{~L} 2) / \mathrm{s}-\mathrm{FB} /(4, \mathrm{~L} 1) / \mathrm{b}$ \\
25 & $\mathrm{FB} /(4, \mathrm{~L} 1) / \mathrm{s}-\mathrm{FB} /(4, \mathrm{R} 1) / \mathrm{b}$ \\
26 & $\mathrm{FB} /(4, \mathrm{R} 1) / \mathrm{s}-\mathrm{FB} /(4, \mathrm{R} 2) / \mathrm{b}$ \\
27 & $\mathrm{FB} /(4, \mathrm{R} 2) / \mathrm{s}-\mathrm{FB} /(4, \mathrm{R} 3) / \mathrm{b}$ \\
28 & $\mathrm{FB} /(4, \mathrm{R} 3) / \mathrm{s}-\mathrm{FB} /(4, \mathrm{R} 4) / \mathrm{b}$ \\
29 & $\mathrm{FB} /(5, \mathrm{~L} 4) / \mathrm{s}-\mathrm{FB} /(5, \mathrm{~L} 3) / \mathrm{b}$ \\
30 & $\mathrm{FB} /(5, \mathrm{~L} 3) / \mathrm{s}-\mathrm{FB} /(5, \mathrm{~L} 2) / \mathrm{b}$ \\
31 & $\mathrm{FB} /(5, \mathrm{~L} 2) / \mathrm{s}-\mathrm{FB} /(5, \mathrm{~L} 1) / \mathrm{b}$ \\
32 & $\mathrm{FB} /(5, \mathrm{~L} 1) / \mathrm{s}-\mathrm{FB} /(5, \mathrm{R} 1) / \mathrm{b}$ \\
33 & $\mathrm{FB} /(5, \mathrm{R} 1) / \mathrm{s}-\mathrm{FB} /(5, \mathrm{R} 2) / \mathrm{b}$ \\
& $\mathrm{FB} /(5, \mathrm{R} 3) / \mathrm{s}-\mathrm{FB} /(5, \mathrm{R} 4) / \mathrm{b}$ \\
\hline
\end{tabular}

Table 26: Hypothesized FB local neurons linking adjacent segments within the same layer in layers $1-5$. 


\begin{tabular}{|c|l|}
\hline & $\mathrm{Label}$ \\
\hline 1 & $\mathrm{FB} /(5, \mathrm{~L} 1) / \mathrm{s}-\mathrm{FB} /(4, \mathrm{~L} 1) / \mathrm{b}$ \\
2 & $\mathrm{FB} /(4, \mathrm{~L} 1) / \mathrm{s}-\mathrm{FB} /(3, \mathrm{~L} 1) / \mathrm{b}$ \\
3 & $\mathrm{FB} /(3, \mathrm{~L} 1) / \mathrm{s}-\mathrm{FB} /(2, \mathrm{~L} 1) / \mathrm{b}$ \\
4 & $\mathrm{FB} /(2, \mathrm{~L} 1) / \mathrm{s}-\mathrm{FB} /(1, \mathrm{~L} 1) / \mathrm{b}$ \\
5 & $\mathrm{FB} /(5, \mathrm{~L} 2) / \mathrm{s}-\mathrm{FB} /(4, \mathrm{~L} 2) / \mathrm{b}$ \\
6 & $\mathrm{FB} /(4, \mathrm{~L} 2) / \mathrm{s}-\mathrm{FB} /(3, \mathrm{~L} 2) / \mathrm{b}$ \\
7 & $\mathrm{FB} /(3, \mathrm{~L} 2) / \mathrm{s}-\mathrm{FB} /(2, \mathrm{~L} 2) / \mathrm{b}$ \\
8 & $\mathrm{FB} /(2, \mathrm{~L} 2) / \mathrm{s}-\mathrm{FB} /(1, \mathrm{~L} 2) / \mathrm{b}$ \\
9 & $\mathrm{FB} /(5, \mathrm{~L} 3) / \mathrm{s}-\mathrm{FB} /(4, \mathrm{~L} 3) / \mathrm{b}$ \\
10 & $\mathrm{FB} /(4, \mathrm{~L} 3) / \mathrm{s}-\mathrm{FB} /(3, \mathrm{~L} 3) / \mathrm{b}$ \\
11 & $\mathrm{FB} /(3, \mathrm{~L} 3) / \mathrm{s}-\mathrm{FB} /(2, \mathrm{~L} 3) / \mathrm{b}$ \\
12 & $\mathrm{FB} /(2, \mathrm{~L} 3) / \mathrm{s}-\mathrm{FB} /(1, \mathrm{~L} 3) / \mathrm{b}$ \\
13 & $\mathrm{FB} /(5, \mathrm{~L} 4) / \mathrm{s}-\mathrm{FB} /(4, \mathrm{~L} 4) / \mathrm{b}$ \\
14 & $\mathrm{FB} /(4, \mathrm{~L} 4) / \mathrm{s}-\mathrm{FB} /(3, \mathrm{~L} 4) / \mathrm{b}$ \\
15 & $\mathrm{FB} /(3, \mathrm{~L} 4) / \mathrm{s}-\mathrm{FB} /(2, \mathrm{~L} 4) / \mathrm{b}$ \\
16 & $\mathrm{FB} /(2, \mathrm{~L} 4) / \mathrm{s}-\mathrm{FB} /(1, \mathrm{~L} 4) / \mathrm{b}$ \\
17 & $\mathrm{FB} /(5, \mathrm{R} 1) / \mathrm{s}-\mathrm{FB} /(4, \mathrm{R} 1) / \mathrm{b}$ \\
18 & $\mathrm{FB} /(4, \mathrm{R} 1) / \mathrm{s}-\mathrm{FB} /(3, \mathrm{R} 1) / \mathrm{b}$ \\
19 & $\mathrm{FB} /(3, \mathrm{R} 1) / \mathrm{s}-\mathrm{FB} /(2, \mathrm{R} 1) / \mathrm{b}$ \\
20 & $\mathrm{FB} /(2, \mathrm{R} 1) / \mathrm{s}-\mathrm{FB} /(1, \mathrm{R} 1) / \mathrm{b}$ \\
21 & $\mathrm{FB} /(5, \mathrm{R} 2) / \mathrm{s}-\mathrm{FB} /(4, \mathrm{R} 2) / \mathrm{b}$ \\
22 & $\mathrm{FB} /(4, \mathrm{R} 2) / \mathrm{s}-\mathrm{FB} /(3, \mathrm{R} 2) / \mathrm{b}$ \\
23 & $\mathrm{FB} /(3, \mathrm{R} 2) / \mathrm{s}-\mathrm{FB} /(2, \mathrm{R} 2) / \mathrm{b}$ \\
24 & $\mathrm{FB} /(2, \mathrm{R} 2) / \mathrm{s}-\mathrm{FB} /(1, \mathrm{R} 2) / \mathrm{b}$ \\
25 & $\mathrm{FB} /(5, \mathrm{R} 3) / \mathrm{s}-\mathrm{FB} /(4, \mathrm{R} 3) / \mathrm{b}$ \\
26 & $\mathrm{FB} /(4, \mathrm{R} 3) / \mathrm{s}-\mathrm{FB} /(3, \mathrm{R} 3) / \mathrm{b}$ \\
27 & $\mathrm{FB} /(3, \mathrm{R} 3) / \mathrm{s}-\mathrm{FB} /(2, \mathrm{R} 3) / \mathrm{b}$ \\
28 & $\mathrm{FB} /(2, \mathrm{R} 3) / \mathrm{s}-\mathrm{FB} /(1, \mathrm{R} 3) / \mathrm{b}$ \\
29 & $\mathrm{FB} /(5, \mathrm{R} 4) / \mathrm{s}-\mathrm{FB} /(4, \mathrm{R} 4) / \mathrm{b}$ \\
30 & $\mathrm{FB} /(4, \mathrm{R} 4) / \mathrm{s}-\mathrm{FB} /(3, \mathrm{R} 4) / \mathrm{b}$ \\
31 & $\mathrm{FB} /(3, \mathrm{R} 4) / \mathrm{s}-\mathrm{FB} /(2, \mathrm{R} 4) / \mathrm{b}$ \\
32 & $\mathrm{FB} /(2, \mathrm{R} 4) / \mathrm{s}-\mathrm{FB} /(1, \mathrm{R} 4) / \mathrm{b}$ \\
\hline
\end{tabular}

Table 27: Hypothesized FB local neurons linking adjacent layers within the same segment for layers 1-5. 


\begin{tabular}{|c|l|}
\hline & Label \\
\hline 1 & $\mathrm{FB} /(1, \mathrm{~L} 1) / \mathrm{sb}-\mathrm{FB} /(8, \mathrm{~L} 1) / \mathrm{sb}$ \\
2 & $\mathrm{FB} /(1, \mathrm{~L} 2) / \mathrm{sb}-\mathrm{FB} /(8, \mathrm{~L} 2) / \mathrm{sb}$ \\
3 & $\mathrm{FB} /(1, \mathrm{~L} 3) / \mathrm{sb}-\mathrm{FB} /(8, \mathrm{~L} 3) / \mathrm{sb}$ \\
4 & $\mathrm{FB} /(1, \mathrm{~L} 4) / \mathrm{sb}-\mathrm{FB} /(8, \mathrm{~L} 4) / \mathrm{sb}$ \\
5 & $\mathrm{FB} /(1, \mathrm{R} 1) / \mathrm{sb}-\mathrm{FB} /(8, \mathrm{R} 1) / \mathrm{sb}$ \\
6 & $\mathrm{FB} /(1, \mathrm{R} 2) / \mathrm{sb}-\mathrm{FB} /(8, \mathrm{R} 2) / \mathrm{sb}$ \\
7 & $\mathrm{FB} /(1, \mathrm{R} 3) / \mathrm{sb}-\mathrm{FB} /(8, \mathrm{R} 3) / \mathrm{sb}$ \\
8 & $\mathrm{FB} /(1, \mathrm{R} 4) / \mathrm{sb}-\mathrm{FB} /(8, \mathrm{R} 4) / \mathrm{sb}$ \\
9 & $\mathrm{FB} /(2, \mathrm{~L} 1) / \mathrm{sb}-\mathrm{FB} /(7, \mathrm{~L} 1) / \mathrm{sb}$ \\
10 & $\mathrm{FB} /(2, \mathrm{~L} 2) / \mathrm{sb}-\mathrm{FB} /(7, \mathrm{~L} 2) / \mathrm{sb}$ \\
11 & $\mathrm{FB} /(2, \mathrm{~L} 3) / \mathrm{sb}-\mathrm{FB} /(7, \mathrm{~L} 3) / \mathrm{sb}$ \\
12 & $\mathrm{FB} /(2, \mathrm{~L} 4) / \mathrm{sb}-\mathrm{FB} /(7, \mathrm{~L} 4) / \mathrm{sb}$ \\
13 & $\mathrm{FB} /(2, \mathrm{R} 1) / \mathrm{sb}-\mathrm{FB} /(7, \mathrm{R} 1) / \mathrm{sb}$ \\
14 & $\mathrm{FB} /(2, \mathrm{R} 2) / \mathrm{sb}-\mathrm{FB} /(7, \mathrm{R} 2) / \mathrm{sb}$ \\
15 & $\mathrm{FB} /(2, \mathrm{R} 3) / \mathrm{sb}-\mathrm{FB} /(7, \mathrm{R} 3) / \mathrm{sb}$ \\
16 & $\mathrm{FB} /(2, \mathrm{R} 4) / \mathrm{sb}-\mathrm{FB} /(7, \mathrm{R} 4) / \mathrm{sb}$ \\
\hline
\end{tabular}

Table 28: Hypothesized FB local neurons linking nonadjacent layers within the same segment. 


\subsection{Executable Circuit Generation}

To infer the presence of synaptic connections between neurons, the above neuron names were loaded into a NeuroArch database [36] in accordance with its data model. Using a parser for the grammar described in $\S 2.2$, each neuron's name was parsed to extract its constituent arborization records (Tab. 29); these records were reinserted into the database as ArborizationData nodes and connected to the Neuron nodes created for the neuron in each family listed above.

\begin{tabular}{|l|l|l|}
\hline Field & Data Type & Sample Values \\
\hline neurite & set of 'b' or 's' & {$[\mathrm{b}],[\mathrm{b}, \mathrm{s}]$} \\
neuropil & string & $\mathrm{PB}, \mathrm{EB}$ \\
region & set of strings or tuples & {$[\mathrm{L} 1],[(1, \mathrm{R} 1)]$} \\
\hline
\end{tabular}

Table 29: Fields in ArborizationData node. Region strings or tuples conform to the formats described in $\S 3$.

After extraction of arborization data, all pairs of neurons in the database were compared to find those pairs with geometrically overlapping arborizations and differing neurite types (i.e. presynaptic versus postsynaptic). This resulted in the creation of Synapse nodes that were connected to the associated Neuron node pairs in NeuroArch's database.

To illustrate the synapse inference algorithm's operation, consider the neurons EB/ ([R3,R5],[P,M],[1-4])/s-EB/(R4,[P,M],[1-4])/b-LAL/RDG/b-PB/L3/b (Tab. 9) and PB/L4/s$\mathrm{EB} / 2 / \mathrm{b}-\mathrm{LAL} / \mathrm{RVG} / \mathrm{b}$ (Tab. 12). Since the region $\mathrm{EB} /(\mathrm{R} 3, \mathrm{P},[1-4]) / \mathrm{s}$ overlaps with region $\mathrm{EB} / 2 / \mathrm{b}$ (Tab. 1) and the terminal types of the two neurons in the overlapping region differ, we infer the presence of a synapse with information flow from the latter neuron to the former. Figs. 24, 25, 26, 27, 28, 29, 30, 31, and 32 respectively depict the inferred synapses between PB local neurons (Tab. 7), between PB local and PB-EB-LAL neurons (Tab. 12), between PB local and PB-EB-NO neurons (Tab. 11), between EB-LAL-PB neurons (Tab. 9), between EB-LAL-PB and PB local neurons, between EB-LAL-PB and PB-EB-LAL neurons, between EB-LAL-PB and PB-EB-NO neurons, between PB-EB-LAL and EB-LAL-PB neurons, and between PB-EB-NO and EB-LAL-PB neurons; yellow nodes correspond to PB local neurons, pink nodes correspond to PB-EB-LAL neurons, orange nodes correspond to PB-EB-NO neurons, and green nodes correspond to EB-LAL-PB neurons. In all of these figures, each arrow head corresponds to a single inferred synapse. The neuron numbers in the figures correspond to those in the respective tables of neuron names. In all of the following connectivity matrices, a black square denotes the presence of a connection linking a presynaptic neuron on the the $\mathrm{y}$-axis to a postsynaptic neuron on the $\mathrm{x}$-axis. 
bioRxiv preprint doi: https://doi.org/10.1101/051318; this version posted May 23, 2016. The copyright holder for this preprint (which was not certified by peer review) is the author/funder, who has granted bioRxiv a license to display the preprint in perpetuity. It is made available under aCC-BY 4.0 International license.

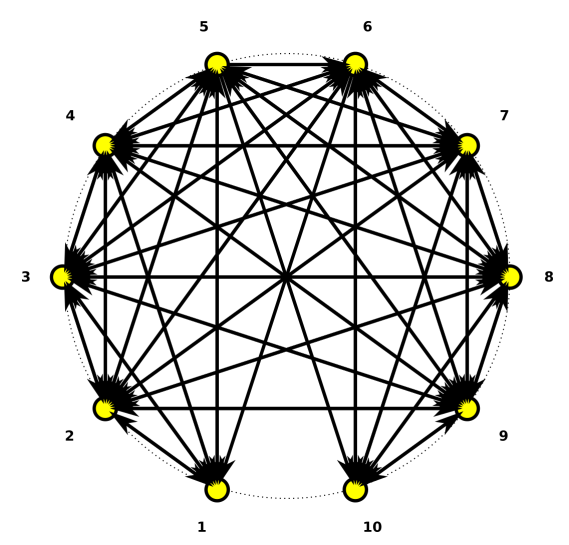

(a) Circuit diagram.

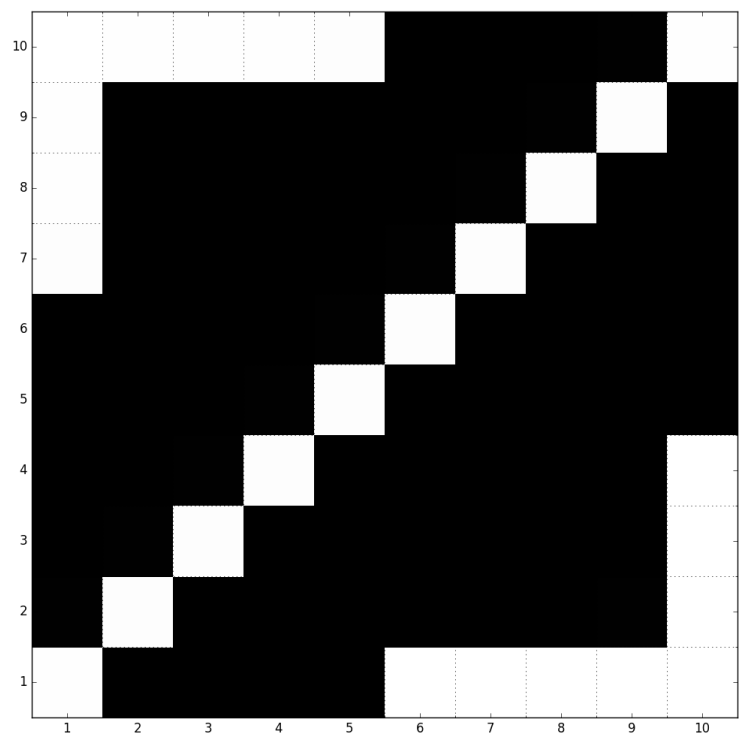

(b) Connectivity matrix.

Figure 24: Inferred synapses between PB local neurons (Tab. 7). 


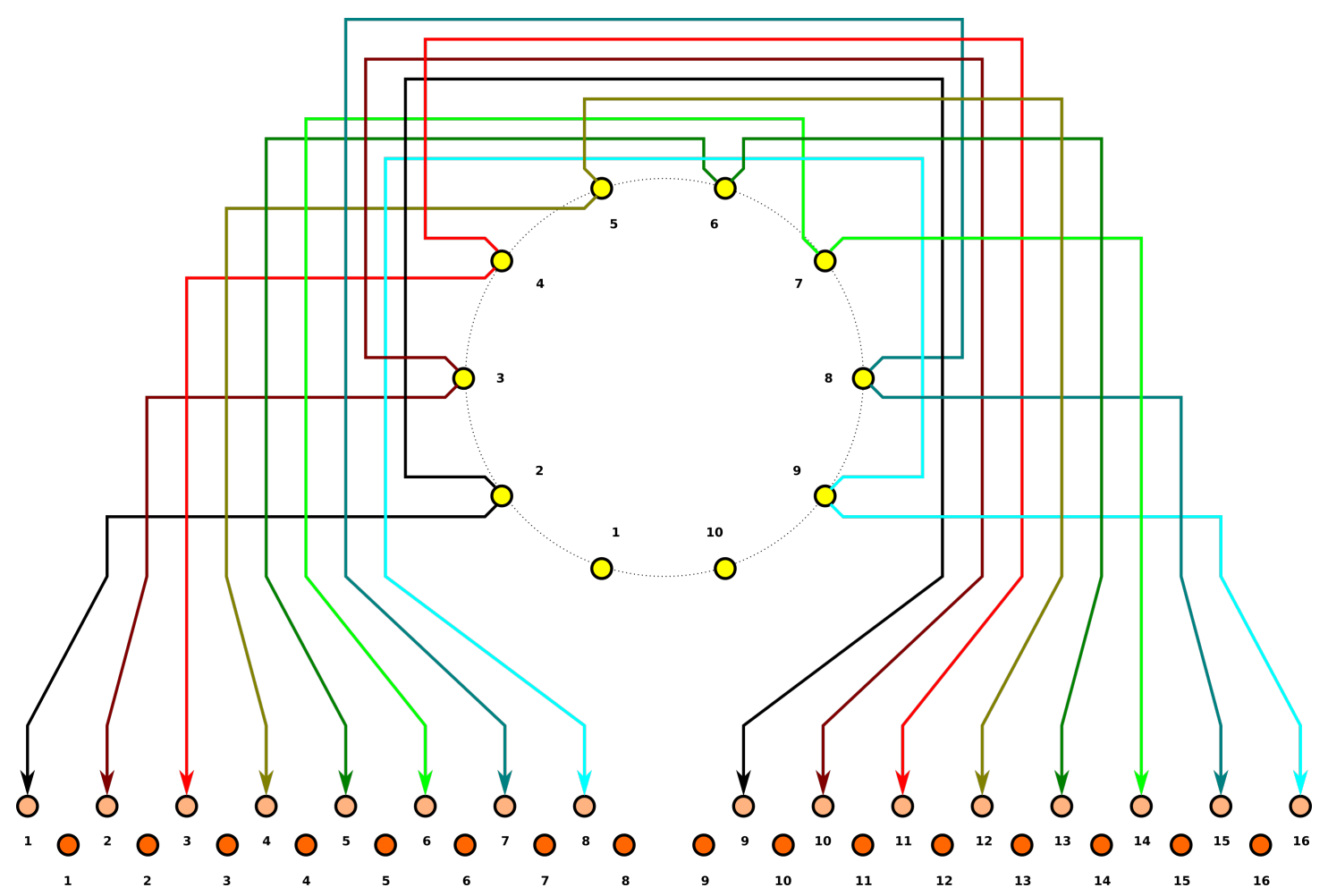

(a) Circuit diagram.

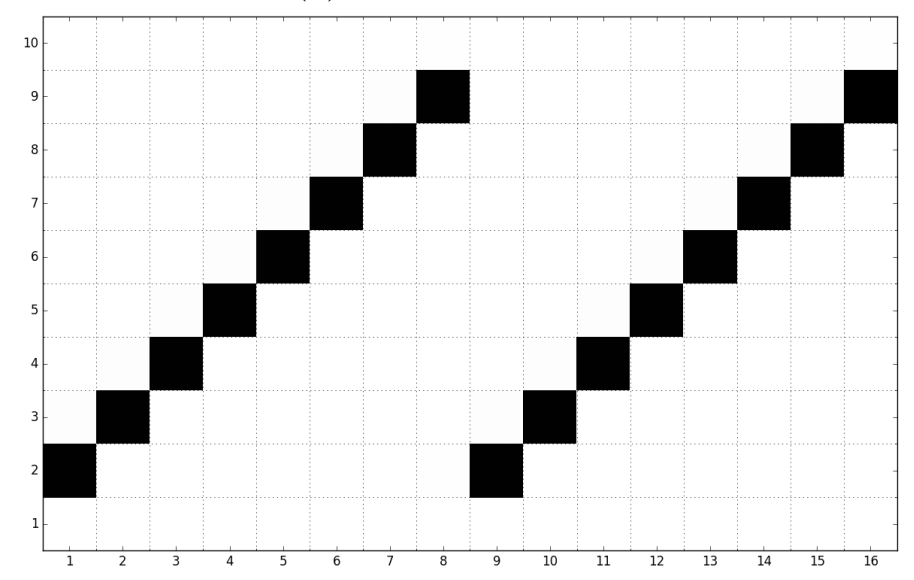

(b) Connectivity matrix.

Figure 25: Inferred synapses between PB local (Tab. 7) and PB-EB-LAL (Tab. 12) neurons. 


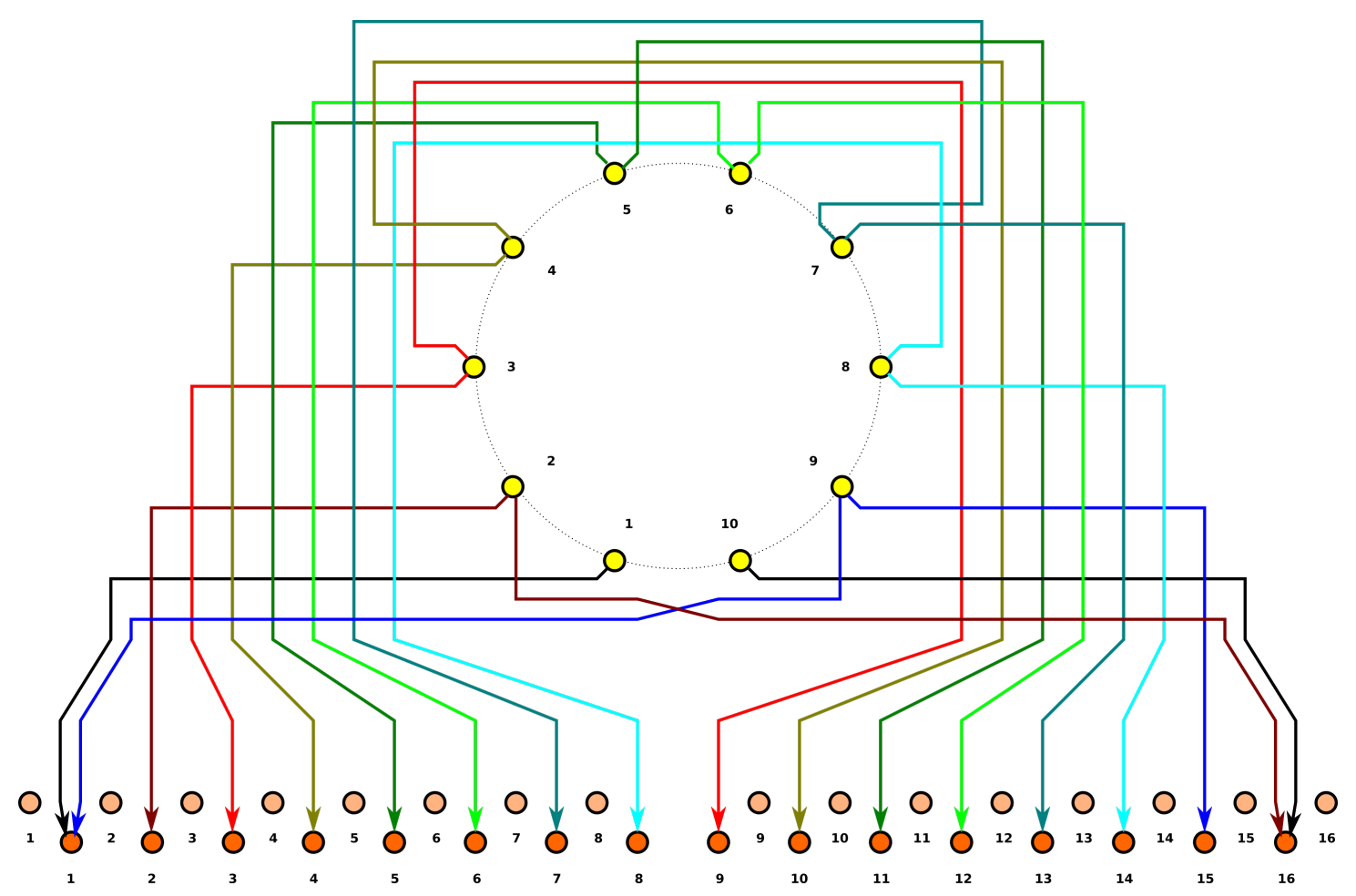

(a) Circuit diagram.

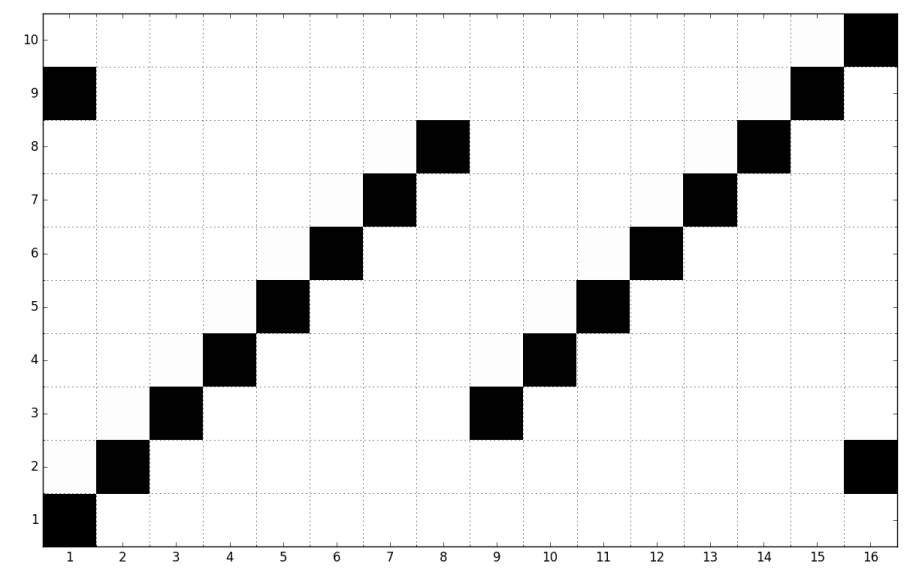

(b) Connectivity matrix.

Figure 26: Inferred synapses between PB local (Tab. 7) and PB-EB-NO (Tab. 11) neurons. 


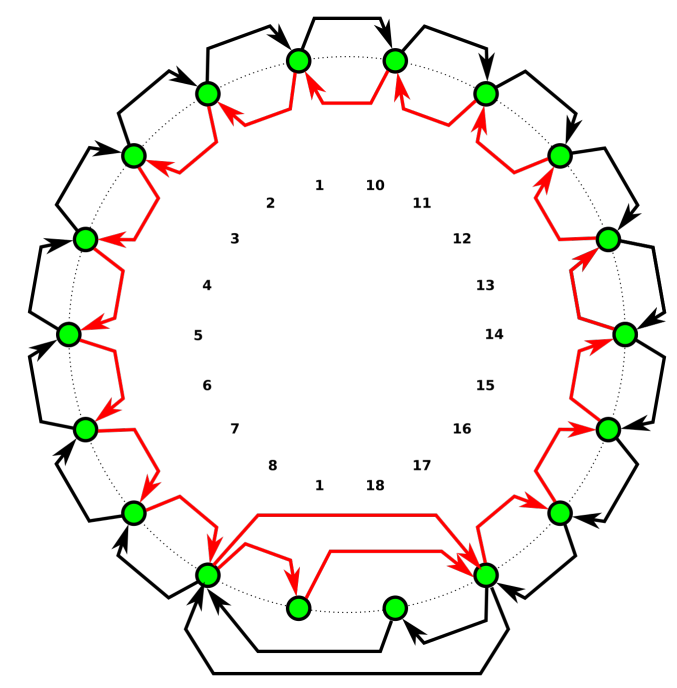

(a) Circuit diagram.

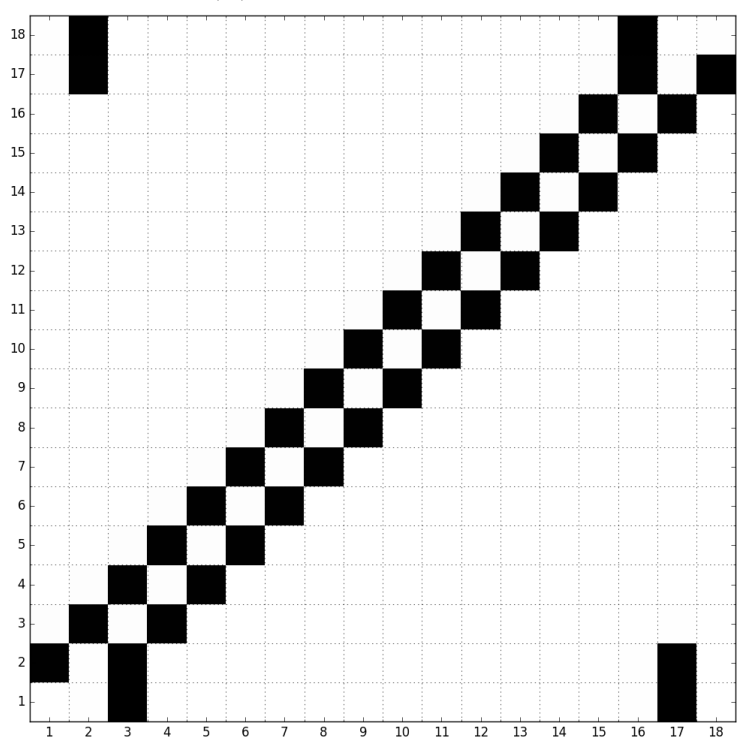

(b) Connectivity matrix.

Figure 27: Inferred synapses between EB-LAL-PB (Tab. 9) neurons. 


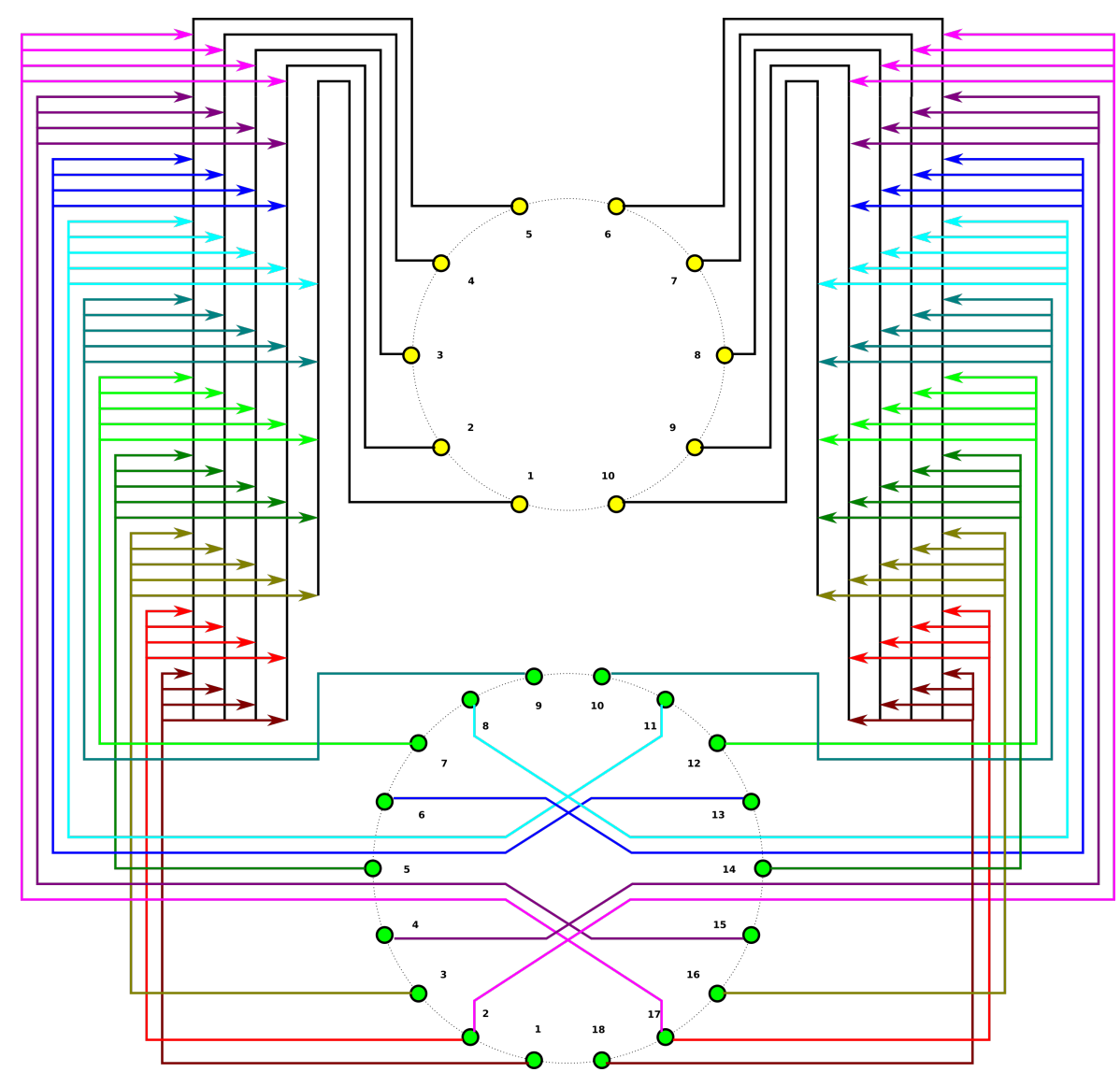

(a) Circuit diagram.

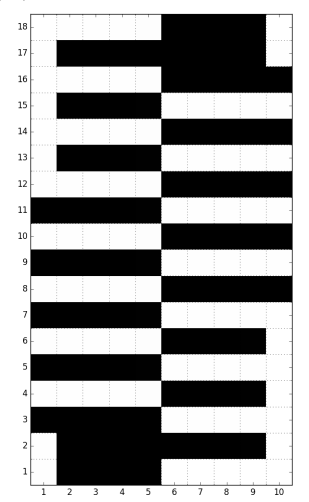

(b) Connectivity matrix.

Figure 28: Inferred synapses between EB-LAL-PB (Tab. 9) and PB local (Tab. 7) neurons. 


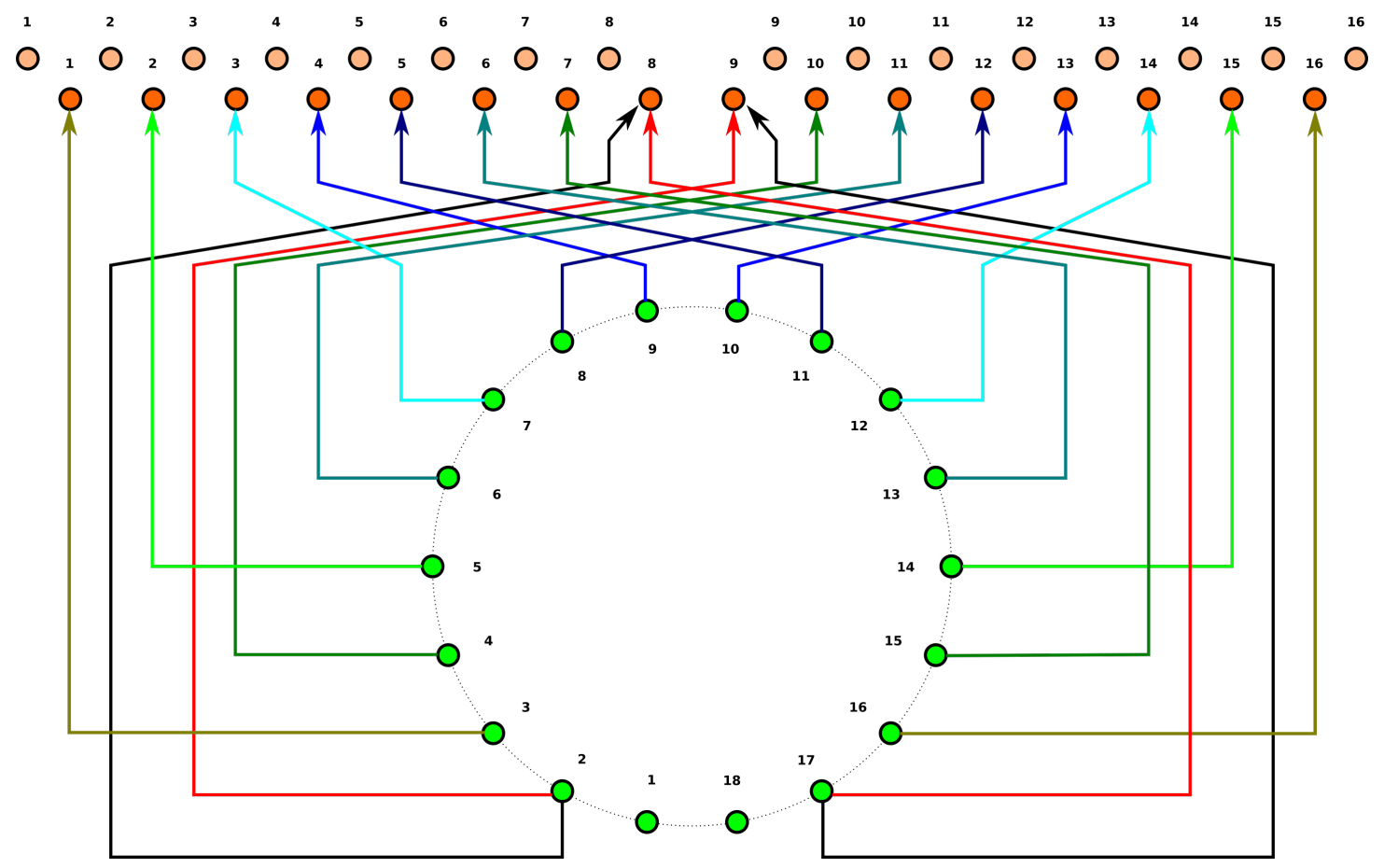

(a) Circuit diagram.

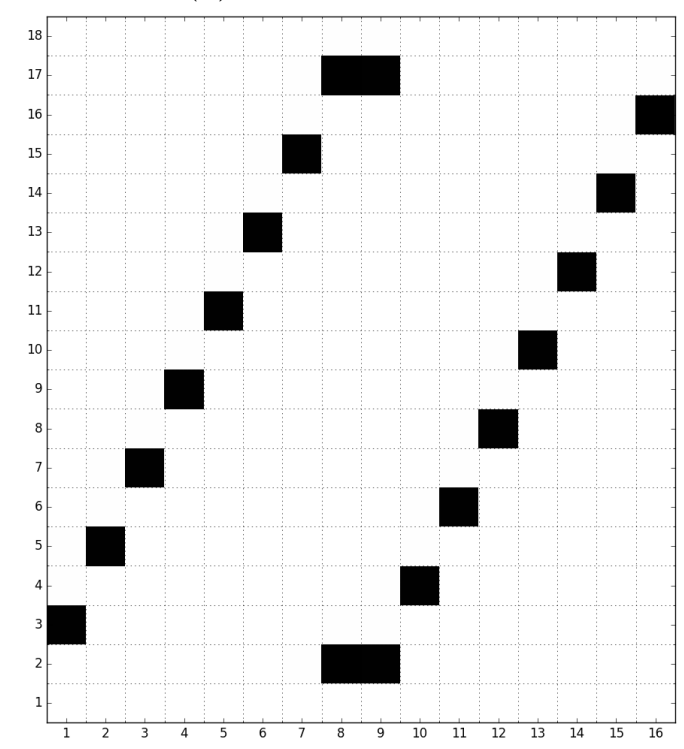

(b) Connectivity matrix.

Figure 29: Inferred synapses between EB-LAL-PB (Tab. 9) and PB-EB-LAL (Tab. 12) neurons. 


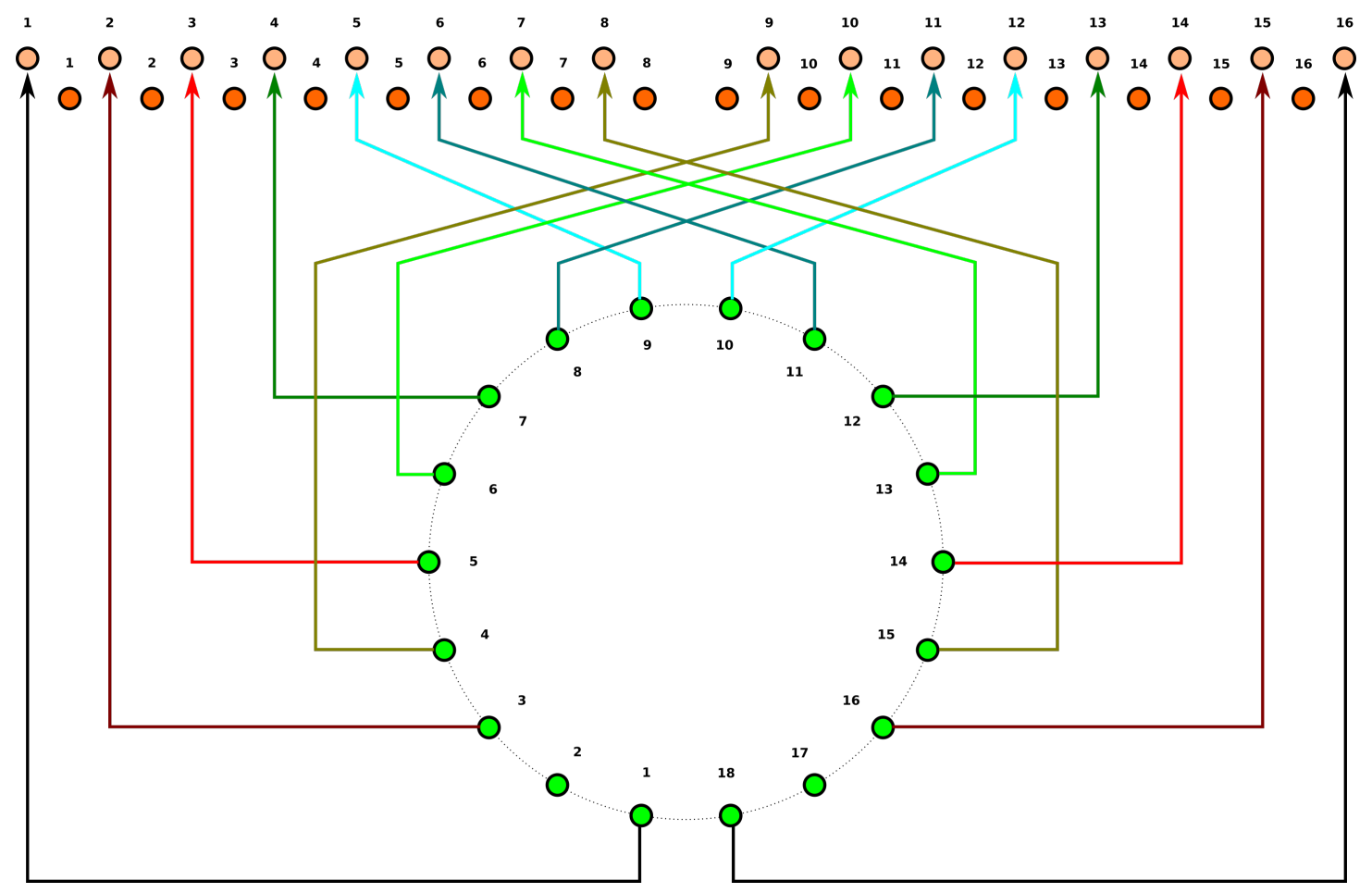

(a) Circuit diagram.

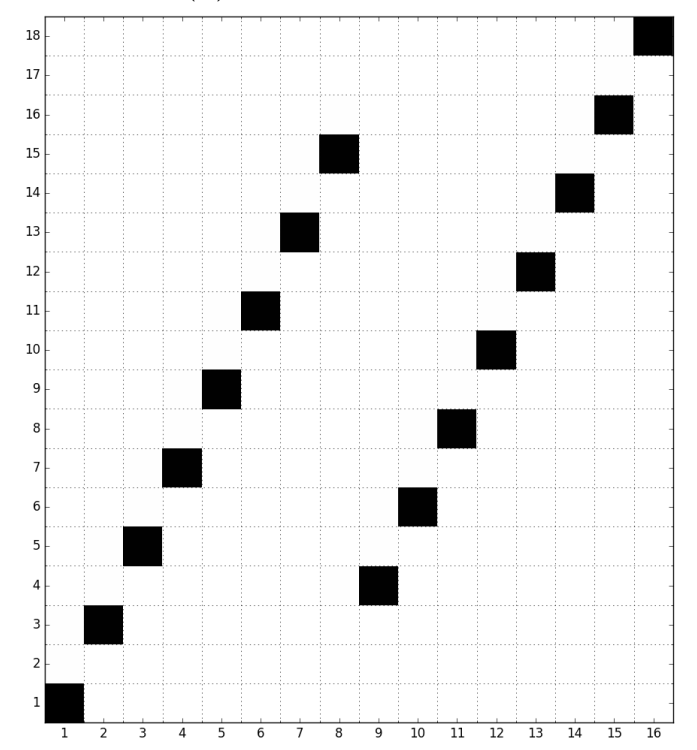

(b) Connectivity matrix.

Figure 30: Inferred synapses between EB-LAL-PB (Tab. 9) and PB-EB-NO (Tab. 11) neurons. 


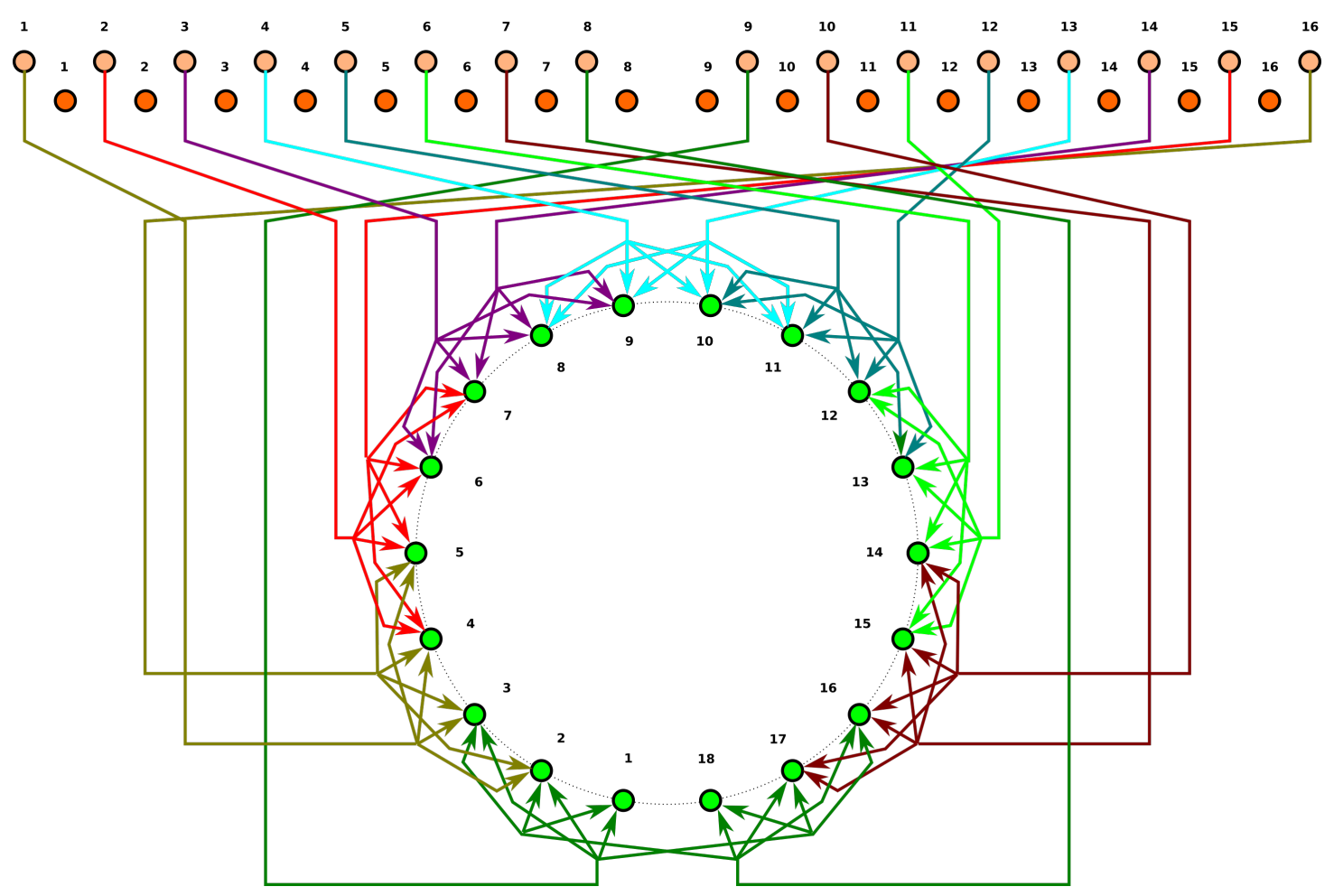

(a) Circuit diagram.

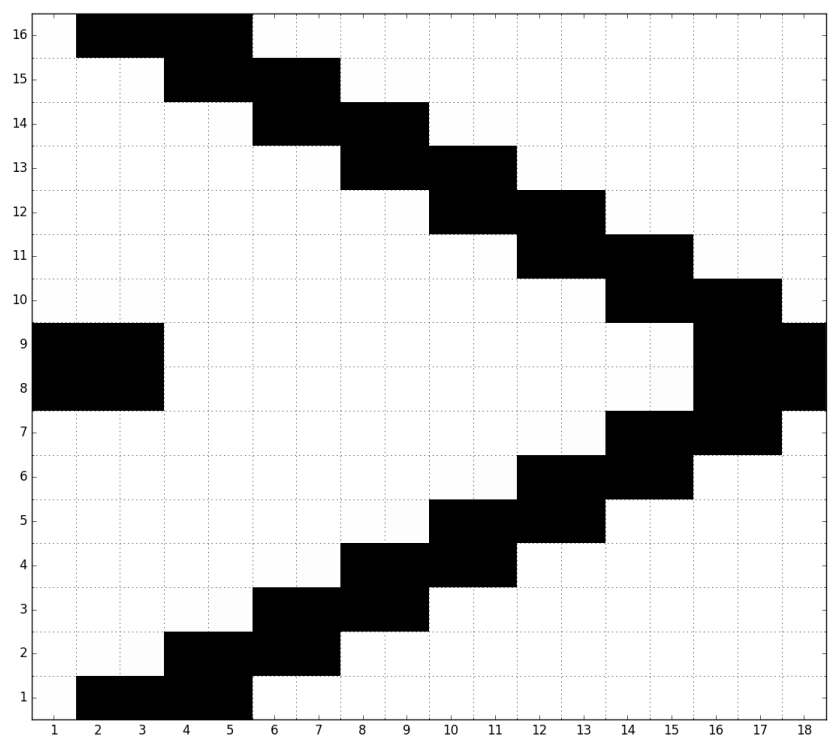

(b) Connectivity matrix.

Figure 31: Inferred synapses between PB-EB-LAL (Tab. 12) and EB-LAL-PB (Tab. 9) neurons. 


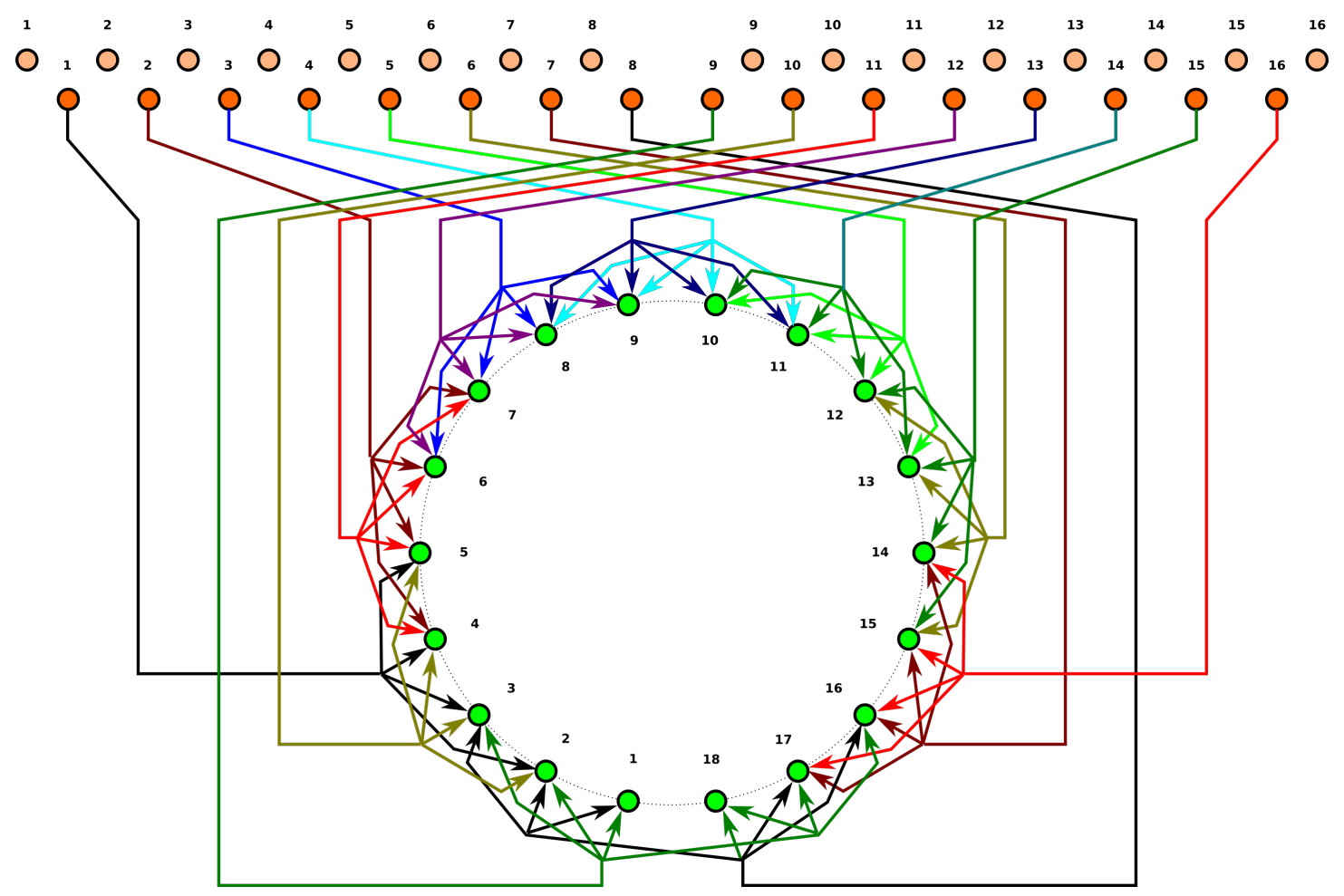

(a) Circuit diagram.

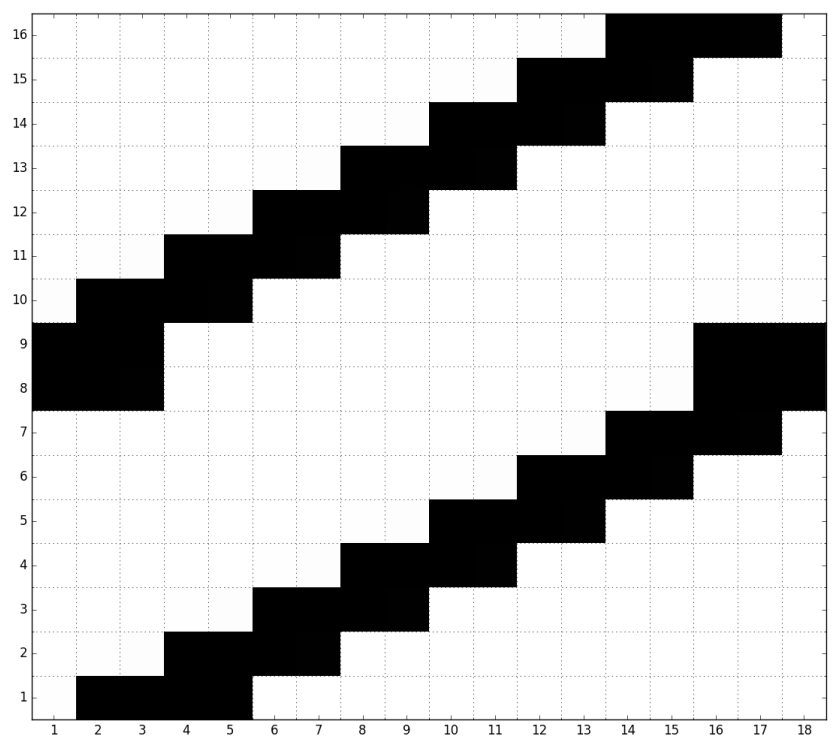

(b) Connectivity matrix.

Figure 32: Inferred synapses between PB-EB-NO (Tab. 11) and EB-LAL-PB (Tab. 9) neurons. 
Neuron and synapse models were instantiated for each respective biological neuron and synapse in NeuroArch's database to construct LPUs corresponding to the BU, FB, EB, and PB neuropils. All neurons were modeled as Leaky Integrate-and-Fire neurons, and all synapses modeled to produce alpha function responses to presynaptic spikes. Communication ports were created for every neuron model instance comprised by one LPU connected to a synapse model instance in the other neuropil; the connectivity pattern linking the ports associated with the neuron and synapse models was also added to the NeuroArch database. NeuroArch's API was used to extract the constructed LPUs and patterns and dispatch them to Neurokernel [37] for execution.

\subsection{Executing the Circuit}

To test the executability of the generated circuit and its ability to respond to input data, the generated model was driven by a simple visual stimulus consisting of an illuminated vertical bar proceeding horizontally across the 2D visual space (Fig. 33). Since the central complex neuropils do not receive direct connections from the vision neuropils, the visual stimulus was passed into three banks of receptive fields whose outputs were respectively provided to BU, bu, and PB as input (Fig. 34). The receptive fields for BU and bu each consisted of 80 evenly spaced 2D grids of circular Gaussians that correspond to one of the microglomeruli in BU; each receptive field was connected to one BU-EB neuron such that the 16 neurons in each of the 5 groups described in $\S 5.4$.1 processed input from a rectangle occupying $\frac{1}{5}$ of the $2 \mathrm{D}$ visual space. The receptive fields for $\mathrm{PB}$ consisted of 18 vertical rectangular regions with a constant magnitude; each receptive field was connected to all local and projection neurons that innervated the glomerulus corresponding to the receptive field region. The responses of the neurons in each family to the two input signals are organized in the same order in the respective raster plots.
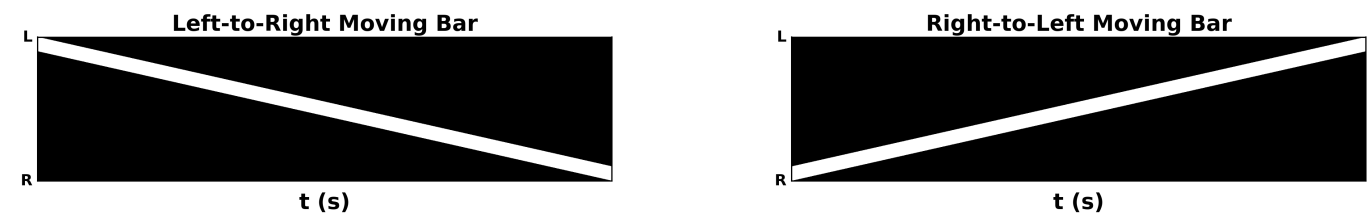

Figure 33: Moving bar visual input to generated CX model. The plots depict the movement of an illuminated vertical bar horizontally across a dark background. 


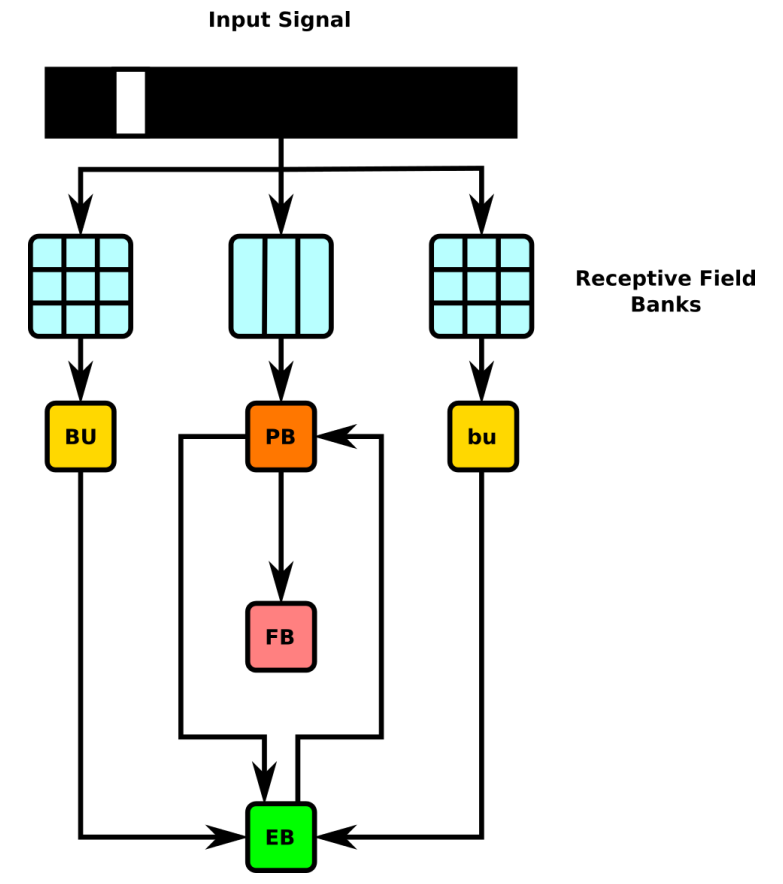

Figure 34: Schematic of information flow in generated CX model. 2D visual signals are passed through rectangular grids of Gaussian receptive fields whose outputs drive BU-EB neurons and through a bank of vertical rectangular receptive fields whose outputs drive neurons that innervate the PB glomeruli. The generated model only comprises neurons that innervate the depicted LPUs (BU, bu, EB, FB, and PB).

\subsection{Use Cases}

The NeuroArch and Neurokernel pipeline used to generate the CX model described above enables analysis and manipulation of the model using computational analogues to experimental techniques.

\subsubsection{Virtual Electrophysiology}

One can use NeuroArch/Neurokernel to concurrently probe the responses different sets of neurons in multiple neuropils in a computational experiment. Figs. 35 and 36 depict the responses of neurons innervating the $\mathrm{PB}$ and $\mathrm{BU} / \mathrm{bu}$ neuropils to the signal depicted in Fig. 33. 

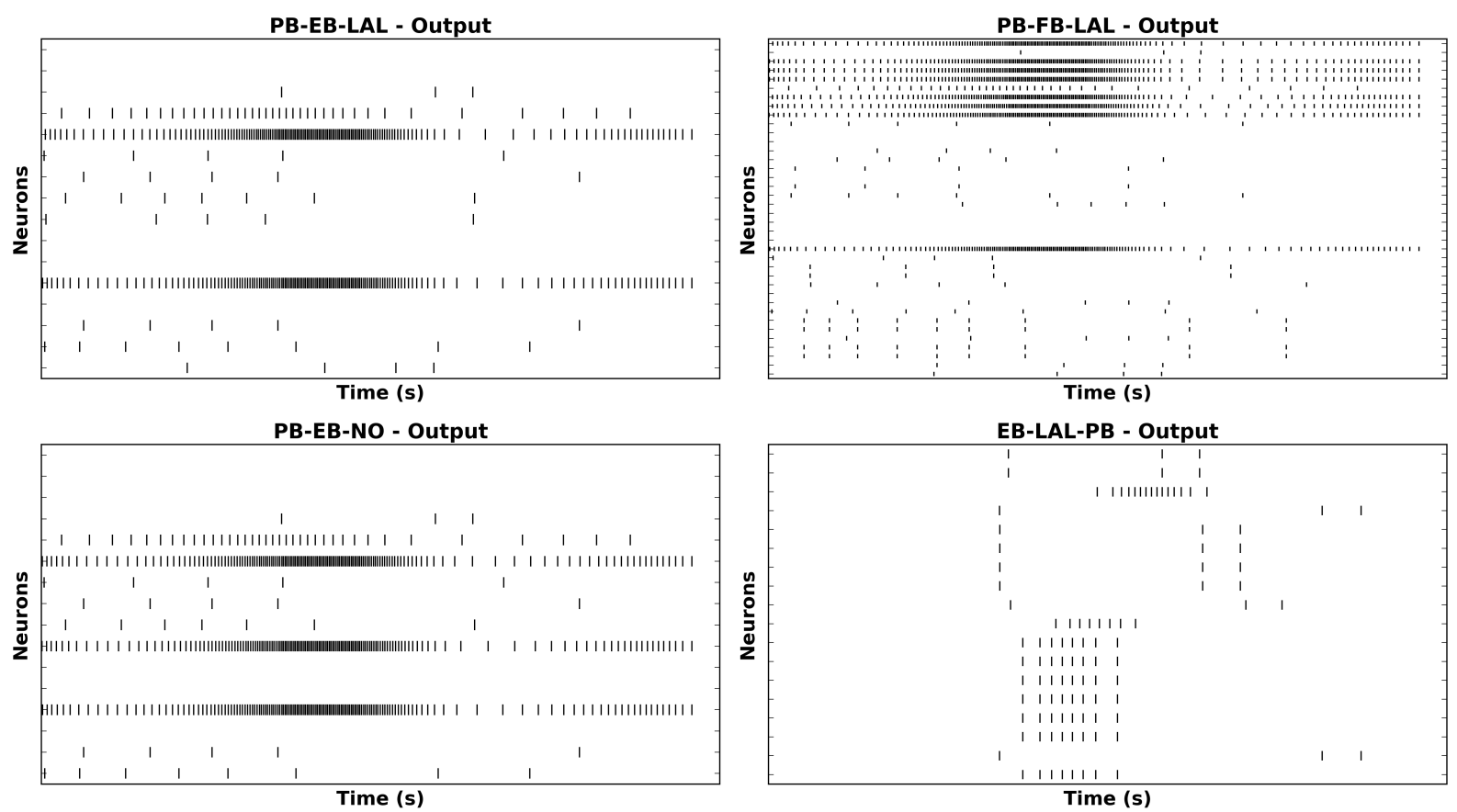

(a) Response to bar moving left to right.
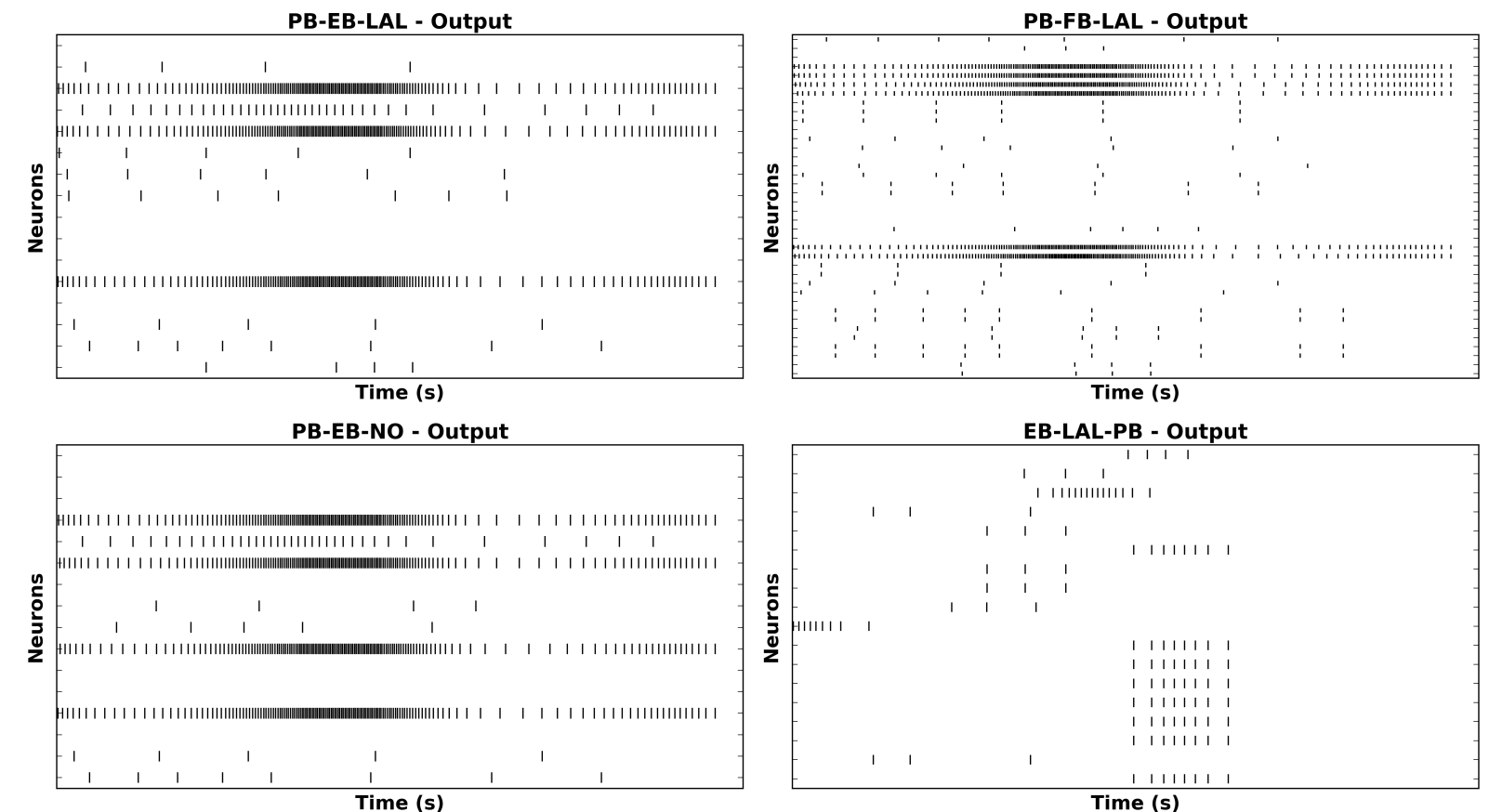

(b) Response to bar moving right to left.

Figure 35: Response of CX projection neurons innervating PB to moving bar input. 

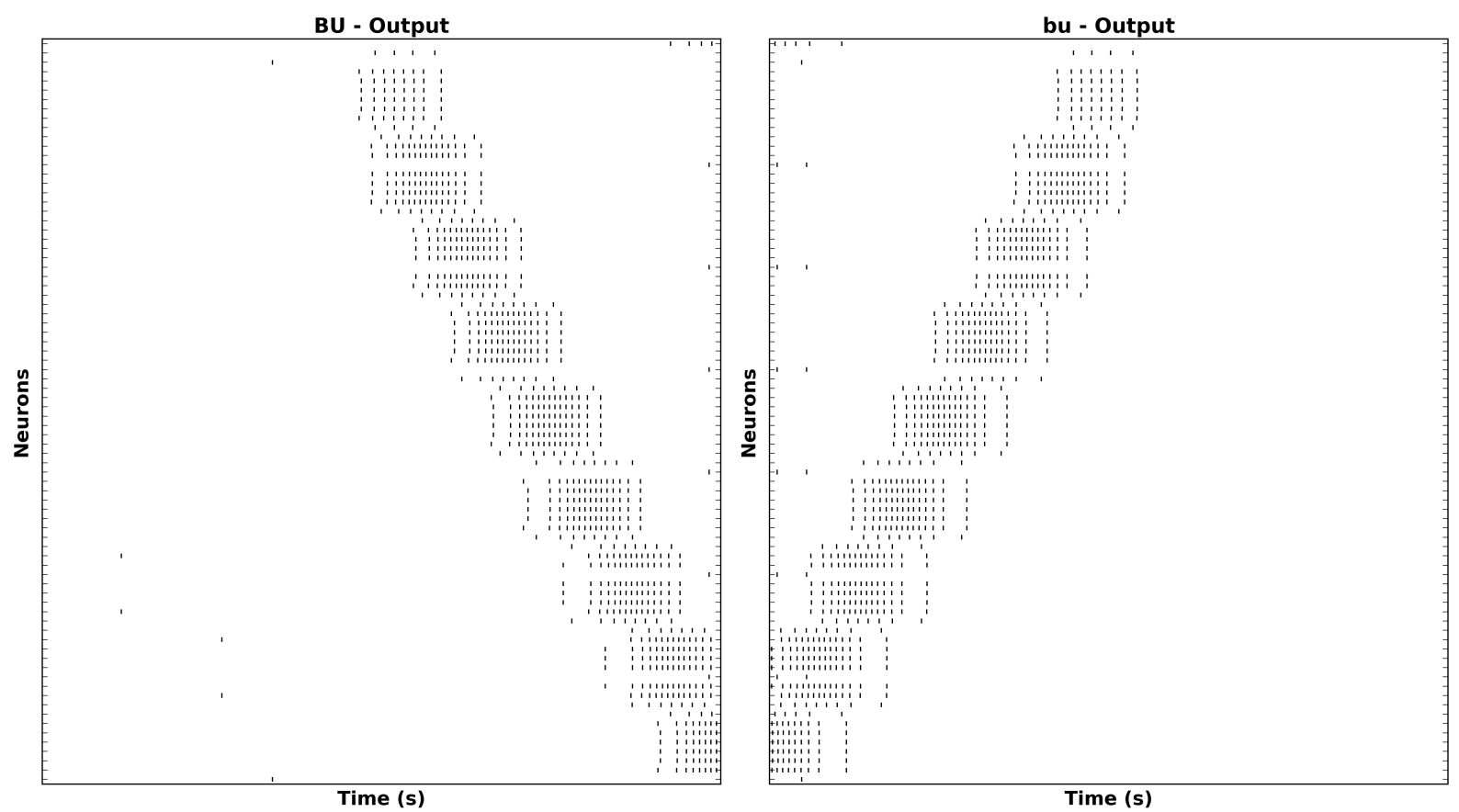

(a) Response to bar moving left to right.
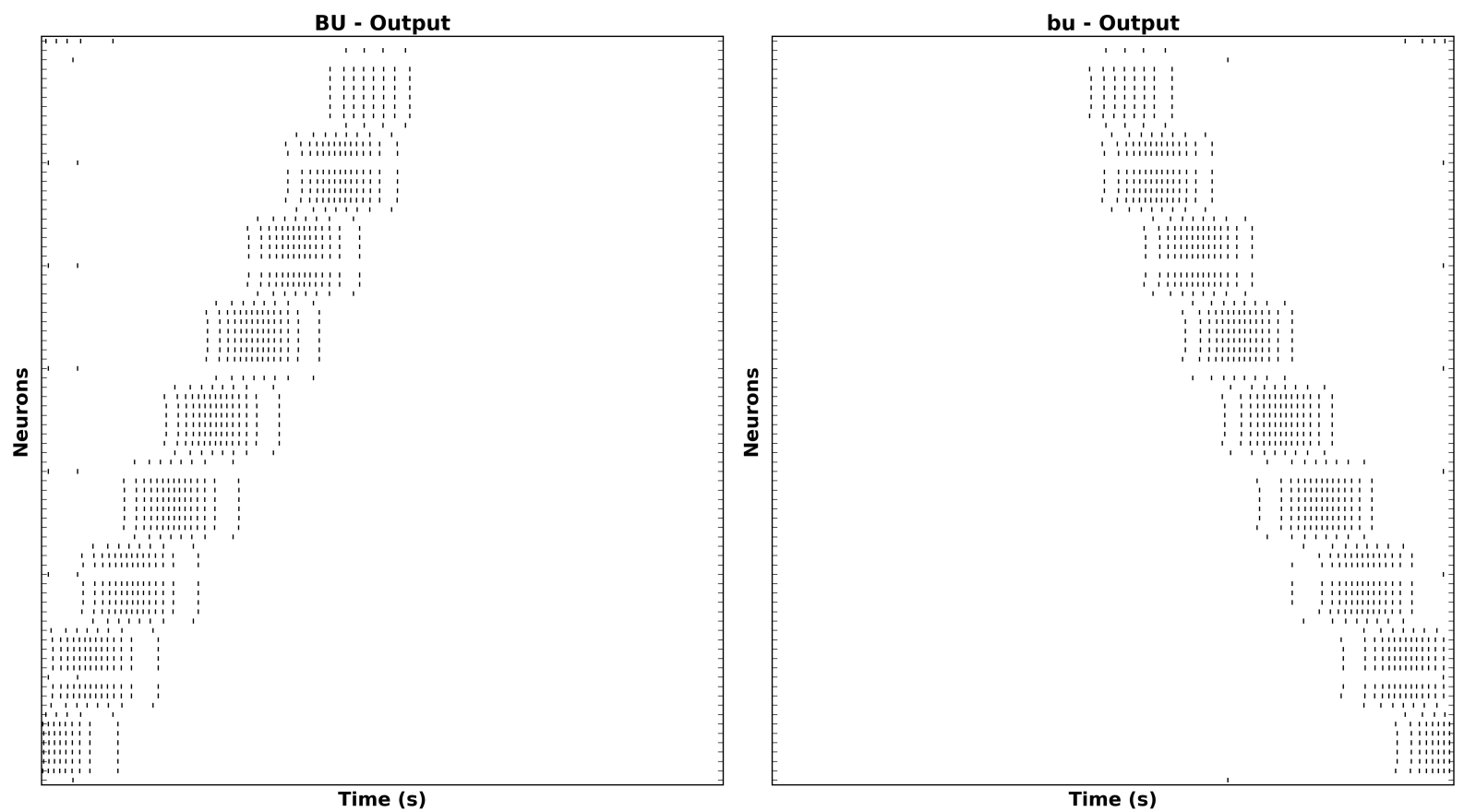

(b) Response to bar moving right to left.

Figure 36: Response of CX projection neurons innervating BU/bu to moving bar input. 


\subsubsection{Virtual Genetic Manipulation}

To test hypotheses regarding incompletely characterized parts of the fly brain, one can create models that either attempt to replicate abnormal behaviors or emulate abnormal circuit structures observed in different mutant fly strains. For example, one can attempt to model phenotypes corresponding to mutations affecting the structure of PB (e.g., no bridge, tay bridge, etc.) by altering the PB model generation process accordingly. Given that these mutations are known to alter the fly's step length [4, p. 7] and since neurons innervating the motor ganglia are known to be postsynaptic to those that innervate LAL, it is reasonable to expect that analogous modifications to the structure of PB may alter the observed output of CX projection neurons that innervate LAL.

We used NeuroArch to emulate the no bridge mutant by altering the PB local neurons to remove all local connections between the left and right sides of $\mathrm{PB}$ and positing the existence of additional local neurons caused by the mutation (Fig. 37); the synapse inference algorithm was then run on the modified database to construct a mutant CX model. Although descriptions of the no bridge mutant suggest that several of the medial glomeruli are not present, our model does not alter any of the other known neurons in CX. The effects of the mutation on the response of the $\mathrm{PB}$ projection neuron families can be observed by comparing the mutant model output in Fig. 38 to Fig. 35. As the BU-EB neurons do not receive any input from other neurons in the generated model, their responses in the mutant model (Fig. 39) are identical to those in the original model.

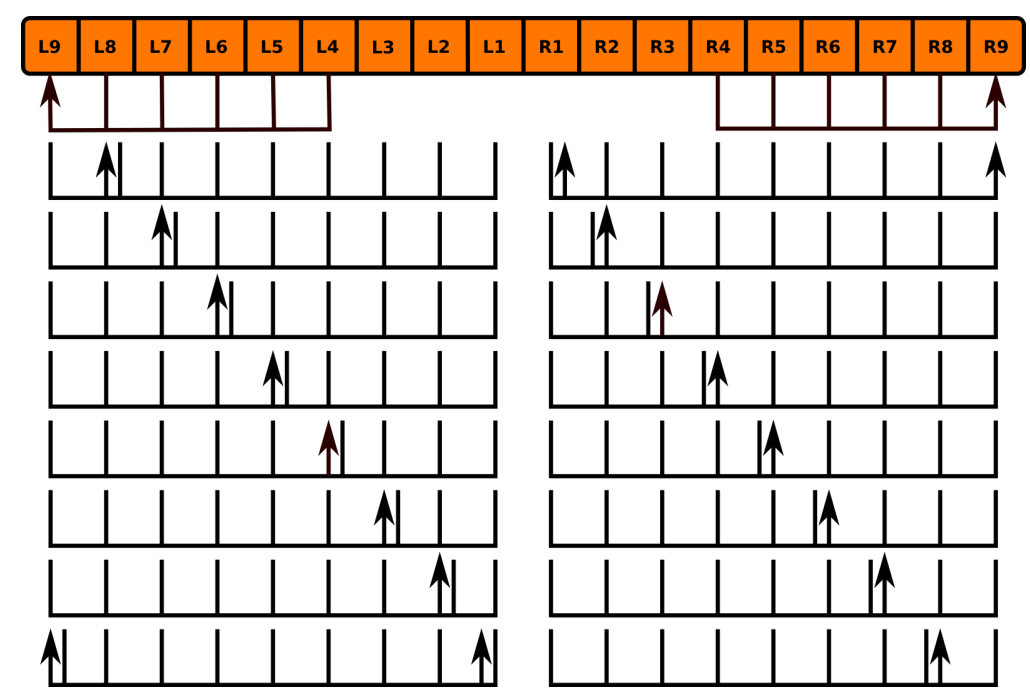

Figure 37: Hypothesized innervation pattern of $\mathrm{PB}$ local neurons in no bridge mutant (Tab. 30). 


\begin{tabular}{|c|l|}
\hline & Label \\
\hline 1 & $\mathrm{~PB} / \mathrm{R} 9 / \mathrm{b}-\mathrm{PB} / \mathrm{R}[4-8] / \mathrm{s}$ \\
2 & $\mathrm{~PB} / \mathrm{L} 9 / \mathrm{b}-\mathrm{PB} / \mathrm{L}[4-8] / \mathrm{s}$ \\
3 & $\mathrm{~PB} / \mathrm{L} 2 / \mathrm{b}-\mathrm{PB} / \mathrm{L}[1-9] / \mathrm{s}$ \\
4 & $\mathrm{~PB} / \mathrm{R} 7 / \mathrm{b}-\mathrm{PB} / \mathrm{R}[1-9] / \mathrm{s}$ \\
5 & $\mathrm{~PB} / \mathrm{L} 7 / \mathrm{b}-\mathrm{PB} / \mathrm{L}[1-9] / \mathrm{s}$ \\
6 & $\mathrm{~PB} / \mathrm{R} 2 / \mathrm{b}-\mathrm{PB} / \mathrm{R}[1-9] / \mathrm{s}$ \\
7 & $\mathrm{~PB} / \mathrm{L} 3 / \mathrm{b}-\mathrm{PB} / \mathrm{L}[1-9] / \mathrm{s}$ \\
8 & $\mathrm{~PB} / \mathrm{R} 6 / \mathrm{b}-\mathrm{PB} / \mathrm{R}[1-9] / \mathrm{s}$ \\
9 & $\mathrm{~PB} / \mathrm{L} 6 / \mathrm{b}-\mathrm{PB} / \mathrm{L}[1-9] / \mathrm{s}$ \\
10 & $\mathrm{~PB} / \mathrm{R} 3 / \mathrm{b}-\mathrm{PB} / \mathrm{R}[1-9] / \mathrm{s}$ \\
11 & $\mathrm{~PB} / \mathrm{L} 4 / \mathrm{b}-\mathrm{PB} / \mathrm{L}[1-9] / \mathrm{s}$ \\
12 & $\mathrm{~PB} / \mathrm{R} 5 / \mathrm{b}-\mathrm{PB} / \mathrm{R}[1-9] / \mathrm{s}$ \\
13 & $\mathrm{~PB} / \mathrm{L} 5 / \mathrm{b}-\mathrm{PB} / \mathrm{L}[1-9] / \mathrm{s}$ \\
14 & $\mathrm{~PB} / \mathrm{R} 4 / \mathrm{b}-\mathrm{PB} / \mathrm{R}[1-9] / \mathrm{s}$ \\
15 & $\mathrm{~PB} / \mathrm{R} 8 / \mathrm{b}-\mathrm{PB} / \mathrm{R}[1-9] / \mathrm{s}$ \\
16 & $\mathrm{~PB} / \mathrm{L} 1 \mid \mathrm{L} 9 / \mathrm{b}-\mathrm{PB} / \mathrm{L}[1-9] / \mathrm{s}$ \\
17 & $\mathrm{~PB} / \mathrm{L} 8 / \mathrm{b}-\mathrm{PB} / \mathrm{L}[1-9] / \mathrm{s}$ \\
18 & $\mathrm{~PB} / \mathrm{R} 1 \mid \mathrm{R} 9 / \mathrm{b}-\mathrm{PB} / \mathrm{R}[1-9] / \mathrm{s}$ \\
\hline
\end{tabular}

Table 30: Hypothesized PB local neurons in the no bridge mutant. 

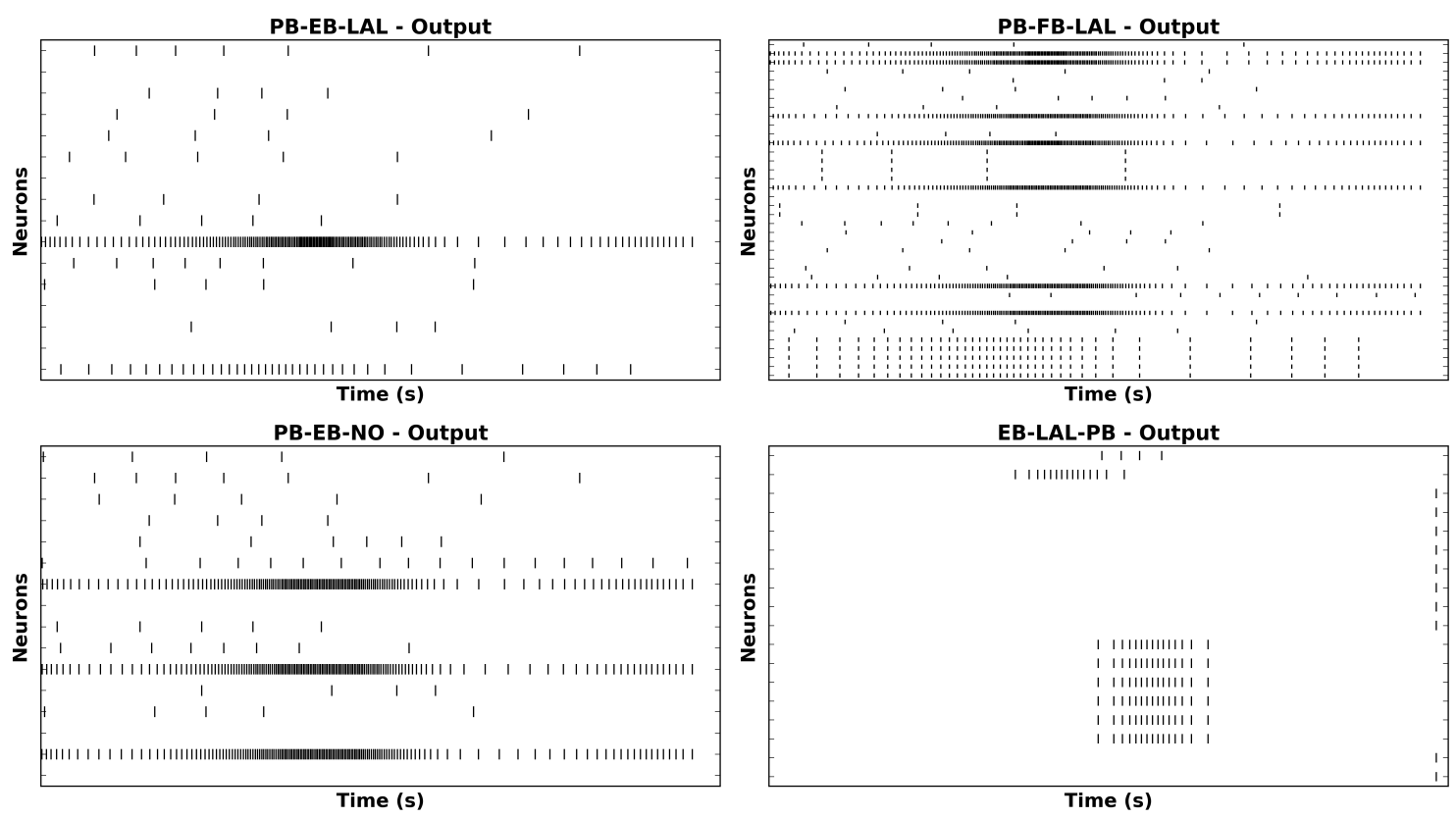

(a) Response to bar moving left to right.
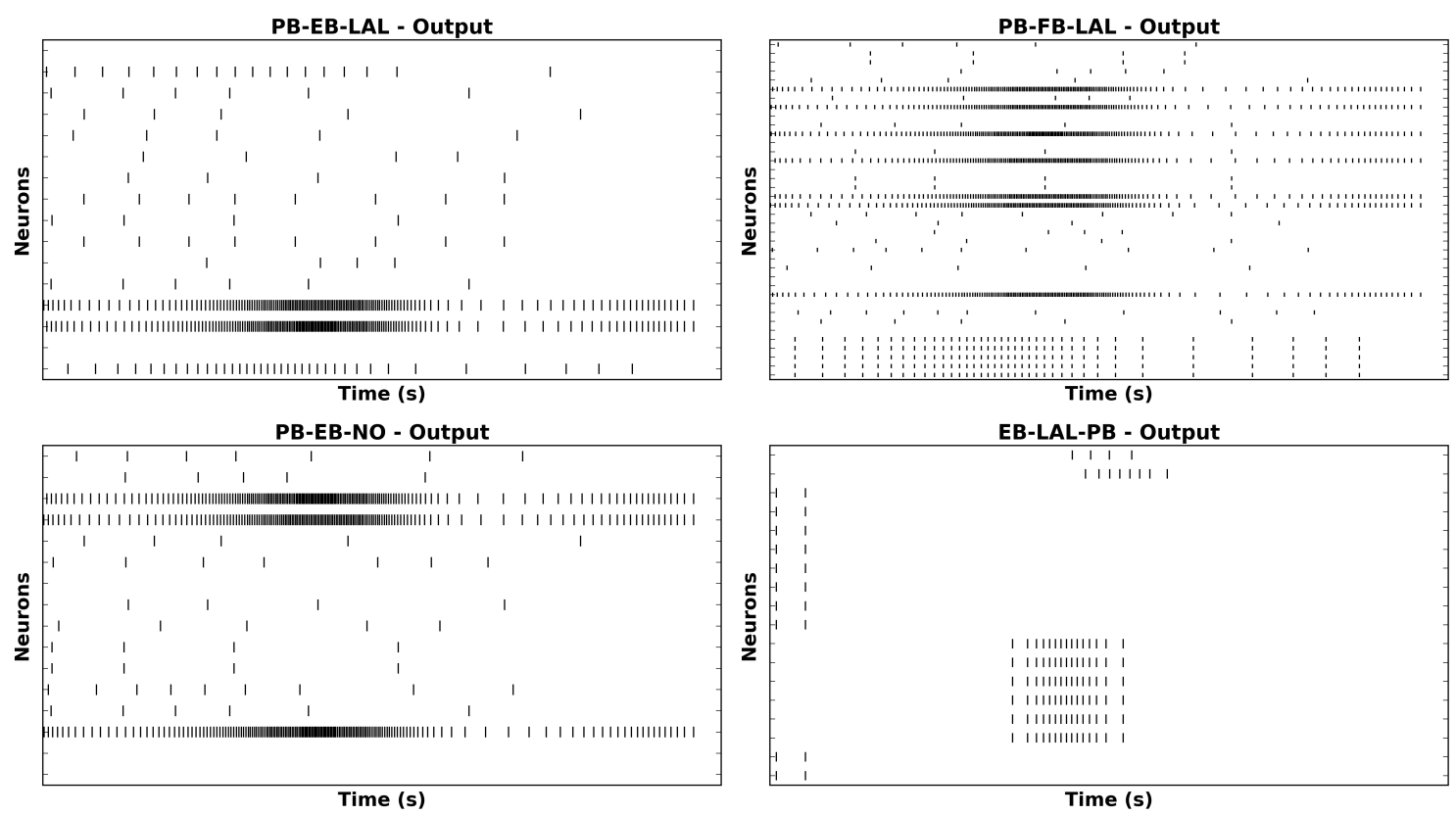

(b) Response to bar moving right to left.

Figure 38: Response of CX projection neurons innervating $\mathrm{PB}$ in constructed no bridge mutant CX model to moving bar input. 

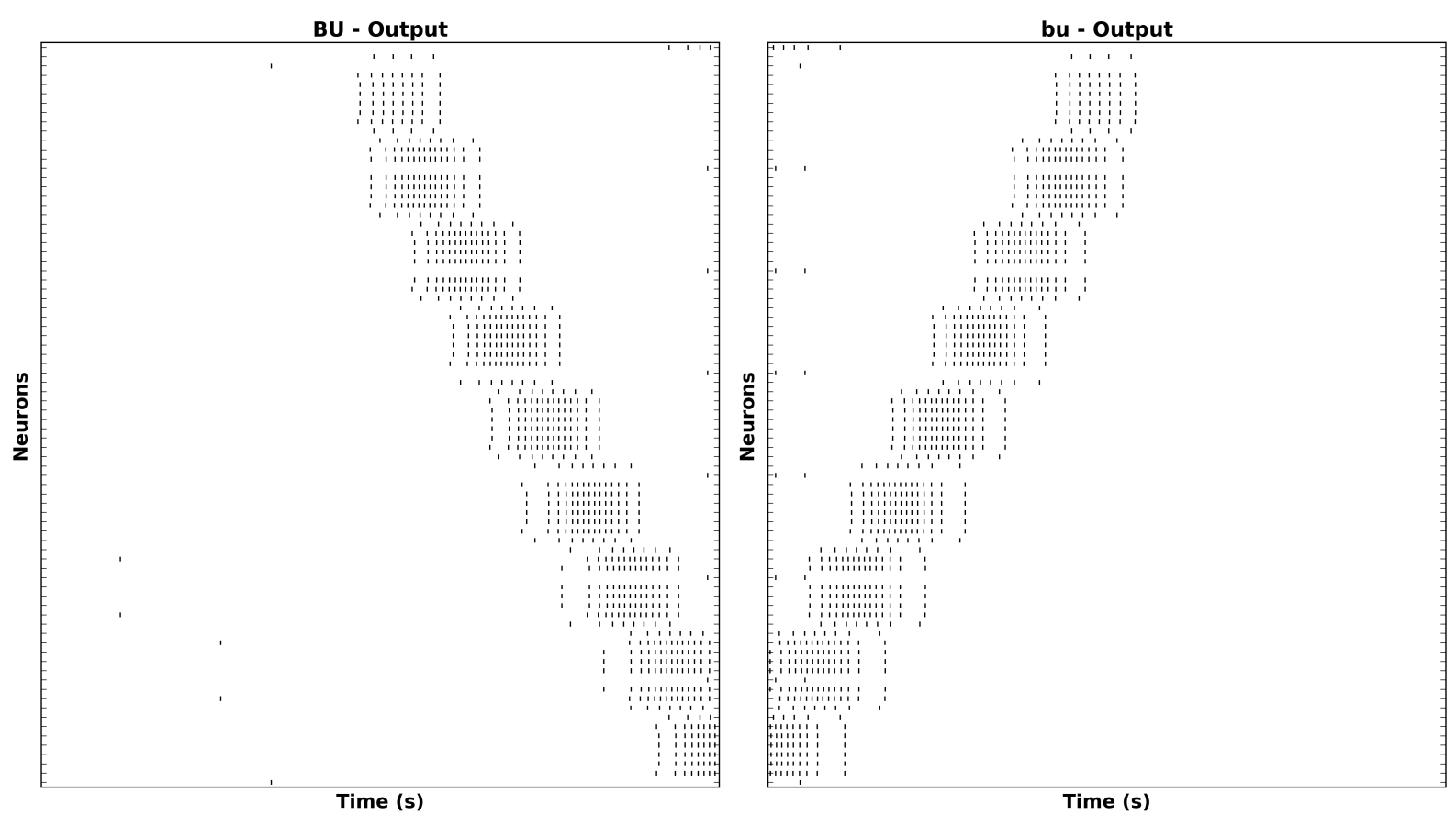

(a) Response to bar moving left to right.
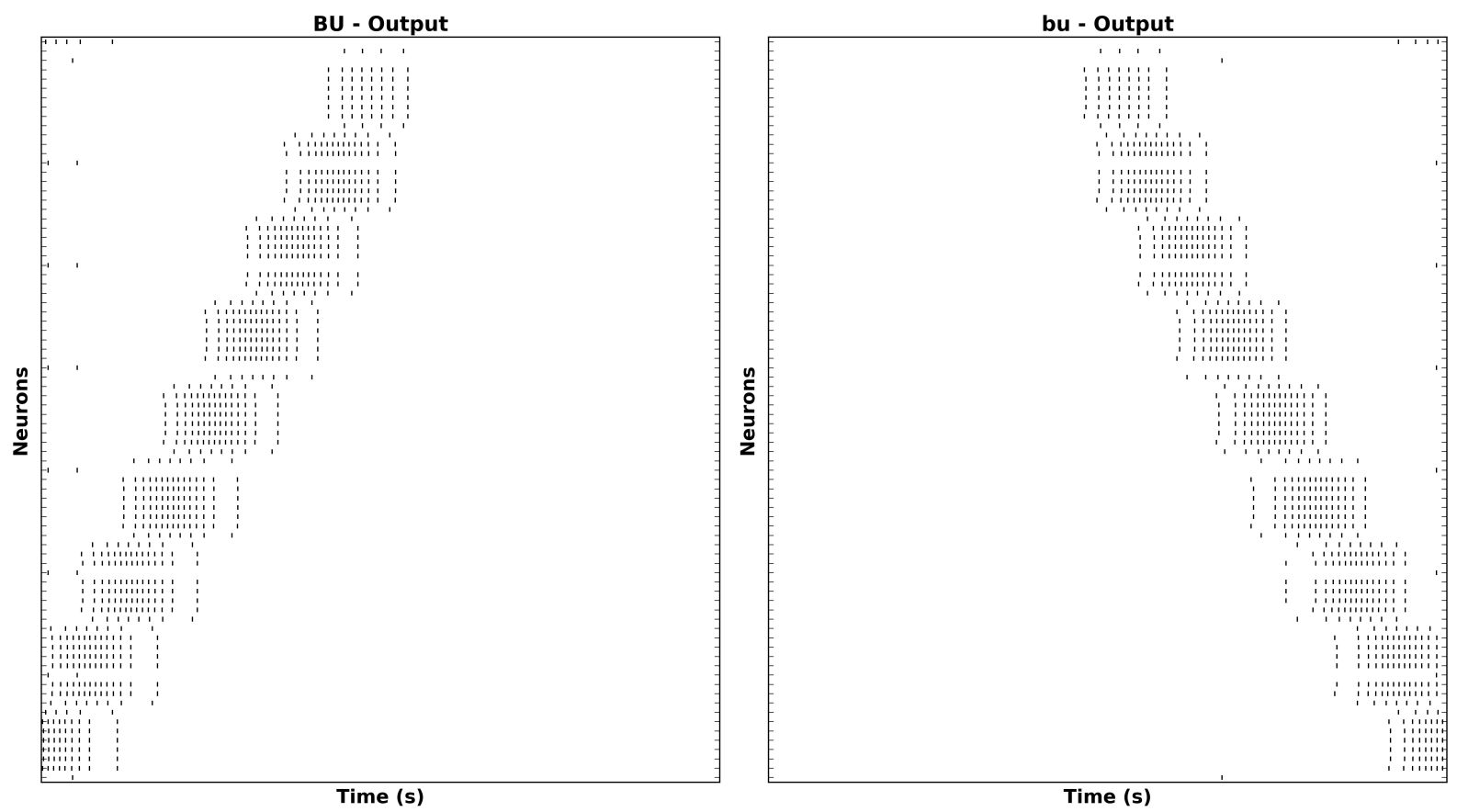

(b) Response to bar moving right to left.

Figure 39: Response of CX projection neurons innervating BU/bu to moving bar input. 


\subsection{Related Work}

Since the synapse inference algorithm described above relies entirely on binary arborization overlap information, it cannot infer the number of synapses between neurons. Ongoing work by the developers of the FlyCircuit database [3] that utilizes neuron morphology to infer the number of synapses between neurons will enable the construction of more biologically informed executable circuit models of the central complex ${ }^{2}$.

\section{Acknowledgements}

The research detailed in this document was supported in part by the AFOSR under grant \#FA9550-12-10232, in part by NSF under grant \#1544383 and in part by the Department of Electrical Engineering at Columbia University.

\section{References}

[1] Chih-Yung Lin, Chao-Chun Chuang, Tzu-En Hua, Chun-Chao Chen, Barry J. Dickson, Ralph J. Greenspan, and Ann-Shyn Chiang. A Comprehensive Wiring Diagram of the Protocerebral Bridge for Visual Information Processing in the Drosophila Brain. Cell Reports, 3(5):1739-1753, May 2013. http://dx.doi.org/10.1016/j.celrep. 2013. 04.022.

[2] Alfonso Martín-Peña, Angel Acebes, José-Rodrigo Rodríguez, Valerie Chevalier, Sergio Casas-Tinto, Tilman Triphan, Roland Strauss, and Alberto Ferrús. Cell types and coincident synapses in the ellipsoid body of Drosophila. European Journal of Neuroscience, 39(10):1586-1601, May 2014. http://dx.doi.org/10.1111/ejn.12537.

[3] Ann-Shyn Chiang, Chih-Yung Lin, Chao-Chun Chuang, Hsiu-Ming Chang, ChangHuain Hsieh, Chang-Wei Yeh, Chi-Tin Shih, Jian-Jheng Wu, Guo-Tzau Wang, and Yung-Chang Chen. Three-dimensional reconstruction of brain-wide wiring networks in Drosophila at single-cell resolution. Current Biology, 21(1):1-11, January 2011. http://dx.doi.org/10.1016/j.cub.2010.11.056.

[4] R. Strauss. Neurobiological Models of the Central Complex and the Mushroom Bodies. In Paolo Arena and Luca Patanè, editors, Spatial Temporal Patterns for Action-Oriented Perception in Roving Robots II, number 21 in Cognitive Systems Monographs, pages 3-41. Springer International Publishing, January 2014. http://link.springer.com/ chapter/10.1007/978-3-319-02362-5_1.

[5] Tanya Wolff, Nirmala A. Iyer, and Gerald M. Rubin. Neuroarchitecture and neuroanatomy of the Drosophila central complex: A GAL4-based dissection of protocerebral

\footnotetext{
${ }^{2}$ C.C. Lo, private communication
} 
bridge neurons and circuits. The Journal of Comparative Neurology, 523(7):997-1037, May 2015. http://dx.doi.org/10.1002/cne.23705.

[6] Keram Pfeiffer and Uwe Homberg. Organization and Functional Roles of the Central Complex in the Insect Brain. Annual Review of Entomology, 59(1):165-184, 2014. http://dx.doi.org/10.1146/annurev-ento-011613-162031.

[7] Kirsa Neuser, Tilman Triphan, Markus Mronz, Burkhard Poeck, and Roland Strauss. Analysis of a spatial orientation memory in Drosophila. Nature, 453(7199):1244-1247, June 2008. http://dx. doi .org/10.1038/nature07003.

[8] Johannes D. Seelig and Vivek Jayaraman. Feature detection and orientation tuning in the Drosophila central complex. Nature, 503:262-266, November 2013. http://dx . doi.org/10.1038/nature12601.

[9] John A. Bender, Alan J. Pollack, and Roy E. Ritzmann. Neural Activity in the Central Complex of the Insect Brain Is Linked to Locomotor Changes. Current Biology, 20(10):921-926, May 2010. http://dx.doi.org/10.1016/j.cub.2010.03.054.

[10] Tobias Bockhorst and Uwe Homberg. Amplitude and dynamics of polarization-plane signaling in the central complex of the locust brain. Journal of Neurophysiology, page jn.00742.2014, January 2015. http://dx.doi.org/10.1152/jn.00742.2014.

[11] James Phillips-Portillo. The Central Complex of the Flesh Fly, Neobellieria bullata: Recordings and Morphologies of Protocerebral Inputs and Small-Field Neurons. The Journal of Comparative Neurology, 520(14):3088-3104, October 2012. http://dx.doi. org/10.1002/cne.23134.

[12] Peter T. Weir, Bettina Schnell, and Michael H. Dickinson. Central complex neurons exhibit behaviorally gated responses to visual motion in Drosophila. Journal of Neurophysiology, 111(1):62-71, January 2014. http://dx.doi.org/10.1152/jn. 00593.2013.

[13] Johannes D. Seelig and Vivek Jayaraman. Neural dynamics for landmark orientation and angular path integration. Nature, 521(7551):186-191, May 2015. http://dx.doi. org/10.1038/nature14446.

[14] Shin-ya Takemura. Connectome of the fly visual circuitry. Microscopy (Oxford, England), 64(1):37-44, February 2015. http://dx.doi.org/10.1093/jmicro/dfu102.

[15] U. Hanesch, K. F. Fischbach, and M. Heisenberg. Neuronal architecture of the central complex in Drosophila melanogaster. Cell and Tissue Research, 257(2):343-366, 1989. http://dx.doi.org/10.1007/BF00261838.

[16] J.M. Young and J.D. Armstrong. Structure of the adult central complex in Drosophila: organization of distinct neuronal subsets. The Journal of Comparative Neurology, 518(9):1500-1524, 2010. http://dx.doi.org/10.1002/cne.22284. 
[17] P. Arena, S. Maceo, L. Patane, and R. Strauss. A spiking network for spatial memory formation: Towards a fly-inspired ellipsoid body model. In The 2013 International Joint Conference on Neural Networks (IJCNN), pages 1-6, August 2013. http://dx.doi. org/10.1109/I JCNN. 2013.6706882.

[18] P. Arena, L. Patanè, and P. S. Termini. A Computational Model for the Insect Brain. In Paolo Arena and Luca Patanè, editors, Spatial Temporal Patterns for Action-Oriented Perception in Roving Robots II, number 21 in Cognitive Systems Monographs, pages 43-80. Springer International Publishing, January 2014. http ://dx . doi .org/10 . 1007/ 978-3-319-02362-5_2.

[19] Eduardo J. Izquierdo and Randall D. Beer. Connecting a Connectome to Behavior: An Ensemble of Neuroanatomical Models of C. elegans Klinotaxis. PLoS Comput Biol, 9(2):e1002890, February 2013. http://dx.doi.org/10.1371/journal.pcbi.1002890.

[20] Kei Ito, Kazunori Shinomiya, Masayoshi Ito, J. Douglas Armstrong, George Boyan, Volker Hartenstein, Steffen Harzsch, Martin Heisenberg, Uwe Homberg, Arnim Jenett, Haig Keshishian, Linda L. Restifo, Wolfgang Rössler, Julie H. Simpson, Nicholas J. Strausfeld, Roland Strauss, Leslie B. Vosshall, and Insect Brain Name Working Group. A Systematic Nomenclature for the Insect Brain. Neuron, 81(4):755-765, February 2014. http://dx.doi.org/10.1016/j.neuron.2013.12.017.

[21] Bryan Ford. Parsing expression grammars: a recognition-based syntactic foundation. In ACM SIGPLAN Notices, volume 39, pages 111-122. ACM, 2004. http://dx.doi . org/10.1145/982962.964011.

[22] J.M. Young and J.D. Armstrong. Building the central complex in Drosophila: The generation and development of distinct neural subsets. The Journal of Comparative Neurology, 518(9):1525-1541, 2010. http://dx.doi.org/10.1002/cne.22285.

[23] Hideo Otsuna, Kazunori Shinomiya, and Kei Ito. Parallel neural pathways in higher visual centers of the Drosophila brain that mediate wavelength-specific behavior. Frontiers in Neural Circuits, 8, February 2014. http://dx.doi.org/10.3389/fncir.2014. 00008 .

[24] Wayne Pereanu, Abilasha Kumar, Arnim Jennett, Heinrich Reichert, and Volker Hartenstein. A development-based compartmentalization of the Drosophila central brain. The Journal of comparative neurology, 518(15):2996-3023, August 2010. http: //dx.doi.org/10.1002/cne.22376.

[25] Hideo Otsuna and Kei Ito. Systematic analysis of the visual projection neurons of Drosophila melanogaster. I. Lobula-specific pathways. The Journal of Comparative Neurology, 497(6):928-958, August 2006. http://dx.doi.org/10.1002/cne.21015.

[26] Chun-Chao Chen, Jie-Kai Wu, Hsuan-Wen Lin, Tsung-Pin Pai, Tsai-Feng Fu, ChiaLin Wu, Tim Tully, and Ann-Shyn Chiang. Visualizing Long-Term Memory Formation 
in Two Neurons of the Drosophila Brain. Science, 335(6069):678-685, February 2012. http://dx.doi.org/10.1126/science.1212735.

[27] Lily Kahsai and Åsa M.E. Winther. Chemical neuroanatomy of the Drosophila central complex: Distribution of multiple neuropeptides in relation to neurotransmitters. The Journal of Comparative Neurology, 519(2):290-315, 2011. http://dx.doi.org/10. $1002 /$ cne. 22520.

[28] Richard W. Daniels, Maria V. Gelfand, Catherine A. Collins, and Aaron DiAntonio. Visualizing glutamatergic cell bodies and synapses in Drosophila larval and adult CNS. The Journal of Comparative Neurology, 508(1):131-152, May 2008. http://dx.doi . org/10.1002/cne.21670.

[29] Zhengmei Mao and Ronald L. Davis. Eight Different Types of Dopaminergic Neurons Innervate the Drosophila Mushroom Body Neuropil: Anatomical and Physiological Heterogeneity. Frontiers in Neural Circuits, 3, July 2009. http://dx.doi.org/10.3389/ neuro.04.005.2009.

[30] D. R. Nässel. Histamine in the brain of insects: a review. Microscopy Research and Technique, 44(2-3):121-136, February 1999. http://dx.doi .org/10.1002/(SICI) 1097-0029(19990115/01) 44:2/3\%3C121 : :AID-JEMT6\%3E3.0.CO;2-F.

[31] Sebastian Busch, Mareike Selcho, Kei Ito, and Hiromu Tanimoto. A map of octopaminergic neurons in the Drosophila brain. The Journal of Comparative Neurology, 513(6):643-667, April 2009. http://dx.doi.org/10.1002/cne.21966.

[32] A. M. Vallés and K. White. Serotonin-containing neurons in Drosophila melanogaster: development and distribution. The Journal of Comparative Neurology, 268(3):414-428, February 1988. http://dx.doi.org/10.1002/cne.902680310.

[33] U. Müller. The nitric oxide system in insects. Progress in Neurobiology, 51(3):363-381, February 1997. http://dx.doi.org/10.1016/S0301-0082(96)00067-6.

[34] Stanley Heinze and Uwe Homberg. Neuroarchitecture of the central complex of the desert locust: Intrinsic and columnar neurons. The Journal of Comparative Neurology, 511(4):454-478, December 2008. http://dx.doi.org/10.1002/cne.21842.

[35] Alex D. M. Dewar, Antoine Wystrach, Paul Graham, and Andrew Philippides. Navigation-specific neural coding in the visual system of Drosophila. Bio Systems, 136:120-127, October 2015. http://dx.doi.org/10.1016/j.biosystems.2015.07. 008.

[36] Lev E. Givon, Aurel A. Lazar, and Nikul H. Ukani. NeuroArch: A Graph dB for Querying and Executing Fruit Fly Brain Circuits. December 2015. http://dx.doi. org/10.5281/zenodo. 44225. 
[37] Lev E. Givon and Aurel A. Lazar. Neurokernel: An open source platform for emulating the fruit fly brain. PLoS ONE, January 2016. http://dx.doi.org/10.1371/journal. pone.0146581. s001. Also available as Neurokernel RFC \#4: http: //dx. doi .org/10. $5281 /$ zenodo. 31947.

Neurokernel RFC \#6 